Evandro Catai

\title{
ANÁLISE DOS EFEITOS DA RETRAÇÃO E FLUÊNCIA EM VIGAS MISTAS
}

Dissertação apresentada à Escola de Engenharia de São Carlos da Universidade de São Paulo, como parte dos requisitos para a obtenção do título de Mestre em Engenharia de Estruturas

ORIENTADOR: Prof. Dr. José Jairo de Sáles.

São Carlos 
SUMÁRIO.

RESUMO

ABSTRACT

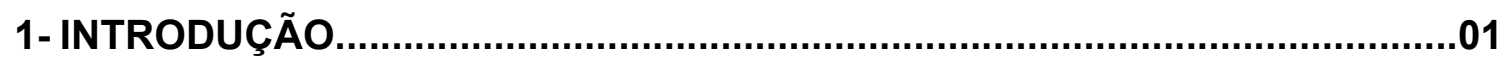

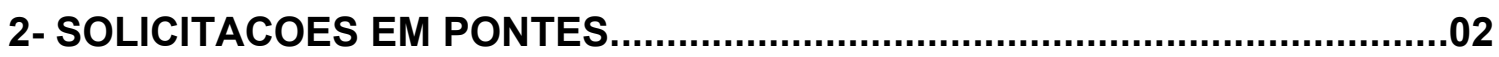

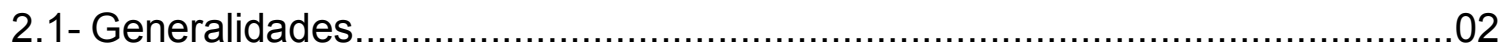

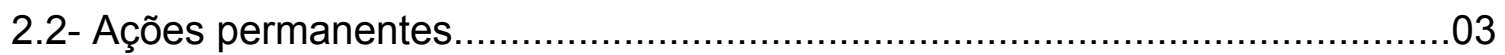

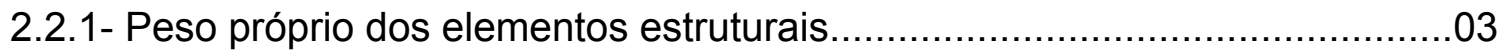

2.2.2- Peso próprio dos elementos não estruturais................................................

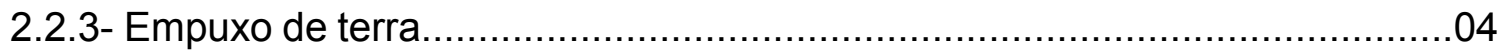

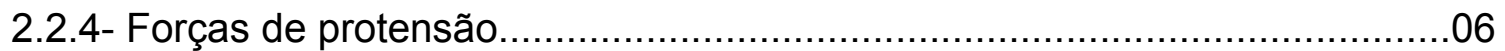

2.2.5- Deformações impostas: retração, fluência e deslocamento de apoio...........06

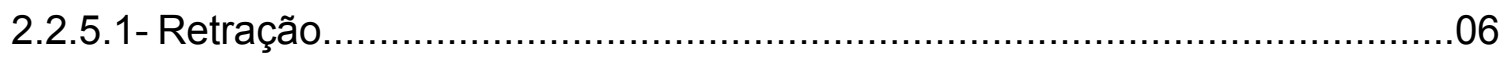

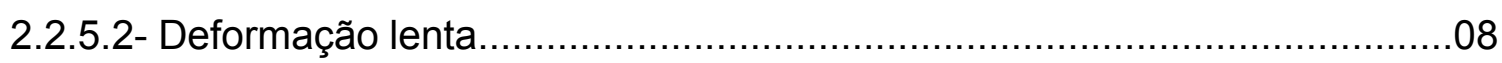

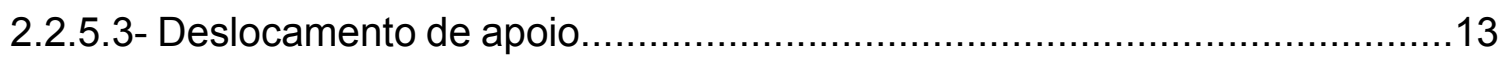

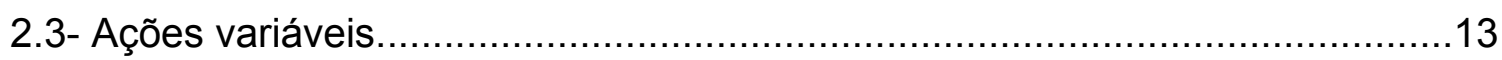

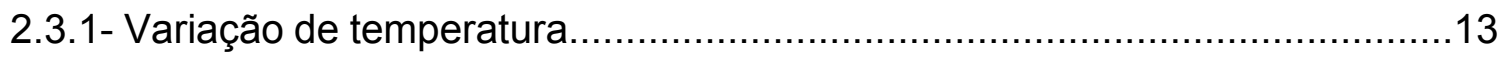

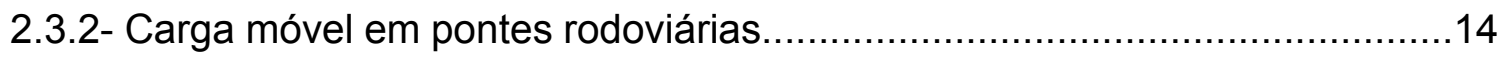

2.3.3- Solicitações no guarda-rodas e defensas centrais e extremas....................19

2.3.4- Carga móvel em pontes ferroviárias......................................................19

2.3.5- Impacto vertical - Efeitos da ação dinâmica.............................................20

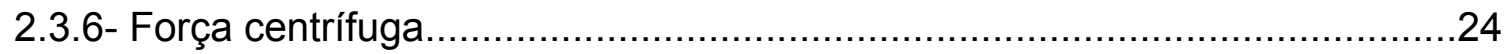

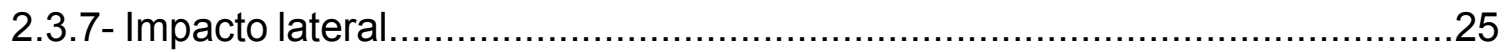

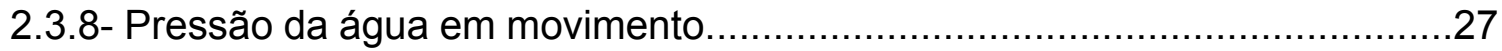


2.3.9- Força longitudinal por frenagem ou aceleração......................................28

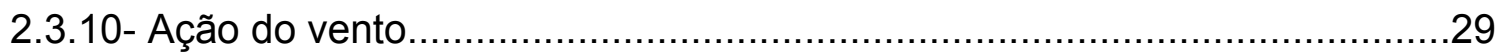

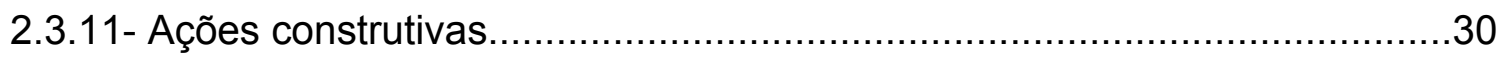

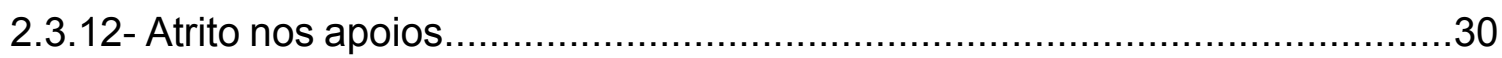

2.3.13- Empuxo de terra provocado pela carga móvel....................................30

2.4- Ações excepcionais.......................................................................... 31

3- COMBINAÇÃO DAS AÇÕES.................................................................33

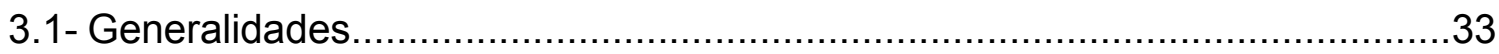

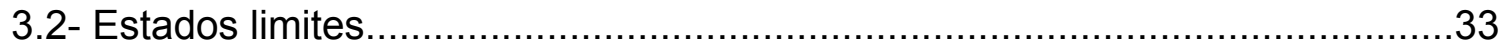

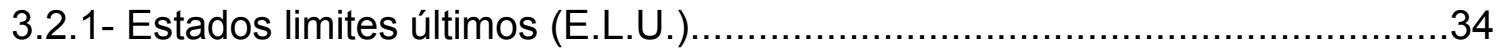

3.2.2- Estados limites de serviço (E.L.S.).....................................................

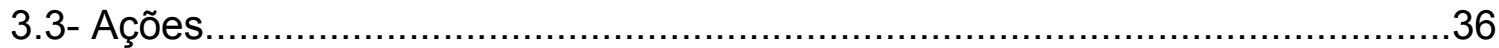

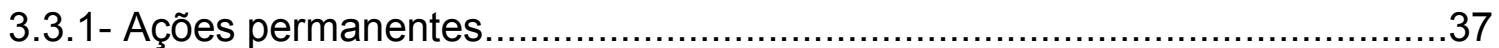

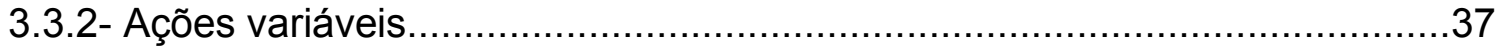

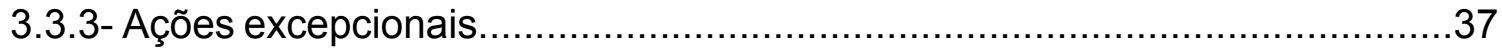

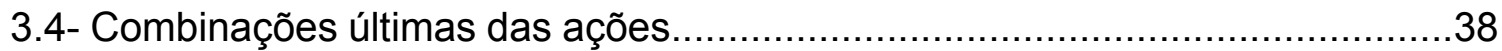

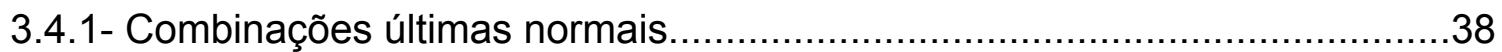

3.4.2- Combinações últimas especiais ou de construção....................................38

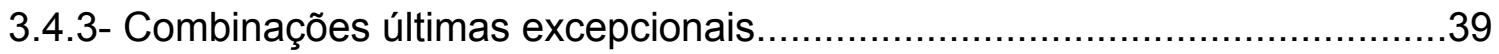

3.5- Coeficientes de ponderação para combinações últimas...............................40

3.5.1- Coeficientes de ponderação para ações permanentes..............................40

3.5.2- Coeficiente de ponderação para ações variáveis....................................41

3.5.3- Coeficiente de ponderação para ações excepcionais................................43

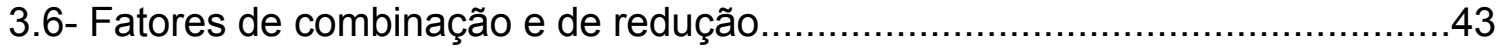

3.7- Fatores de redução para a combinação freqüente, aplicável à verificação da

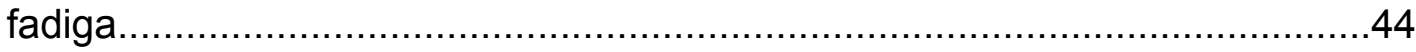

3.8- Combinações das ações em serviço.........................................................45

3.8.1- Combinação quase-permanente de serviço...............................................45

3.8.2- Combinações freqüentes de serviço....................................................45 
3.8.3- Combinações raras de serviço...............................................................45

3.9- Valores a serem considerados na abertura de fissuras..............................46

4- SISTEMAS CONSTRUTIVOS - PONTES EM VIGAS DE ALMA CHEIA........48

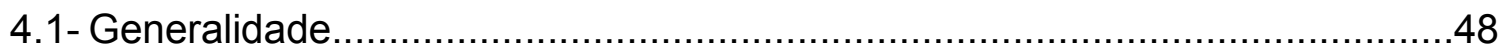

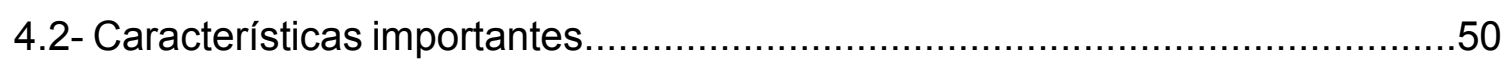

4.3- Exemplos de estruturas de vigas de alma cheia......................................51

4.4- Disposições construtivas atuais............................................................53

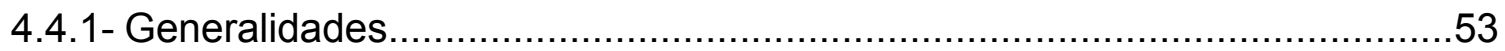

4.4.2- Inovações tecnológicas dos sistemas em pontes mistas.............................54

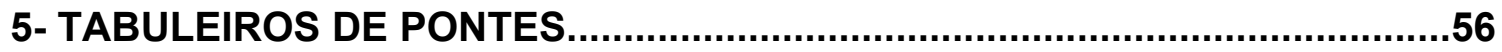

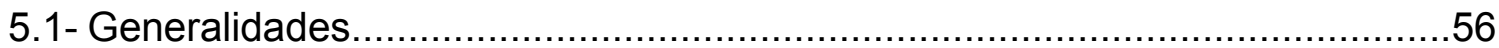

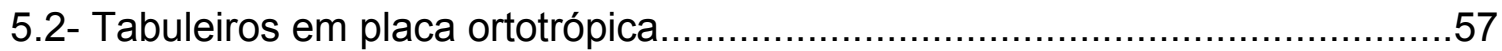

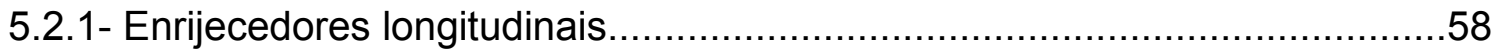

5.2.2- Posicionamento dos enrijecedores longitudinais junto às vigas transversais

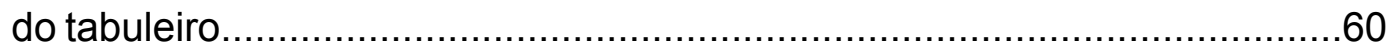

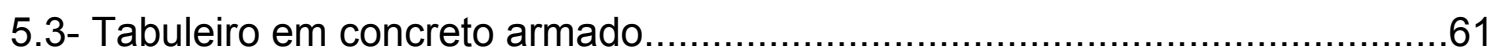

5.4- Utilização de grade de aço como tabuleiro.............................................62

5.5- Tabuleiro em laje pré-moldada juntamente com o concreto moldado in situ.

6- CONECTORES DE CISALHAMENTO......................................................65

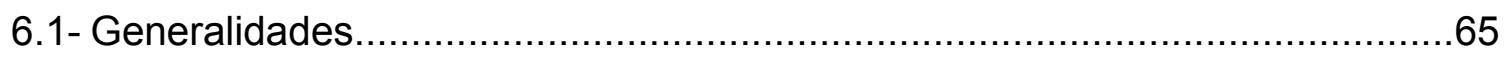

6.2- Comportamento da ligação aço-concreto ao cisalhamento..........................65

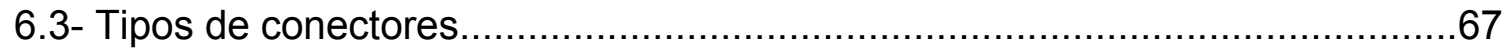

6.3.1- Conectores tipo pino com cabeça (stud bolts).......................................67

6.3.2- Conectores em perfil U laminado........................................................... 73 
6.3.3- Conectores de cisalhamento com características rígidas .74

6.3.4- Outros sistemas de ligação entre a laje de concreto e a viga de aço. .77

\section{7- ESTUDOS DE VIGAS MISTAS CONSIDERANDO OS EFEITOS DA RETRAÇÃO E FLUÊNCIA.}

7.1- Generalidades. .79

7.2- Largura efetiva. .80

7.3- Interação completa - seções compactas .85

7.4- Interação parcial - seções não compactas. 89

7.5- Resistência última ao momento fletor em vigas mistas. .90

7.6- Resistência última ao cisalhamento, referente à seção transversal. 94

7.7- Resistência última ao cisalhamento, referente à ligação aço/concreto. .99

7.8- Estado limite de serviço (deslocamentos). 104

7.9- Efeitos da retração e fluência em vigas mistas. 106

7.9.1- Generalidades 106

7.9.2- Efeitos da retração e fluência em vigas mistas, procedimento baseado por Djuric (1963) 107

7.9.2.1- Propriedades da seção transversal. 107

7.9.2.1.1- Para o tempo $\mathrm{t}=0$ 107

7.9.2.1.2- Para o tempo $t$. 109

7.9.2.2- Distribuição de tensões. 112

7.9.2.2.1- Para o tempo $\mathrm{t}=0$ 112

7.9.2.2.2- Para o tempo t. 115

7.9.3- Determinação dos formulários das tensões em seções mistas segundo Dubas (1975) e Mason (1976).

7.9.4- Considerações a serem feitas na diferença de temperatura entre aço/concreto em vigas simplesmente apoiadas. 124

7.9.5- Efeitos da retração em vigas mistas, de acordo com Dubas (1975) e Mason (1976) 126 
7.9.6- Efeitos da fluência em vigas mistas, considerações feitas por

Dubas (1975) e Mason (1976) 129

7.10- Exemplo numérico - verificação das tensões 131

7.10.1- Propriedades da seção para $t=0$, segundo Djuric (1963). 132

7.10.2- Verificação se a seção é compacta (AASHTO/1996). .133

7.10.3- Verificação das tensões na seção para $t=0$, segundo Djuric (1963). 133

7.10.4- Propriedades da seção para $t=$ :, segundo Djuric (1963). 134

7.10.5- Verificação se a seção é compacta, (AASHTO/1996) 135

7.10.6- Verificação das tensões na seção para $t=$ :, segundo

Djuric (1963) 136

7.10.7- Verificação das tensões, segundo Mason (1976).... 138

7.10.7.1- Características da seção. 138

7.10.7.1.1- Estagio inicial. 138

7.10.7.1.2- Estagio final, considerando os efeitos da retração e fluência. 139

7.10.7.2- Determinação das tensões na seção, segundo Mason (1976)... 141

7.10.8- Comparação dos resultados entre os dois métodos, Mason e Djuric 143

7.10.9- Determinação do Deslocamento 144

8- CONCLUSÕES E RECOMENDAÇÕES 147

9- REFERÊNCIAS BIBLIOGRÁFICAS. 152 
À minha mãe Araceli e ao meu pai Paulo (in memorian) 
AGRADECIMENTOS.

A Deus, pela sua grandeza e generosidade.

Ao Prof. Dr. José Jairo de Sales, pela orientação deste e principalmente pelo respeito e amizade.

Aos meus familiares que me incentivaram durante toda a trajetória deste trabalho.

A todos os colegas, professores e funcionários do Departamento de Estrutura da EESC/USP, que direta ou indiretamente auxiliaram para a realização deste trabalho. 


\section{RESUMO.}

CATAI, E. (2005). Análise dos efeitos da retração e fluência em vigas mistas. Dissertação (Mestrado) - Escola de Engenharia de São Carlos, Universidade de São Paulo, São Carlos, 2005.

Foram realizados estudos das ações e suas combinações, que possam ocorrer nas pontes; também foram apresentados as principais características das pontes em vigas mistas e os tabuleiros utilizados, os conectores de cisalhamento que são utilizados na ligação aço/concreto e os efeitos da retração e fluência das vigas mistas.

No estudo desses efeitos realizou-se uma análise elástica; a seção transversal foi considerada idealizada e as tensões atuantes na seção mista foram obtidas através do método das tensões admissíveis.

Este procedimento foi baseado por Djuric (1963) posteriormente por Mason (1976), considerando interação completa entre aço/concreto e o carregamento sendo aplicado no tempo $\mathrm{t}=0$ e no tempo $\mathrm{t}=$ :.

Verificou-se ao longo do tempo um aumento do deslocamento e uma redistribuição de tensões na seção mista devido os efeitos da retração e fluência.

Palavras-chave: efeitos da retração e fluência, pontes em vigas mistas. 
ABSTRACT.

CATAI, E. (2005). Analysis of the effects of the shrinkage and creep in composite beams. M.Sc. Dissertation - Escola de Engenharia de São Carlos, Universidade de São Paulo, São Carlos, 2005.

It was achieved studies of the actions and it's combinations that can happen at the bridges also it was presented the main characteristics of the bridges in composite beams and the slab applied the shear connectors that are utilized at the joining steel/concrete and the effects of the shrinkage and creep of the composite beams. In the study these effects come about an analysis elastic the cross-section was considered idealized and the stresses that actuate at the composite section were obtained through the method admissible stresses.

This procedure was based by Djuric (1963) later by Mason (1976) considering full interaction between steel/concrete and the load being applied at the time $t=0$ and at the time $\mathrm{t}=$ :.

It was verified along the time a rise of the deflection and a redistribution of the stresses at the composite section due to the effects of the shrinkage and creep.

keywords: effects of the shrinkage and creep, bridge in composite beams. 


\section{1- INTRODUÇÃO.}

A construção de pontes em estruturas mistas pode ser resumida à existência de tabuleiro de concreto armado moldado in loco ou pré-moldado apoiado em uma estrutura metálica, que pode ser formada por vigas de alma cheia ou treliças.

A união entre o tabuleiro e a estrutura metálica é garantida com a utilização de conectores, que possibilitam o funcionamento em conjunto destes elementos, sendo os responsáveis pela transmissão dos esforços cisalhantes longitudinais na região de contato destes elementos.

A estrutura mista possui algumas peculiaridades, como fornecer uma considerável economia de aço quando comparado com as pontes metálicas; seu peso próprio reduzido perante as estruturas de concreto armado e protendido, conseqüentemente proporcionando economia nas fundações.

Outra vantagem das pontes em vigas mistas, como nas estruturas prémoldadas, é a eliminação de cimbramentos durante a concretagem da laje.

No trabalho foi dada ênfase ao estudo dos efeitos da retração e fluência em vigas mistas. A laje ao deformar-se ao longo do tempo devido a estes efeitos, e de apresentar uma interação completa com a viga de aço, é certo que aconteça uma redistribuição de tensões na seção mista. 


\section{2- SOLICITAÇÕES EM PONTES.}

\section{1- Generalidades.}

As ações atuantes em pontes são prescritas na norma NBR 7187 (2003) "Projeto de pontes de concreto armado de protendido - procedimento", e definidas da seguinte maneira:

a) Ações permanentes:

- Peso próprio dos elementos estruturais,

- Peso próprio dos elementos não estruturais,

- Empuxo de terra e de água,

- Forças de protensão,

- Deformações impostas: retração, fluência, deslocamento de apoio.

b) Ações variáveis:

- Variações de temperatura,

- Carga móvel: pontes rodoviárias e ferroviárias,

- Solicitações no guarda-rodas, defensas centrais e extremas,

- Impacto vertical: efeitos da ação dinâmica,

- Força centrífuga,

- Impacto lateral,

- Pressão da água em movimento,

- Força longitudinal: efeitos da frenagem e aceleração,

- Ação do vento, 
- Ações construtivas,

- Atrito nos apoios,

- Empuxo de terra provocado por cargas móveis.

c) Ações excepcionais.

- Choque de veículos em pilares,

- Choque de embarcações em pilares.

\section{2- Ações permanentes.}

\subsection{1- Peso próprio dos elementos estruturais.}

Em pontes metálicas a avaliação prévia do peso próprio da estrutura, segundo o EUROCODE 1 (1996), é a soma de todos os elementos individuais multiplicado por 1,1 devido às ligações.

Quanto ao concreto armado, especificamente o tabuleiro, o peso específico é igual a $25 \mathrm{kN} / \mathrm{m}^{3}$, um pré-dimensionamento é realizado de maneira que seja determinado seu peso próprio.

Caso este valor estimado seja $5 \%$ maior do que o peso próprio resultante do dimensionamento definitivo, é necessário refazer os cálculos das solicitações.

\subsection{2- Peso próprio dos elementos não estruturais.}

Em caso de pontes rodoviárias considera-se a pavimentação, com uma solicitação de $24 \mathrm{kN} / \mathrm{m}^{3}$, e eventuais manutenções no pavimento com uma sobrecarga de $2 \mathrm{kN} / \mathrm{m}^{2}$. Também deve considerar o peso próprio das defensas e guarda-rodas. Em pontes ferroviárias são considerados os lastros ferroviários com um peso específico aparente de $18 \mathrm{kN} / \mathrm{m}^{3}$. É previsto que o lastro atinja o nível superior dos dormentes e que preencha os espaços limitados pelo guarda-lastro (figura 2.1). Quanto aos trilhos e dormentes são consideradas solicitações de 8 kN/m. 


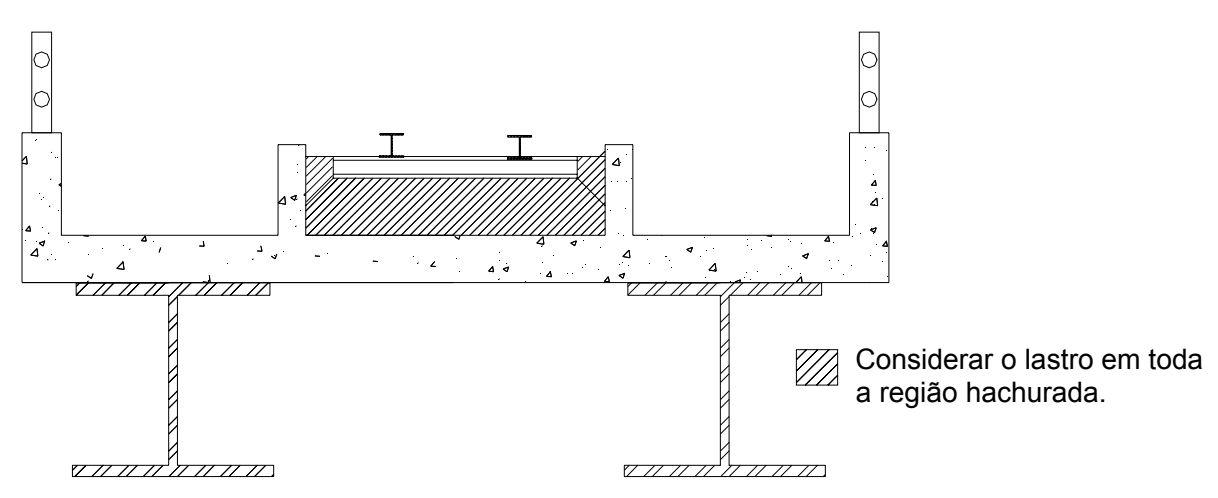

Figura 2.1- Seção transversal esquemática de ponte ferroviária.

\subsection{3- Empuxo de terra.}

A determinação do empuxo de terra deve ser realizada através dos princípios da Mecânica dos Solos, em função de sua natureza (empuxo ativo e passivo), inclinação do talude e a característica do terreno.

Como simplificação a NBR 7187 (2003), admite-se que o solo não tenha coesão e que não haja atrito do terreno com a estrutura, desde que esteja a favor da segurança.

Deve ser considerado o peso específico do solo úmido igual a $18 \mathrm{kN} / \mathrm{m}^{3}$ e o ângulo de atrito interno seja no máximo de $30^{\circ}$, não considerando o efeito de impacto.

O empuxo ativo $\left(E_{a}\right)$ é considerado em cortinas e encontros nas situações mais desfavoráveis. Apenas é permitindo levar em consideração o empuxo passivo $\left(\mathbf{E}_{\mathbf{p}}\right)$ em casos de cortinas atirantadas.

$\mathrm{Na}$ figura 2.2, temos as situações que devem ser considerados os empuxos $E_{a} e$ $E_{p}$, e desprezando o empuxo passivo $E_{p}^{\prime}$. 


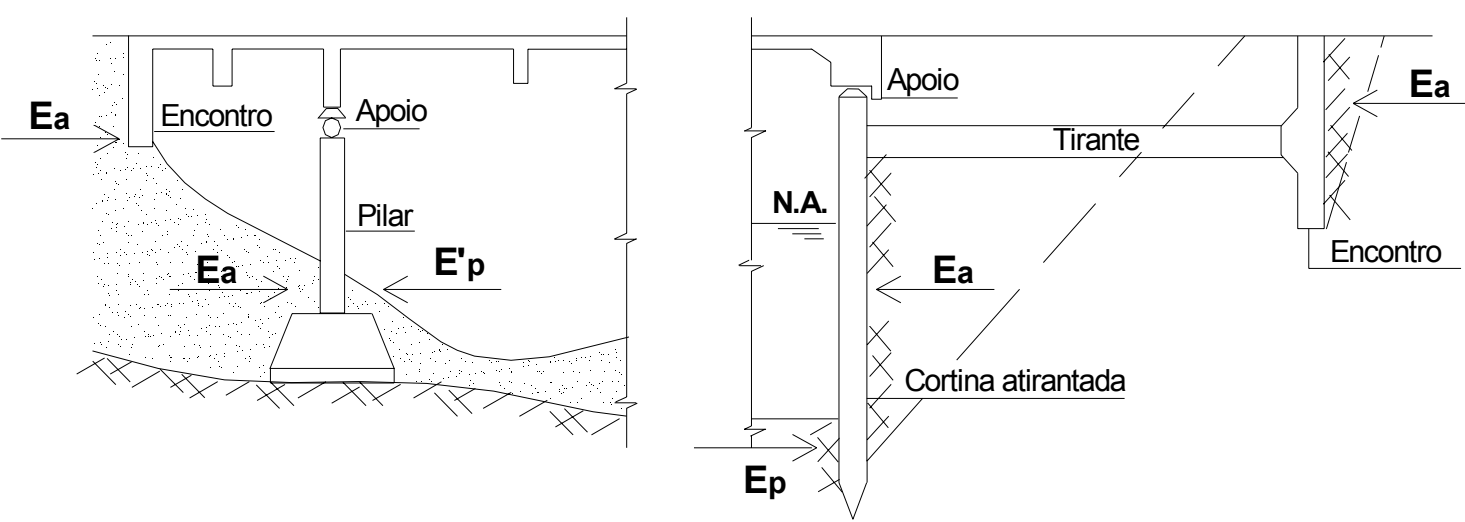

Figura 2.2- Considerações de empuxos passivos e ativos nos diferentes elementos estruturais.

Em caso de pilares isolados implantados em taludes (figura 2.2), o empuxo ativo sobre eles deve ser determinado de maneira que a ação do aterro sobre o pilar seja dada por uma largura fictícia igual ao triplo da largura real do pilar (figura 2.3).

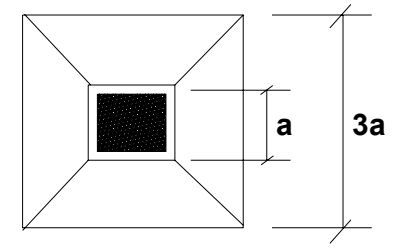

Figura 2.3- Considerações de empuxos em pilares isolados.

Em um grupo de pilares alinhados transversalmente; quando a largura fictícia obtida de acordo com o critério anteriormente adotado, for superior a distância transversal entre os eixos dos mesmos, a nova largura fictícia deve ser igual a:

- Pilares externos, a largura fictícia deve ser igual a semidistância entre eixos acrescidas de 1,5 vezes a largura do pilar,

- Pilares intermediários, a largura fictícia deve ser igual a distância entre eixos. 
Quanto ao empuxo d'água, deve-se considerar as condições mais desfavoráveis, com a devida avaliação dos níveis máximos e mínimos dos cursos d'água e do lençol freático.

Convém lembrar a necessidade de se atentar para uma eventual ação de subpressões em muros de arrimo e cortinas em toda a sua altura, bem como as possíveis obstruções da seção de vazão do curso d'água e suas considerações aos esforços solicitantes.

Para neutralizar os efeitos das pressões hidrostáticas, é prevista uma camada filtrante contínua à face do solo a ser contido, associada a um sistema de drenos.

\subsection{4- Forças de protensão.}

Não serão comentadas neste trabalho, mais detalhes na NBR 6118 (2002) e bibliografias especializadas.

\subsection{5- Deformações impostas: retração, fluência e deslocamento de apoio.}

\subsubsection{1- Retração.}

A retração é a redução de volume do concreto em conseqüência da perda de água, na ausência de solicitações externas.

As principias causas da retração são:

- Retração química: provocada pelas contrações da água quimicamente combinada $\left(A_{n}\right)$ durante a reação com o cimento,

- Retração decorrente da evaporação parcial da água capilar: é a perda de água adsorvida $\left(A_{e}\right)$ através da evaporação, 
- Retração por carbonatação: $\mathrm{Ca}(\mathrm{OH})_{2}+\mathrm{CO}_{2} \rightarrow \mathrm{CaCO}_{3}+\mathrm{H}_{2} \mathrm{O}$<smiles>C1CCC1</smiles>

diminuição

de volume.

Os fatores que afetam a retração podem ser:

- Forma geométrica da peça; quanto menor a espessura maior a retração,

- Idade do concreto; com o passar do tempo a retração diminui devido ao aumento da resistência do concreto,

- Fator água cimento $(\mathrm{a} / \mathrm{c})$; quanto maior for este fator maior a retração devido a grande quantidade de água a ser evaporada, proporcionando mais capilaridade,

- Composição química do cimento; a utilização de cimentos mais resistentes e de secagem rápida aumenta a retração,

- Quantidade de armadura; armaduras especificas ajudam a combater a retração,

- Redutores de água; diminui a retração,

- Processo de cura; hidratação constante aumenta a resistência da pasta diminuindo a retração, conseqüentemente combate a fissuração.

Os valores da deformação específica de retração $\varepsilon_{c s}\left(t_{\infty}, t_{0}\right)$ são mostrados na tabela 2.1. Estes valores são relativos à temperaturas do concreto entre $10^{\circ} \mathrm{C}$ a $20^{\circ} \mathrm{C}$, entretanto pode-se admitir temperaturas entre $0^{\circ} \mathrm{C}$ a $40^{\circ} \mathrm{C}$. 
Além disso, estes valores são válidos a concretos plásticos e de cimento Portland comum.

Tabela 2.1- Valores do coeficiente de retração $\varepsilon_{c s}\left(t_{0}, t_{0}\right) \%$. Fonte: NBR $6118(2002)$.

\begin{tabular}{|c|c|c|c|c|c|c|c|c|c|c|}
\hline \multicolumn{3}{|c|}{$\begin{array}{l}\text { Umidade } \\
\text { Ambiente (\%). }\end{array}$} & \multicolumn{2}{|c|}{40} & \multicolumn{2}{|c|}{55} & \multicolumn{2}{|c|}{75} & \multicolumn{2}{|c|}{90} \\
\hline \multicolumn{3}{|l|}{$\begin{array}{l}\text { Espessura } \\
\text { Equivalente }\end{array}$} & 20 & 60 & 20 & 60 & 20 & 60 & 20 & 60 \\
\hline \multirow{3}{*}{$\varepsilon_{\mathrm{cs}}\left(\mathrm{t}_{\mathrm{t}}, \mathrm{t}_{0}\right) \%$} & $\mathrm{t}_{0}$ (dias) & 5 & $-0,44$ & $-0,39$ & $-0,37$ & $-0,33$ & $-0,23$ & $-0,21$ & $-0,10$ & $-0,09$ \\
\hline & $\mathrm{t}_{0}$ (dias) & 30 & $-0,37$ & $-0,38$ & $-0,31$ & $-0,31$ & $-0,20$ & $-0,20$ & $-0,09$ & $-0,09$ \\
\hline & $\mathrm{t}_{0}$ (dias) & 60 & $-0,32$ & $-0,36$ & $-0,27$ & $-0,30$ & $-0,17$ & $-0,19$ & \begin{tabular}{|l|}
$-0,08$ \\
\end{tabular} & $-0,09$ \\
\hline
\end{tabular}

Sendo:

- $\mathrm{A}_{\mathrm{c}}$ : área de concreto,

- u : perímetro da seção de concreto em contato com a atmosfera,

- $\varepsilon_{\mathrm{cs}}\left(\mathrm{t}_{\infty}, \mathrm{t}_{0}\right)$ : deformação específica de retração.

\subsubsection{2- Deformação lenta - Fluência.}

A fluência é caracterizada pelo aumento progressivo da deformação do concreto na presença de solicitações externas.

Ao atuar uma força de compressão, inicialmente ocorre uma acomodação dos cristais, se a força permanecer ao longo do tempo, a água capilar caminhará a capilares mais finos, ocasionando tensões internas e provocando deformação lenta.

Os fatores que afetam a fluência em geral são os mesmos que afetam a retração, porém podem ser citados: 
- Presença de água capilar,

- Geometria da peça; quanto mais esbeltas, maiores serão os efeitos da fluência,

- Grau de exposição; em peças estruturais expostas ao meio ambiente, maiores serão os efeitos da fluência,

- Variação de umidade; quanto maior for esta variação maior o efeito da fluência,

- Idade do concreto; com o passar do tempo os efeitos da fluência tendem a estagnar (figura 2.4),

- Condições de cura; uma cura adequada diminui os efeitos da fluência,

- Exposição em altas temperaturas; durante o período em que a estrutura esta sendo carregada sob altas temperaturas, a fluência pode ser significativa,

- Magnitudes das tensões; quanto maiores forem às tensões os efeitos da fluência devem ser maiores.

Quando é aplicada uma força em uma peça de concreto, ela se deforma em conseqüência da acomodação dos cristais que a compõem. Segundo a Lei de Hooke, esta deformação é proporcional à carga aplicada, e a proporção é indicada pelo módulo de elasticidade também conhecido como módulo de Young.

Segundo a NBR6118 (2002), a deformação imediata pode ser calculada através da equação: 


$$
\varepsilon_{\mathrm{ce}}=\frac{\sigma_{\mathrm{c}}}{\mathrm{E}_{\mathrm{c}}}
$$

Onde:

- $\varepsilon_{\text {ce }}=$ deformação imediata do concreto,

- $\sigma_{\mathrm{c}}=$ tensão aplicada ao concreto $(\mathrm{MPa})$,

- $\mathrm{E}_{\mathrm{c}}=$ módulo de elasticidade secante do concreto (MPa).

$$
\begin{aligned}
& \mathrm{E}_{\mathrm{c}}=0,85 \mathrm{E}_{\mathrm{ci}} \\
& \mathrm{E}_{\mathrm{ci}}=5.600 \mathrm{f}_{\mathrm{ck}}^{1 / 2}
\end{aligned}
$$

Sendo:

- $\mathrm{E}_{\mathrm{ci}}=$ módulo de elasticidade inicial $(\mathrm{MPa})$,

- $\mathrm{f}_{\mathrm{ck}}=$ resistência característica do concreto à compressão (MPa).

O fator de correção 0,85 é o resultado de $0,75 \times 1,20 \times 0,95$, e são obtidos através de ensaio de curta duração e são especificados da seguinte maneira:

- 0,75: é devido ao efeito Rüsch, que corresponde a $75 \%$ da resistência do concreto,

- 1,20: efeito de maturidade do concreto, na qual aumenta em $20 \%$ a resistência do concreto,

- 0,95: considera a influência da forma e dimensão dos corpos de prova. 
Se o concreto for submetido a uma carga de longa duração, ele deformar-se elasticamente no instante da aplicação da carga $(\mathrm{t}=0)$. Com o decorrer do tempo a deformação irá crescer de maneira assintótica até um valor limite $(t \rightarrow \infty)$.

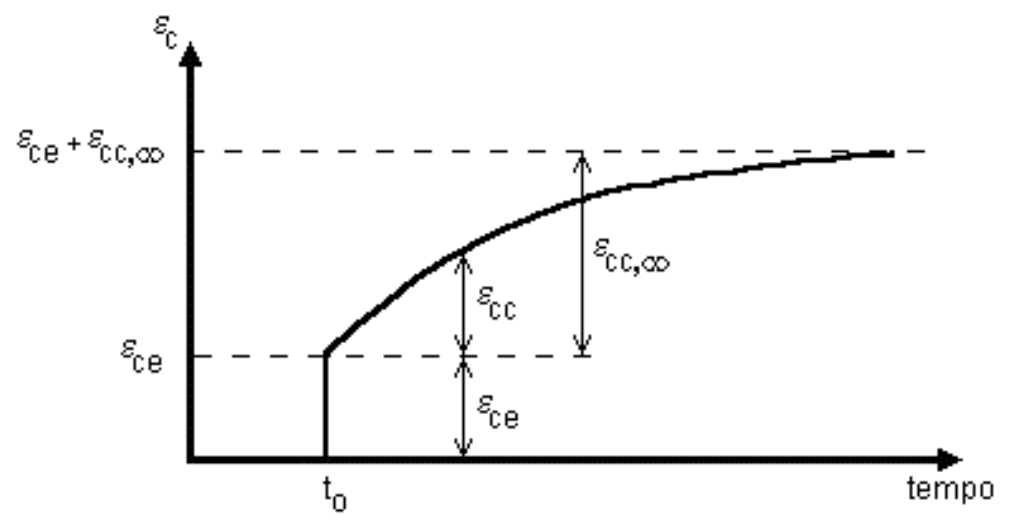

Figura 2.4- Deformações em uma peça submetida a uma compressão constante.

- $\mathrm{t}_{0}=$ instante de aplicação de carga,

- $\varepsilon_{c e}=$ deformação elástica instantânea (concrete, elastic),

- $\varepsilon_{\mathrm{cc}}=$ fluência (concrete, creep),

- $\varepsilon_{\mathrm{cc}, \infty}=$ parcela final da fluência.

Ocorrendo um descarregamento da peça de concreto, parte da deformação é recuperada (recuperação elástica instantânea e retardada), enquanto que a deformação lenta é mantida como deformação residual, como pode ser observado na figura 2.5 . 

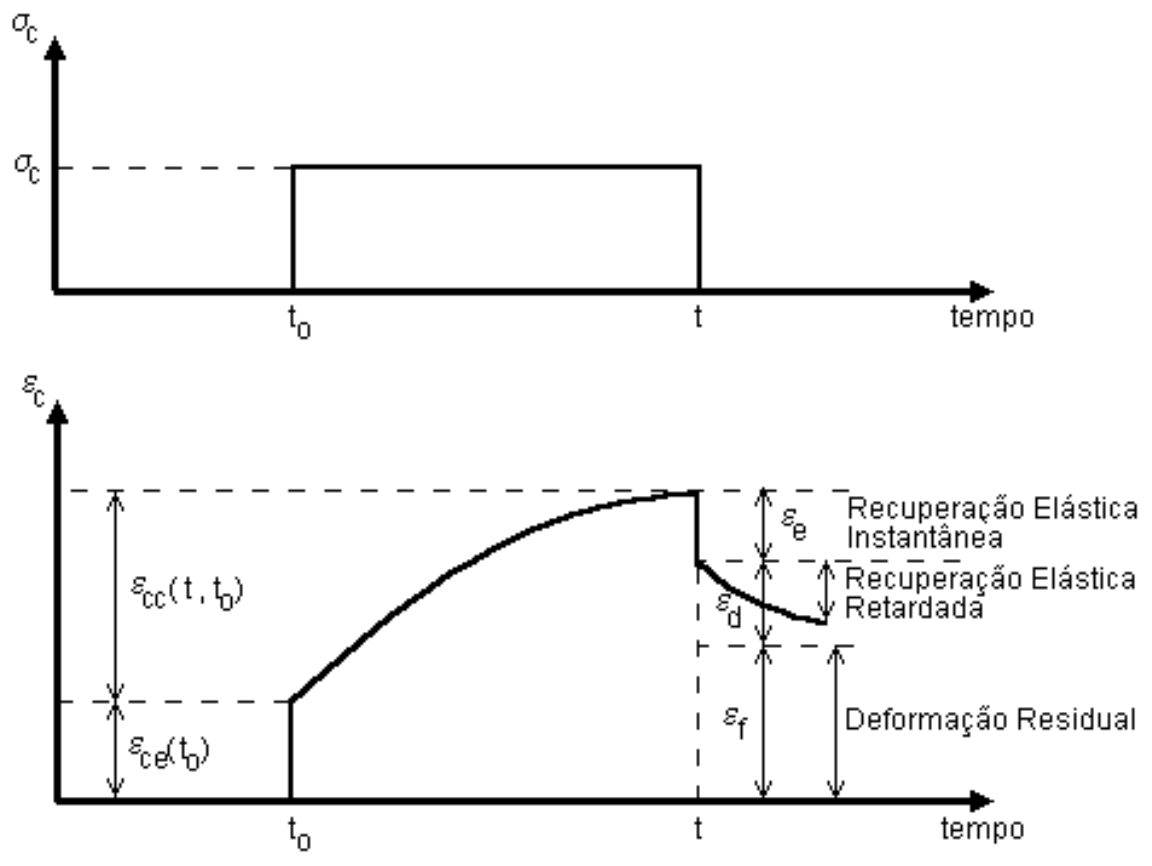

Figura 2.5- Deformações recuperáveis e deformação residual.

- $\varepsilon_{\mathrm{e}}=$ recuperação elástica instantânea,

- $\varepsilon_{\mathrm{d}}=$ deformação elástica recuperável ou deformação elástica retardada,

- $\varepsilon_{\mathrm{f}}=$ deformação lenta permanente ou deformação residual.

De acordo com as definições tem-se: $\varepsilon_{c c}=\varepsilon_{d}+\varepsilon_{f}$ e a relação entre $\varepsilon_{f} / \varepsilon_{d}$ é denominada de coeficiente de deformação lenta ou coeficiente de fluência $\varphi\left(\mathrm{t}_{\infty}, \mathrm{t}_{0}\right)$.

O coeficiente de deformação lenta é influenciado principalmente pelos seguintes fatores:

- Idade do concreto no instante da aplicação da carga,

- Influência climática, principalmente umidade, 
- Composição e resistência do concreto.

Seus valores estão reproduzidos na tabela 2.2 , e são relativos a temperaturas entre $10^{\circ}$ a $20^{\circ} \mathrm{C}$, entretanto pode ser admitida temperatura entre $0^{\circ} \mathrm{C}$ a $40^{\circ} \mathrm{C}$.

Além disso, estes valores são válidos a concretos plásticos e de cimento Portland comum.

Tabela 2.2- Valores do coeficiente de fluência $\varphi\left(t_{0}, t_{\infty}\right)$. Fonte: NBR 6118 (2002).

\begin{tabular}{|l|lr|rr|rr|rr|rr|r|}
\hline $\begin{array}{l}\text { Umidade } \\
\text { Ambiente (\%). }\end{array}$ & \multicolumn{2}{|c|}{40} & \multicolumn{2}{|c|}{55} & \multicolumn{2}{|c|}{75} & \multicolumn{2}{|c|}{90} \\
\hline $\begin{array}{l}\text { Espessura } \\
\text { Equivalente } \\
2 \text { Ac/u (cm). }\end{array}$ & 20 & 60 & 20 & 60 & 20 & 60 & 20 & 60 \\
\hline \multirow{4}{*}{$\varphi\left(\mathrm{t}_{0}, \mathrm{t}_{\infty}\right)}$. & $\mathrm{t}_{0}$ (dias) & 5 & 4,4 & 3,9 & 3,8 & 3,3 & 3,0 & 2,6 & 2,3 & 2,1 \\
\cline { 2 - 11 } & $\mathrm{t}_{0}$ (dias) & 30 & 3,0 & 2,9 & 2,6 & 2,5 & 2,0 & 2,0 & 1,6 & 1,6 \\
\cline { 2 - 11 } & $\mathrm{t}_{0}$ (dias) & 60 & 3,0 & 2,6 & 2,2 & 2,2 & 1,7 & 1,8 & 1,4 & 1,4 \\
\hline
\end{tabular}

\subsubsection{3- Deslocamento de apoio.}

Quando houver a possibilidade de recalques de fundação, o ideal é optar por uma estrutura isostática. Porém se as estruturas ficarem expostas ao efeito de recalque, as mesmas deverão ser estudadas de maneira adequada.

\section{3- Ações variáveis.}

\subsection{1- Variação de temperatura.}

As estruturas mistas se deformam sob ação da variação de temperatura, segundo um coeficiente de dilatação térmica que seja considerado de maneira conjunta para o aço/concreto, e de acordo com Dubas (1975) pode ser igual a $\alpha_{\mathrm{T}}=0,010 \% /{ }^{\circ} \mathrm{C}$.

Analisando a estrutura como um todo, Dubas (1975) considera uma variação extrema de temperatura na estrutura de aço de $30^{\circ} \mathrm{C}$ em relação à média. 
Em estruturas isostáticas esta consideração destina-se apenas a determinação do movimento dos apoios ou dos elementos de transição entre a estrada e a ponte. Ao analisar os efeitos da variação de temperatura entre a viga de aço e a laje de concreto, Dubas (1975) considera uma variação brusca de $\pm 10^{\circ} \mathrm{C}$ isto pode ocasionar uma redistribuição de tensões entre os dois materiais.

Esta diferença de temperatura baseia-se no fato de que as variações de temperatura se manifestem mais rapidamente sobre as vigas de aço, por apresentarem maior coeficiente de transmissão de calor, quando comparadas com o concreto.

\subsection{2- Carga móvel em pontes rodoviárias.}

As cargas a serem consideradas no projeto de pontes rodoviárias, são definidas pela norma NBR 7188 (1984) "Carga móvel em ponte rodoviária e passarela de pedestres".

Apresenta-se na figura 2.6, a carga $Q$ aplicada transversalmente em toda a pista descontando a área do veículo, e a carga Q' referente aos passeios.

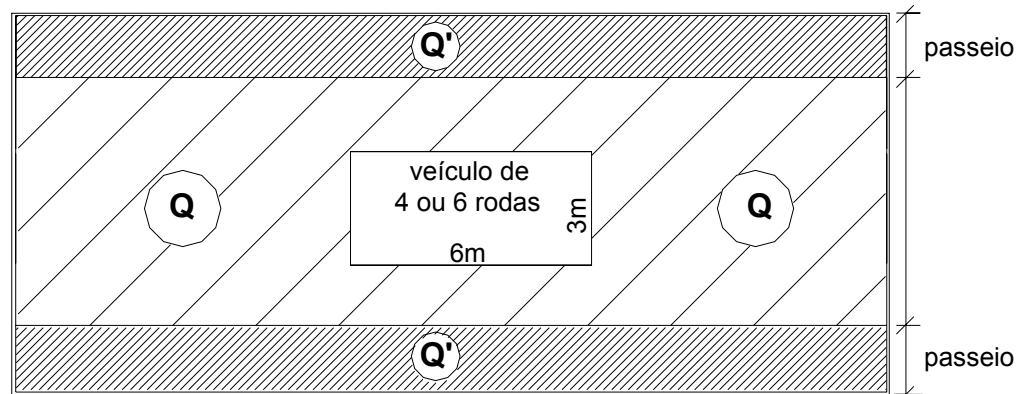

Figura 2.6- Carga móvel constituída por um veículo NBR 7188 (1984).

As cargas $Q$ e Q', são denominadas de cargas fictícias que procuram levar em consideração ações de multidões (Q'), e de outros veículos mais leves(Q) e/ou mais afastado das regiões em que as cargas proporcionem maiores esforços solicitantes. 
Ao realizar um estudo do máximo momento fletor através da linha de influência, o veículo-tipo é posicionado no tramo correspondente juntamente com as cargas $Q$ e Q', e em outras seções, onde estas cargas (sem o veículo) possam provocar aumento dos esforços como mostra a figura 2.7 .

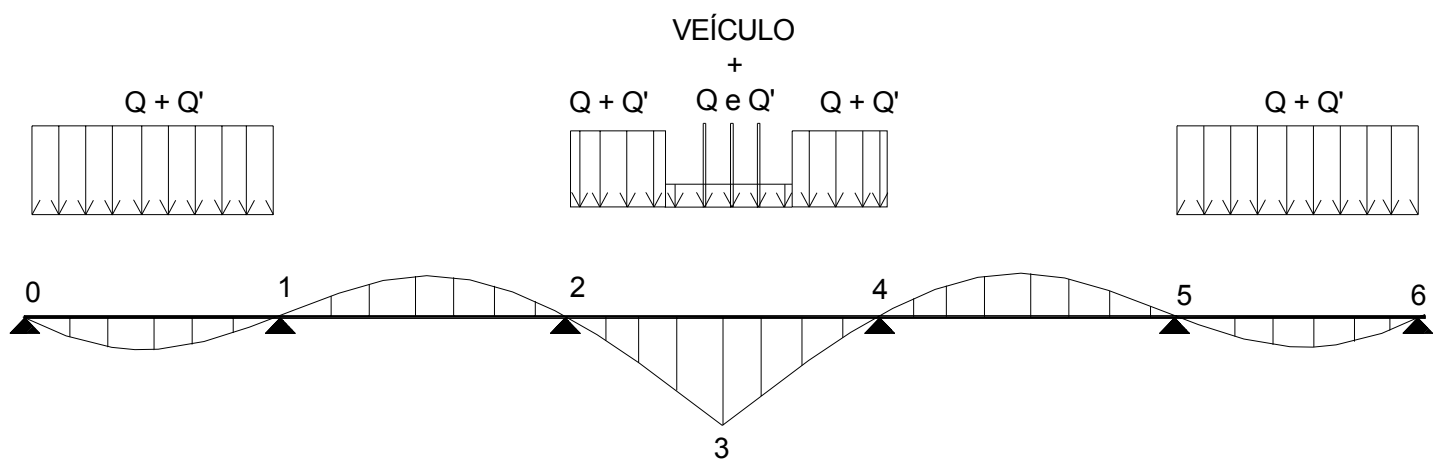

Figura 2.7- Momento fletor máximo na seção 3.

Para a escolha das cargas móveis a NBR 7188 (1984) divide as pontes rodoviárias em três classes: 45, 30, 12.

Em cada uma das classes a norma prevê um trem-tipo composto de um veículo que ocupa um retângulo de $3 \times 6$ metros (figura 2.6) onde atuam seis cargas para as classes 45 e 30, e quatro cargas para a classe 12 .

Os valores das cargas e as características dos veículos estão representados nas tabelas seguintes.

Tabela 2.3- Cargas dos veículos. Fonte: NBR 7188 (1984).

\begin{tabular}{|c|c|l|l|c|l|c|l|l|}
\hline \multirow{2}{*}{$\begin{array}{l}\text { Classe } \\
\text { das } \\
\text { pontes. }\end{array}$} & \multicolumn{3}{|c|}{ Veículo. } & \multicolumn{5}{|c|}{ Carga uniformemente distribuída. } \\
\cline { 2 - 8 } & Tipo. & \multicolumn{2}{|l|}{ Peso total. } & \multicolumn{2}{|c|}{$\mathrm{Q}$} & \multicolumn{2}{c|}{$\mathrm{Q}^{\prime}$} & Disposição da \\
\cline { 2 - 8 } & $\mathrm{kN}$ & $\mathrm{tf}$ & $\mathrm{kN} / \mathrm{m}^{2}$ & $\mathrm{kgf} / \mathrm{m}^{2}$ & $\mathrm{kN} / \mathrm{m}^{2}$ & $\mathrm{kgf} / \mathrm{m}^{2}$ & carga. \\
\hline 45 & 45 & 450 & 45 & 5 & 500 & 3 & 300 & $\begin{array}{l}\text { Carga Q em toda } \\
\text { a pista. } \\
\text { Carga Q' nos } \\
\text { passeios. }\end{array}$ \\
\hline 12 & 30 & 300 & 30 & 5 & 500 & 3 & 300 \\
\hline
\end{tabular}


Tabela 2.4- Características dos veículos. Fonte: NBR 7188 (1984).

\begin{tabular}{|l|c|c|c|c|}
\hline & Unidade. & Tipo 45. & Tipo 30. & Tipo 12. \\
\hline $\begin{array}{l}\text { Quantidade de } \\
\text { eixos. }\end{array}$ & eixo & 3 & 3 & 2 \\
\hline $\begin{array}{l}\text { Peso total do } \\
\text { veículo. }\end{array}$ & $\mathrm{kN}-\mathrm{tf}$ & $450-45$ & $300-30$ & $120-12$ \\
\hline $\begin{array}{l}\text { Peso de cada roda } \\
\text { Dianteira. }\end{array}$ & $\mathrm{kN}-\mathrm{tf}$ & $75-7,5$ & $50-5$ & $20-2$ \\
\hline $\begin{array}{l}\text { Peso de cada roda } \\
\text { traseira. }\end{array}$ & $\mathrm{kN}-\mathrm{tf}$ & $75-7,5$ & $50-5$ & $40-4$ \\
\hline $\begin{array}{l}\text { Peso de cada roda } \\
\text { intermediária. }\end{array}$ & $\mathrm{KN}-\mathrm{t}_{\mathrm{f}}$ & $75-7,5$ & $50-5$ & \\
\hline $\begin{array}{l}\text { Largura b de } \\
\text { cada roda dianteira. }\end{array}$ & $\mathrm{m}$ & 0,50 & 0,40 & 0,20 \\
\hline $\begin{array}{l}\text { Largura b de } \\
\text { cada roda traseira. }\end{array}$ & $\mathrm{m}$ & 0,50 & 0,40 & 0,30 \\
\hline $\begin{array}{l}\text { Largura } \mathrm{b}_{2} \text { de } \\
\text { cada roda intermediária. }\end{array}$ & $\mathrm{m}$ & 0,50 & 0,40 & \\
\hline $\begin{array}{l}\text { Comprimento de } \\
\text { contato de cada roda. }\end{array}$ & $\mathrm{m}$ & 0,20 & 0,20 & 0,20 \\
\hline $\begin{array}{l}\text { Área de contato } \\
\text { de cada roda }\end{array}$ & $\mathrm{m}$ & $0,20 \times \mathrm{b}$ & $0,20 \times \mathrm{b}$ & $0,20 \times \mathrm{b}$ \\
\hline $\begin{array}{l}\text { Distância entre os } \\
\text { eixos. }\end{array}$ & $\mathrm{m}$ & 1,50 & 1,50 & 3,00 \\
\hline $\begin{array}{l}\text { Distância entre os } \\
\text { centros de roda de cada } \\
\text { eixo. }\end{array}$ & 2,00 & 2,00 & 2,00 \\
\hline
\end{tabular}

A figura 2.8 apresenta um esboço do veículo - tipo posicionado na estrutura.
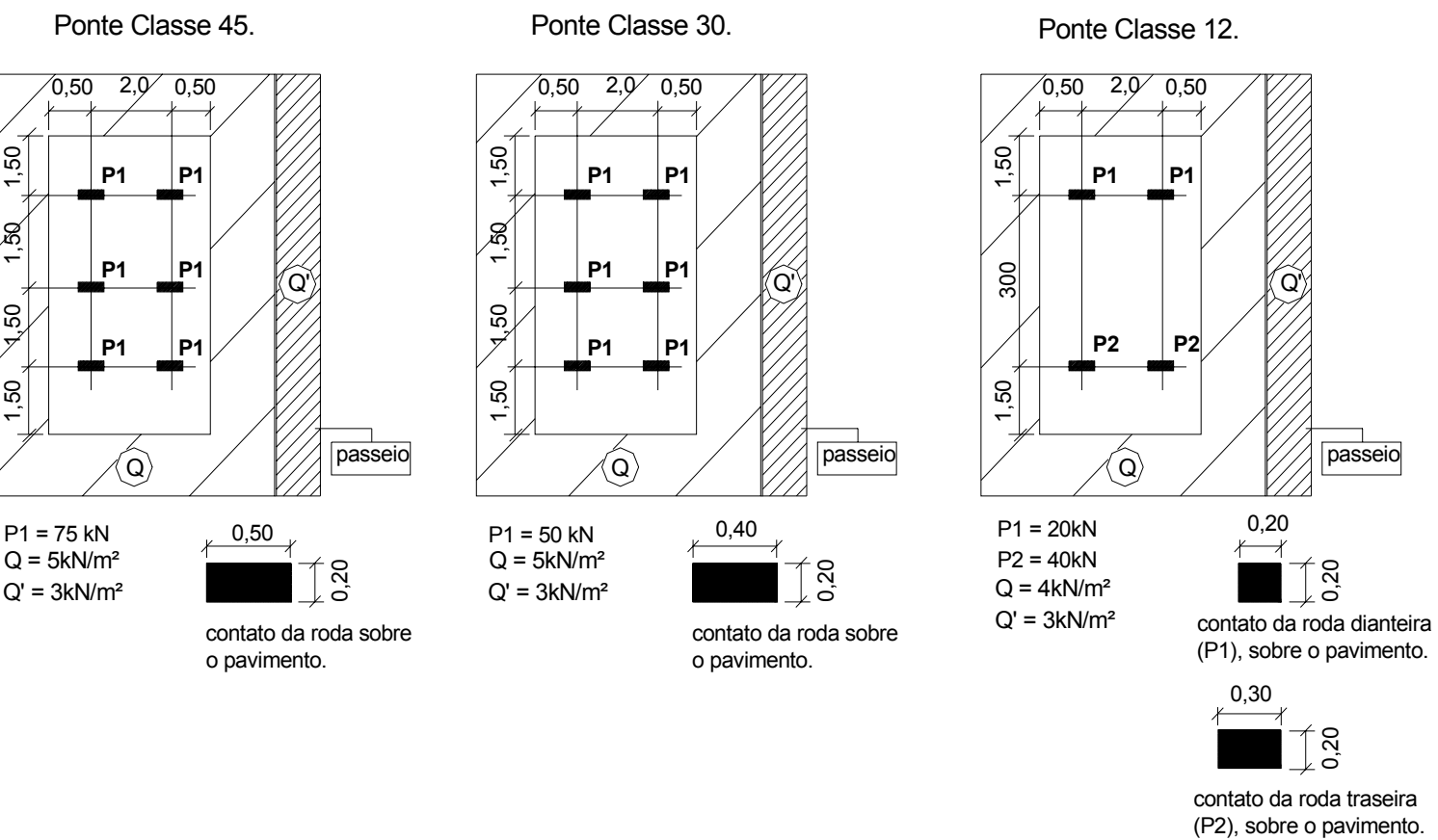

Figura 2.8- Considerações das cargas dos veículos. Fonte: NBR 7188 (1984), cotas em metros. 
Notas: A NBR 7188 (1984) estabelece que qualquer estrutura de transposição com geometria, finalidade e carregamento por ela não prevista, a carga móvel deve ser fixada em instrução especial redigida pelo órgão com jurisdição sobre a referida obra.

Em particular as pontes utilizadas com certa freqüência por veículos especiais transportando cargas de peso excepcional devem ser verificadas para o trem-tipo também especial.

Os parâmetros deste trem-tipo e das condições de travessia devem ser atribuídos pelo órgão que tenha jurisdição sobre as referidas pontes.

Com relação aos passeios a NBR 7188 (1984) estabelece que os mesmos devem ser carregados com a carga Q' sem considerar o efeito dinâmico. Nos elementos estruturais que apóiam estes passeios considera-se uma sobrecarga de $5 \mathrm{kN} / \mathrm{m}^{2}$, desprezando o efeito dinâmico.

A AASHTO (1996) estabelece o carregamento em pontes rodoviárias, em um modelo de caminhão ou carregamento uniformemente distribuído na faixa de tráfego, juntamente com uma carga concentrada em vãos simplesmente apoiados ou duas para vãos contínuos.

Há quatro classes de carregamentos, designadas por: H20, H15, HS20, HS15. Caso existam outros tipos de carregamentos, os mesmos serão obtidos por análise prévia do seu peso correspondente para o caminhão específico, com o correspondente carregamento na faixa de tráfego.

Os caminhões - modelo determinados pela AASHTO (1996) estão apresentados na figura 2.9. 


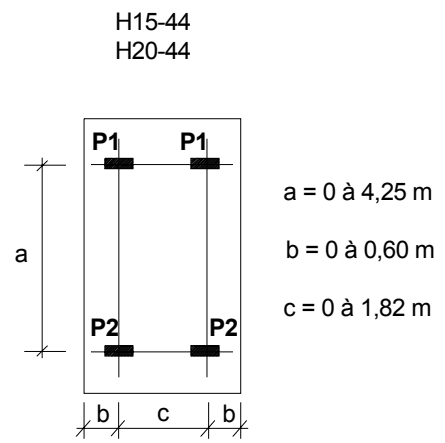

H15-44: P1 = 3000lbs.

$\mathrm{P} 2=12000 \mathrm{lbs} . \mathrm{H} 15(133 \mathrm{kN})$.

H20-44: P1 = 4000lbs.

$\mathrm{P} 2=16000 \mathrm{lbs} . \quad \mathrm{H} 20(180 \mathrm{kN})$

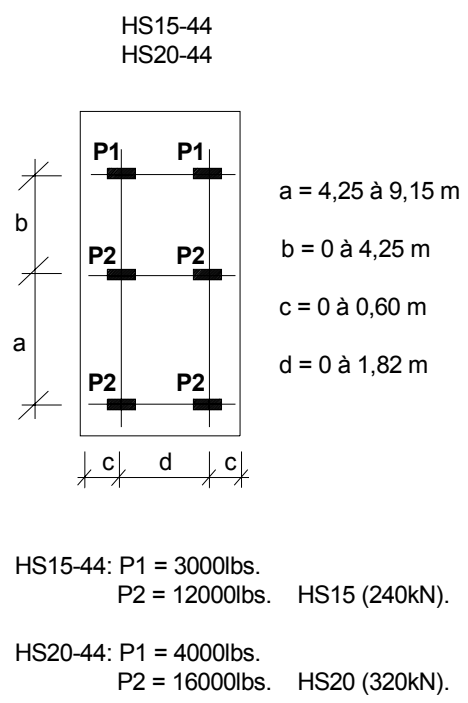

Figura 2.9- Considerações de veículos: Fonte: AASHTO (1996).

O espaçamento variável do HS-loading é devido à variabilidade no comprimento dos caminhões, e para que sejam feitas análises em vãos contínuos, de maneira que o seu posicionamento determine o máximo momento negativo.

Quanto ao carregamento uniformemente distribuído aplicado na faixa de tráfego, está representado na figura 2.10.

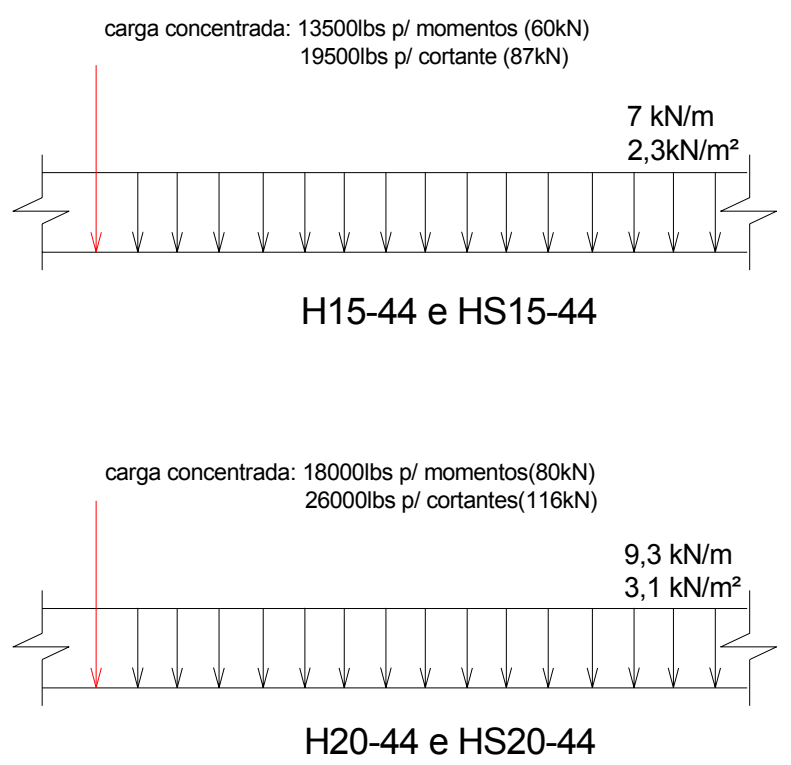

Figura 2.10- Considerações de cargas distribuídas. Fonte: AASHTO (1996). 
Para a determinação da solicitação máxima em vãos simplesmente apoiados ou contínuos, o tipo de carregamento a ser adotado, seja carregamento uniformemente distribuído ou o carregamento devido as cargas do caminhão, será aquele que produzir maior solicitação na região a ser verificada.

\subsection{3- Solicitações no guarda-rodas e defensas centrais e extremas.}

O dimensionamentos deve ser feito considerando uma força concentrada horizontal de $60 \mathrm{kN}$ aplicada na aresta superior sem considerar o efeito dinâmico. A figura 2.11 mostra a aplicação desta força.

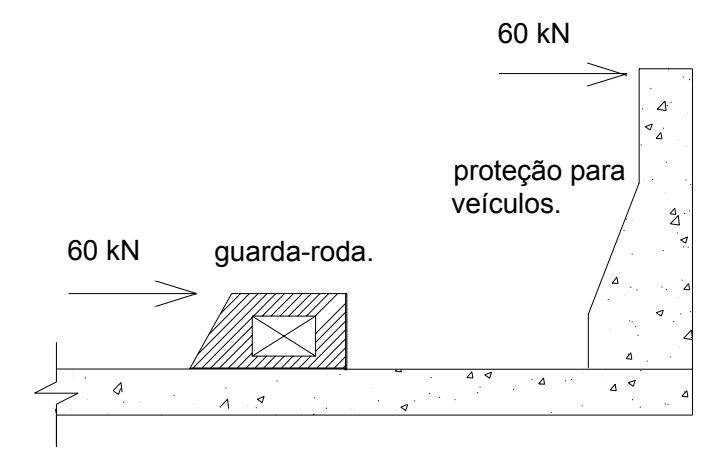

Figura 2.11- Força horizontal em defensas e guarda-rodas.

\subsection{4- Carga móvel em pontes ferroviárias.}

A NBR 7189 (1985) estabelece quatro trens-tipo:

- TB360: ferrovias sujeitas a transporte de minério de ferro e outros carregamentos equivalentes,

- TB270: ferrovias sujeitas a transporte de carga em geral,

- TB240: verificação de estabilidade e projeto de reforço, 
- TB170: vias exclusivas ao transporte de passageiros em regiões metropolitanas.

A designação dos trens-tipo é feita pela carga dos eixos mais pesados da locomotiva. A tabela e figura seguintes exemplificam melhor estas condições.

Tabela 2.5- Cargas referentes aos diferentes trens-tipo. Fonte: NBR 7189 (1985).

\begin{tabular}{|l|l|l|l|l|l|l|}
\hline Trens-tipo. & $\mathrm{Q}(\mathrm{kN})$ & $\mathrm{q}(\mathrm{kN} / \mathrm{m})$ & $\mathrm{q}^{\prime}(\mathrm{kN} / \mathrm{m})$ & $\mathrm{a}(\mathrm{m})$ & $\mathrm{b}(\mathrm{m})$ & $\mathrm{c}(\mathrm{m})$ \\
\hline TB-360 & 360 & 120 & 20 & 1,00 & 2,00 & 2,00 \\
\hline TB-270 & 270 & 90 & 15 & 1,00 & 2,00 & 2,00 \\
\hline Tb-240 & 240 & 80 & 15 & 1,00 & 2,00 & 2,00 \\
\hline TB-170 & 170 & 25 & 15 & 11,00 & 2,50 & 5,00 \\
\hline
\end{tabular}

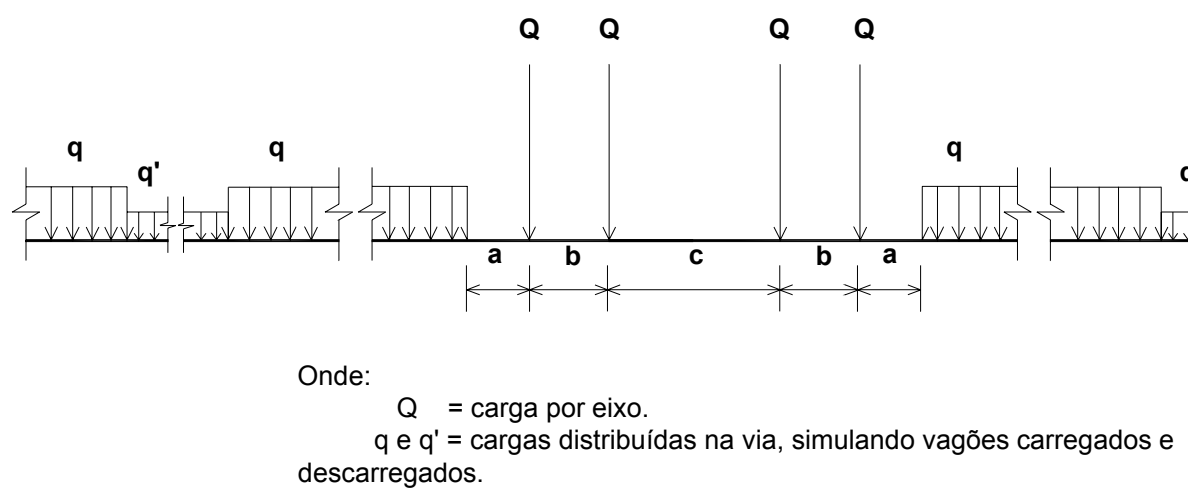

Figura 2.12- Trem-tipo em pontes ferroviárias. Fonte: NBR 7189(1985).

\subsection{5- Impacto vertical - Efeitos da ação dinâmica.}

A análise estrutural estática, considera que as cargas sejam aplicadas de maneira que sua intensidade cresça gradualmente de zero ao valor máximo, no entanto as cargas móveis que atuam nas pontes são aplicadas bruscamente.

Apenas a parte estática das cargas não corresponderia à realidade, em virtude das variações nos carregamentos dos veículos e trens.

Uma análise mais precisa pode ser realizada com os fundamentos da dinâmica das estruturas, entretanto para a simplificação do trabalho são consideradas as ações dinâmicas como se fossem cargas estáticas, multiplicando as cargas móveis por um fator chamado de coeficiente de impacto. 
Ao analisar a expressão abaixo (válida para rodovias e ferrovias), pode-se concluir que à medida que o vão é aumentado a influência dos efeitos dinâmicos decresce, em conseqüência do aumento da carga permanente G.

$$
\phi=1+\frac{0,4}{1+0,2 l}+\frac{0,6}{1+4 G / Q} \text { (Norma Francesa, apud Martinelli) }
$$

Sendo:

- L: vão em metros,

- G: carga permanente,

- Q: carga móvel máxima.

Também pode ser visto que a ação dinâmica é mais acentuada em pontes metálicas do que em pontes de concreto (maior a carga permanente), e por outro lado constata-se que o efeito dinâmico é maior em pontes ferroviárias (maior carga móvel) do que em pontes rodoviárias.

De acordo com a NBR 7187 (2003) os coeficientes de impacto devem ser determinados da seguinte maneira:

Para elementos estruturais de ponte rodoviária:

$$
\Phi=1,4-0,007 \times L \geq 1,0
$$

Para elementos estruturais de ponte ferroviária:

$$
\Phi=0,001 \times\left(1600-60 \times L^{1 / 2}+2,25 \times L\right) \geq 1,20
$$


Sendo L o vão teórico do elemento carregado, qualquer que seja o sistema estrutural, em metros. Em caso de vigas em balanço, o valor de $\mathrm{L}$ a ser empregado na expressão, corresponde a duas vezes o comprimento da mesma.

Em elementos contínuos, cada tramo terá seu coeficiente de impacto em função de seu respectivo vão teórico. Em pontes rodoviárias se os diferentes vãos não forem excessivamente desiguais $L_{\min } / L_{\text {máx }} \geq 0,7$, o coeficiente de impacto poderá ser único, enquanto que nas pontes ferroviárias é necessário considerar o impacto vertical para cada vão.

O efeito dinâmico pode ser desprezado nas pontes rodoviárias, quando o vão for maior ou igual a $57,14 \mathrm{~m}$.

Ao contrário, em pontes ferroviárias nunca é deixado de considerar o efeito dinâmico, sendo o coeficiente de impacto mínimo igual a $\phi=1,2$ para vãos maiores ou iguais a $169 \mathrm{~m}$.

A NBR 7187 (2003) permite utilizar também o coeficiente de impacto igual a 1, nas seguintes situações:

- Na determinação do empuxo de terra provocado por cargas móveis, figura 2.13. Esta recomendação da norma é em virtude da atenuação dos efeitos dinâmicos através do maciço de terra.

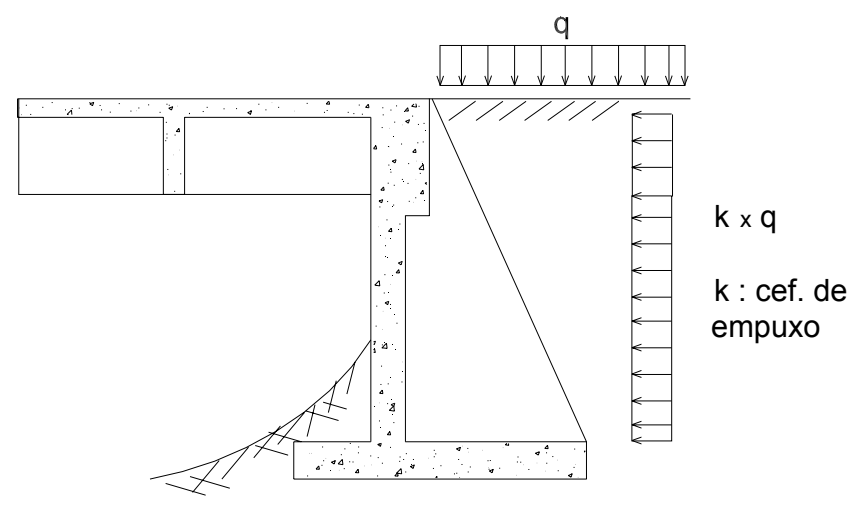

Figura 2.13- Empuxo de terra provocado pelas cargas móveis. 
- No dimensionamento de fundações profundas, devido à relação $G / Q$ ser suficientemente grande para atenuar os efeitos dinâmicos,

- No dimensionamento de elementos estruturais que suportam os passeios das pontes rodoviárias. O carregamento destes elementos leva em consideração a aglomeração de pessoas $\left(4\right.$ pessoas $\left./ \mathrm{m}^{2}\right)$ ou estacionamento de veículos, tais situações não produzem efeitos dinâmicos.

Notas: A AASHTO (1996) especifica o coeficiente de impacto em pontes rodoviárias igual a:

$$
\phi=[15,2 /(L+38)]+1
$$

- L : vão em metros.

Ao fazer uma comparação entre os coeficientes de impacto de pontes rodoviárias; observa-se que a NBR 7187 (2003) seu coeficiente de impacto apresenta um comportamento linear enquanto o coeficiente de impacto especificado pela AASHTO apresenta característica exponencial.

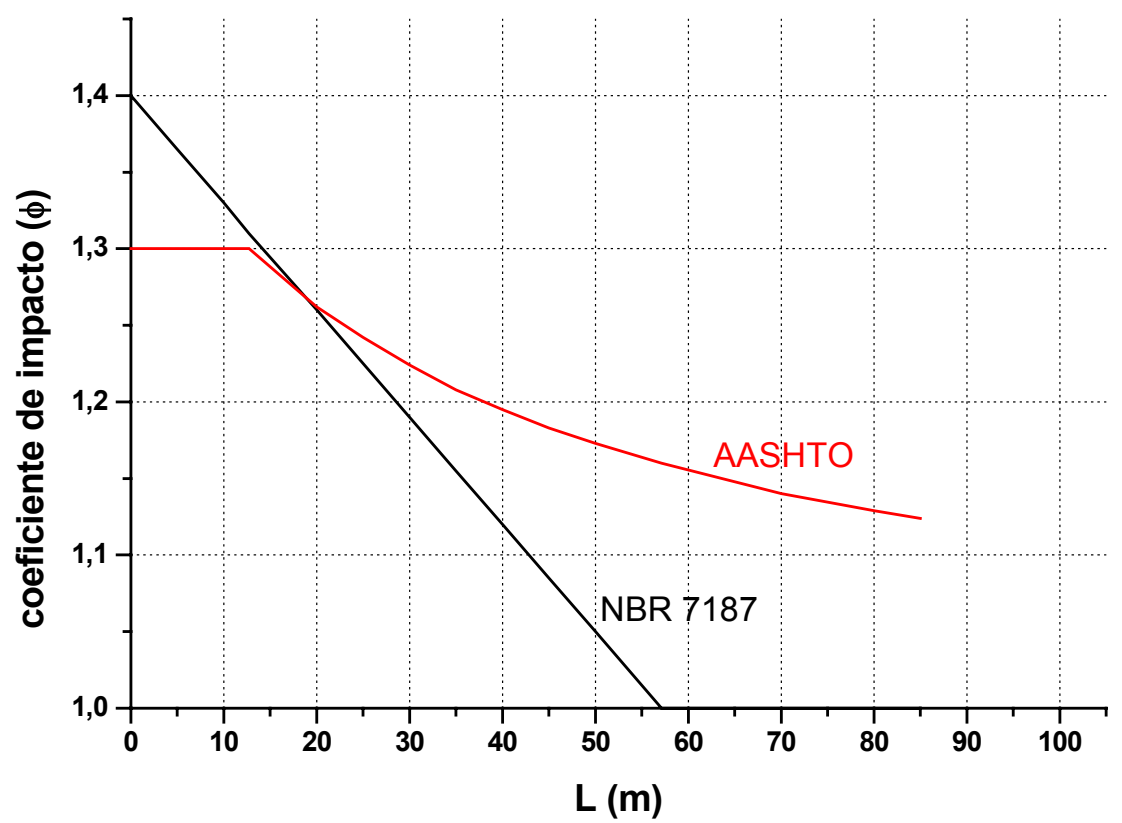

Figura 2.14- Gráfico comparativo dos coeficientes de impacto. 
O impacto, segundo a AASHTO (1996) deve ser considerado nos seguintes elementos estruturais:

- Superestrutura,

- Pilares,

- Pórticos de concreto e estacas de aço, localizadas acima do solo,

O impacto, segundo a AASHTO (1996), não deve ser considerado nos seguintes casos:

- Paredes de contenção,

- Blocos de fundação e estacas,

- Estruturas de madeira utilizadas no reforço de treliças,

- Passarelas e passeios,

\subsection{6- Força centrífuga.}

Esta força é manifestada nas pontes curvas, é aplicada pelo veículo através do atrito das rodas com a pavimentação, enquanto nas pontes ferroviárias esta força atua no centro de gravidade do trem, posicionada a $1,60 \mathrm{~m}$ acima do topo do trilho.

$\mathrm{Na}$ prática admite-se que a força centrífuga seja uniformemente distribuída ao longo do eixo da estrutura, com uma intensidade prescrita pela NBR 7187 (2003). Em rodovias a força centrífuga é obtida em função do tráfego e do raio de curvatura; enquanto nas ferrovias depende da largura das bitolas, procurando considerar a diferença de velocidades usuais entre bitola larga e bitola estreita. Bitola larga ou estreita corresponde a distância entre os trilhos. 
a) Pontes ferroviárias destinadas a linhas de bitola larga (1,60m).

- Raio $\leq 1200 m: F_{\text {centrifuga }}=15 \%$ da carga móvel + impacto

- Raio > 1200m: $F_{\text {centrifuga }}=(18000 /$ Raio $) \%$ da carga móvel + impacto

b) Pontes ferroviárias destinadas a linhas de bitola estreita $(1,00 \mathrm{~m})$.

- Raio $\leq 750 m: F_{\text {centrifuga }}=10 \%$ da carga móvel + impacto

- Raio > 750m: $F_{\text {centrifuga }}=(7500 /$ Raio $) \%$ da carga móvel + impacto

c) Pontes rodoviárias.

- Raio $\leq 300 \mathrm{~m}: \mathrm{F}_{\text {centrifuga }}=0,25 \times \mathrm{Pv}$ (peso do veículo-tipo)

- Raio > 300m: $F_{\text {centrifuga }}=(75 / R)$ x Pv (peso do veículo-tipo)

Para o dimensionamento das vigas principais, a força centrífuga deve atuar no centro de gravidade destas vigas juntamente com o momento aplicado (resultado da multiplicação do braço de alavanca com a força centrífuga).

Esta solicitação pode ser combatida por elementos estruturais denominados de contraventamento, ou pela própria laje do tabuleiro.

A força centrífuga também deve ser considerada no dimensionamento dos aparelhos de apoio e da infraestrutura.

\subsection{7- Impacto lateral.}

O impacto lateral é considerado em pontes ferroviárias, visto que o trem possui movimento não retilíneo, e devido a presença de folgas entre o friso da rodas e o trilho, ocorrem choques entre si. 
Segundo a NBR 7187 (2003) este efeito é representado por uma força concentrada no topo do trilho.

Ela deve ser posicionada na situação mais desfavorável com uma intensidade de $20 \%$ da carga do eixo mais pesado da locomotiva. Os valores e o posicionamento desta força está mostrado na tabela e figura seguintes.

Tabela 2.6- Valores da força devido ao impacto lateral.

\begin{tabular}{|l|l|l|l|l|}
\hline TB & 360 & 270 & 240 & 170 \\
\hline$F_{H}(k N)$ & 72 & 54 & 48 & 34 \\
\hline
\end{tabular}

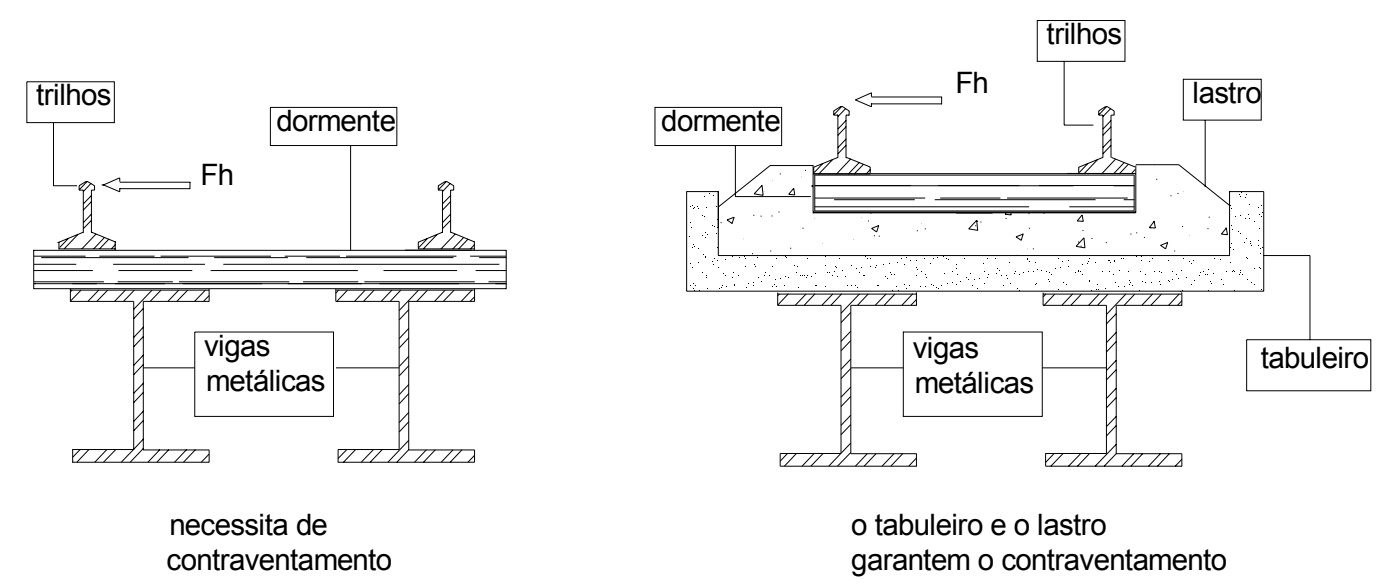

Figura 2.15- Impacto lateral em pontes ferroviárias.

Caso a ponte seja curva o impacto lateral não é superposto com a força centrífuga, devendo considerar a situação mais desfavorável.

Em pontes com dormentes aplicados diretamente sobre os vigamentos, é necessário prever um adequado contraventamento. Caso possua vigamentos sobre a laje mais a presença de um lastro, os mesmos auxiliarão no enrijecimento. A consideração do impacto lateral também é importante no dimensionamento da infraestrutura e dos aparelhos de apoio. 


\subsection{8- Pressão da água em movimento.}

Segundo a NBR 7187 (2003) a pressão da água em movimento que atua sobre pilares e elementos de fundações, pode ser determinada através da expressão:

$$
p=k \times V_{a}^{2}
$$

Onde:

- $\mathrm{p}$ : pressão estática equivalente, $\mathrm{kN} / \mathrm{m}^{2}$,

- $V_{a}$ é a velocidade da água em $\mathrm{m} / \mathrm{s}$,

- K é o coeficiente adimensional com valor igual a 0,34 para elementos com seção transversal circular.

Para elementos de seção retangular, o valor de k é representado na tabela 2.7.

Tabela 2.7- Valores de k em função do ângulo de incidência da água a face do elemento.

\begin{tabular}{|c|c|c|}
\hline Ângulo de incidência & $\mathrm{K}$ & \\
\hline $90^{\circ}$ & 0,71 & \\
\hline $45^{\circ}$ & 0,54 & $\square$ \\
\hline $0^{\circ}$ & 0 & $\sqrt{ }$ \\
\hline
\end{tabular}

Em situações intermediárias o valor de k deve ser obtido por interpolação linear. É comum que galhos e troncos de árvores sejam levados pelo rio, portanto esta pressão pode ser bem maior devido ao fato desse material se prender nos pilares. 
Em situações em que o efeito dinâmico da água seja importante, a NBR 7187 (2003) estabelece que o estudo destes efeitos seja fundamentado na teoria da hidrodinâmica.

\subsection{9- Força longitudinal por frenagem ou aceleração.}

Em casos em que ocorra aceleração e/ou freadas bruscas sobre as pontes, pode ocorrer sobre as mesmas forças longitudinais ao longo da ponte.

Geralmente o tabuleiro de concreto resiste bem as estes esforços, transmitindo-os aos elementos de apoio, pilares e fundações.

A norma NBR 7187 (2003) define as forças horizontais de frenagem e aceleração da seguinte maneira:

a) Pontes ferroviárias:

- Frenagem: $15 \%$ da carga móvel sem impacto,

- Aceleração: $25 \%$ do peso total sobre os eixos motores (locomotiva).

b) Pontes rodoviárias:

Tanto as forças de frenagem como as de aceleração são dadas as mesmas considerações, adotando-se o maior valor entre as duas alternativas:

- $5 \%$ do carregamento total do tabuleiro, com as cargas móveis uniformemente distribuídas sem impacto excluindo o passeio,

- $30 \%$ do peso do veículo - tipo.

Notas: Essas forças longitudinais são sempre aplicadas na superfície de rolamento (pavimentação ou no topo do trilho). 


\subsubsection{0- Ação do vento.}

A NBR 7187 (2003) não indica nenhum procedimento para a determinação da ação do vento em pontes, recomenda apenas basear-se na NBR 6123 (1988) "Ação do Vento em Edifícios".

Apresenta-se o procedimento indicado pala antiga norma NB-2 (1961), onde a ação de vento é considerada uniformemente distribuída, horizontalmente e normal ao eixo da ponte.

São admitidos dois casos de carregamento: tabuleiro sem tráfego e tabuleiro com tráfego.

No primeiro caso considera-se como superfície de incidência do vento a projeção da estrutura sobre o plano normal à direção do vento.

No segundo caso essa projeção é acrescida de uma faixa limitada na parte superior, por uma linha paralela a ponte, distante da superfície de rolamento de $2 \mathrm{~m}$ e $3,5 \mathrm{~m}$. Estes valores são respectivamente de pontes rodoviárias e ferroviárias, na figura 2.16 apresenta maiores detalhes.

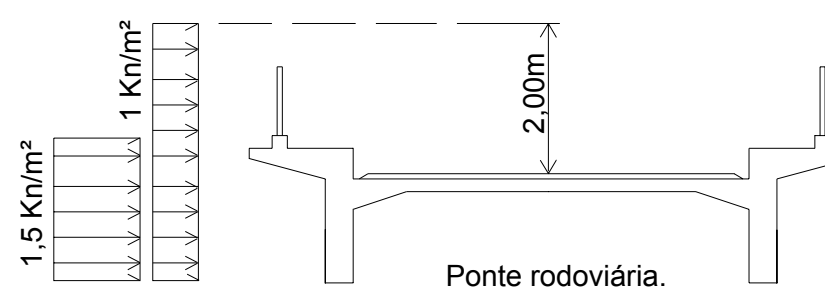

$1,5 \mathrm{kN} / \mathrm{m}^{2}$ - ponte descarregada.

$1,0 \mathrm{kN} / \mathrm{m}^{2}$ - ponte carregada.

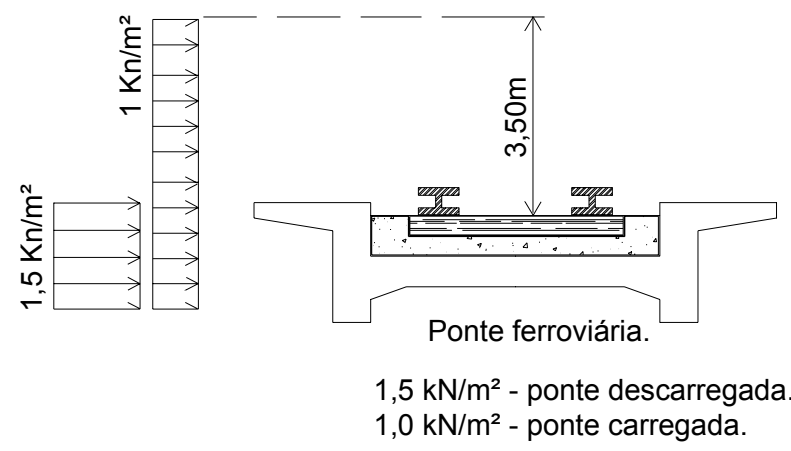

Figura 2.16- Ações de vento a serem consideradas nas pontes. Fonte: NB-2 (1961). 
Pontes descarregadas admite-se que a pressão do vento seja de $1,5 \mathrm{kN} / \mathrm{m}^{2}$ e pontes carregadas $1 \mathrm{kN} / \mathrm{m}^{2}$, independente da finalidade da ponte.

A força do vento é aplicada a uma certa altura da superfície de rolamento, que se traduz em momento e uma força horizontal aplicada no plano médio das vigas principais, fazendo-se do uso necessário de contraventamento.

Deve-se dar a mesma importância desta ação, no dimensionamento da infraestrutura e dos aparelhos de apoio.

\subsubsection{1- Ações construtivas.}

A NBR 7187 (2003) estabelece que no projeto devem ser consideradas as ações que possam ocorrer durante o período de construção, principalmente o peso de equipamentos e estruturas auxiliares de montagem e lançamento dos elementos estruturais.

\subsubsection{2- Atrito nos apoios.}

O atrito faz com que apareçam forças horizontais sobre os aparelhos de apoio, pilares e superestrutura.

De acordo com a antiga NB2 (1961) a força de atrito deve ser de 3\% da carga permanente mais a carga móvel sem impacto, nos aparelhos de apoio de rolamento e $20 \%$ nos aparelhos de escorregamentos.

\subsubsection{3- Empuxo de terra provocado por cargas móveis.}

Além das ações atuantes nas estruturas que arrimam talude, comentadas no item 2.2.3, pode ocorrer nos encontros e cortinas solicitações devido à sobrecarga de veículos adentrando ou deixando a ponte, estas solicitações devem ser adicionadas às anteriores.

Esta sobrecarga é considerada e posicionada na cabeceira da ponte, de maneira que seja transformado o peso do veículo - tipo em carga uniformemente 
distribuída somada a carga distribuída q, que considera o efeito de outros veículos.

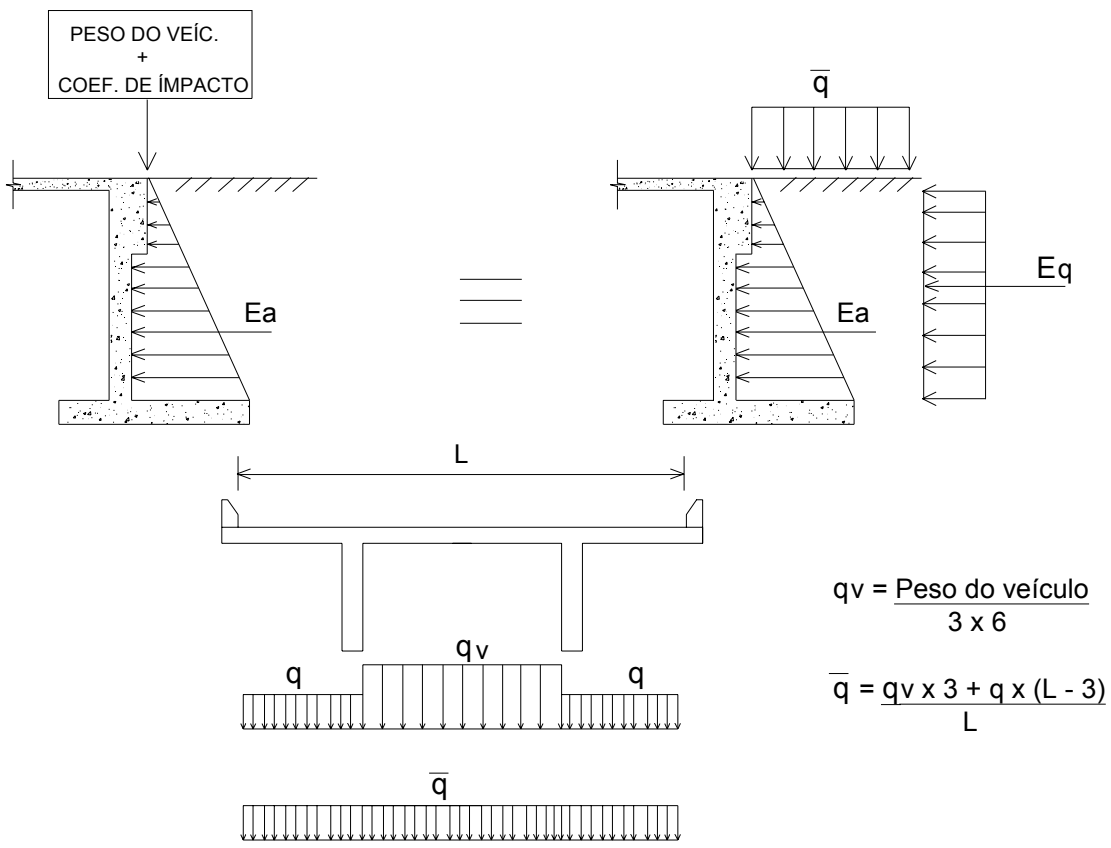

Figura 2.17- Empuxo de terra provocado por cargas móveis.

O carregamento é considerado como aterro adicional, de altura $h_{a}$ dividido pelo peso específico do solo, como mostra a figura 2.18.

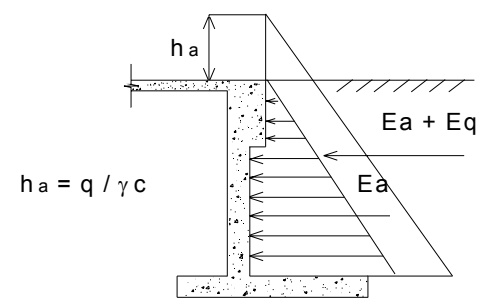

Figura 2.18- Transformação da carga móvel distribuída em altura de terra.

\section{4- Ações excepcionais.}

A norma NBR 8681 (2003) estabelece que ações excepcionais são aquelas que possuem duração extremamente curta e baixa probabilidade de ocorrência 
durante a vida útil da estrutura, mas que devem ser consideradas no projeto em determinadas situações.

A NBR 7187 (2003) considera como ações excepcionais choques de veículos e de embarcações, e estabelece que os pilares passíveis de serem atingidos devem ser verificados a sua segurança.

É dispensada esta verificação se for previsto em projeto, dispositivos capazes de proteger a estrutura contra este tipo de acidente.

A norma alemã DIN 1072 (1973), define forças horizontais de 1000 kN na direção longitudinal e 500 kN na direção transversal de maneira não simultânea, posicionadas a $1,20 \mathrm{~m}$ da superfície de rolamento, tais ações são consideradas no dimensionamento da infraestrutura. 


\section{3- COMBINAÇÃO DAS AÇÕES.}

\section{1- Generalidades.}

Considera-se quatro pontos básicos na elaboração de um projeto estrutural:

- Segurança,

- Durabilidade,

- Funcionalidade na utilização,

- Economia na construção e manutenção.

A NBR 8681 (2003) fixa condições exigíveis na verificação das estruturas usuais, estabelecendo definições e critérios de quantificação das ações e das resistências a serem consideradas no projeto de estruturas.

Os critérios de verificação da segurança e os de quantificação das ações, são válidos para as estruturas e peças estruturais construídas com qualquer dos materiais empregados na construção civil.

\section{2- Estados limites.}

Estados limites são aqueles que quando atingidos, tornam a estrutura inutilizável ou as deixam incapaz de satisfazer as exigências previstas para seu uso adequado.

A NBR 8681 (2003) define dois estados limites, estados limites últimos (ELU) e estados limites de serviço (ELS). 


\subsection{1- Estados limites últimos (ELU).}

Os estados limites últimos são aqueles relacionados ao esgotamento da capacidade resistente da estrutura no seu todo ou em parte, devido às solicitações normais e tangenciais.

No projeto, os estados limites últimos são caracterizados como:

- Perda de equilíbrio global ou parcial, admitindo a estrutura como um corpo rígido,

- Ruptura ou deformação plástica excessiva dos materiais,

- Transformação da estrutura no todo ou em parte, em sistema hipostático,

- Instabilidade por deformação,

- Instabilidade dinâmica.

Os critérios de combinações últimas são os seguintes:

- Ações permanentes: devem figurar em todas as combinações de ações,

- Ações variáveis nas combinações últimas normais: em cada combinação última, uma das ações variáveis é considerada como principal, admitindose que ela atue com seu valor característico $F_{k}$. As demais ações variáveis são consideradas como secundárias, admitindo-se que elas atuem com seus valores reduzidos de combinação $\psi_{0} F_{k}$,

- Ações variáveis nas combinações últimas especiais: quando existir a ação variável especial considera-se o seu valor representativo. As demais ações variáveis devem ser consideradas com valores correspondentes a uma 
probabilidade não desprezível de atuação simultânea com a ação variável especial,

- Ações variáveis nas combinações últimas excepcionais: Quando existir a ação excepcional deve ser considerado com seu valor representativo. As demais ações variáveis devem ser consideradas, com valores correspondentes a uma probabilidade de atuação simultânea com a ação variável excepcional.

\subsection{2- Estados limites de serviço (ELS).}

O estado limite de serviço é um estado que por sua ocorrência, repetição e duração causam efeitos estruturais que não respeitam as condições especificadas para o uso normal da construção, ou que são indícios de comprometimento da durabilidade da estrutura.

No período de vida útil da estrutura, os estados limites de serviço são os seguintes:

- Danos localizados que comprometem a durabilidade da estrutura,

- Deformações excessivas que afetam a utilização normal da construção,

- Vibração excessiva,

- Formação de fissuras,

- Aberturas de fissuras,

- Compressão excessiva,

- Descompressão. 
Notas: Os dois últimos estados limites de utilização são considerados em peças estruturais em concreto protendido, que por sua vez não serão abordados, pois não fazem parte do conteúdo deste trabalho.

Os estados limites de serviço decorrem de ações cujas combinações podem ter três diferentes ordens de grandeza de permanência na estrutura, que são:

- Combinações quase-permanentes: combinações que podem atuar durante grande parte do período de vida da estrutura, da ordem da metade deste período. Estas combinações são utilizadas na verificação de deformações (flechas) com relação aos esforços de flexão,

- Combinações freqüentes: combinações que se repetem muitas vezes durante o período de vida da estrutura, da ordem de $10^{5}$ vezes em 50 anos, ou que tenham duração total igual a uma parte não desprezível desse período, da ordem de 5\%. Estas combinações são utilizadas na verificação de aberturas de fissuras,

- Combinações raras: combinações que podem atuar no máximo algumas horas durante o período de vida da estrutura. Estas combinações são utilizadas na verificação de formação de fissuras.

\section{3- Ações.}

Para o estabelecimento das regras de combinações das ações, as mesmas são classificadas segundo sua variabilidade no tempo, em três categorias:

- Ações permanentes diretas e indiretas,

- Ações variáveis normais e especiais,

- Ações excepcionais. 


\subsection{1- Ações permanentes.}

- Ações permanentes diretas: são considerados os pesos próprios das estruturas e de todos os elementos construtivos permanentes, os pesos próprios dos equipamentos e empuxos de terra.

- Ações permanentes indiretas: são consideradas as ações de protensão, os recalques de apoio, retração e fluência dos materiais.

\subsection{2- Ações variáveis.}

São consideradas as cargas acidentais, cargas móveis, força em decorrência da frenagem, impacto e centrífuga, efeitos do vento, variações de temperatura, atrito nos aparelhos de apoio, pressões hidrostáticas e hidrodinâmicas.

Em função de sua probabilidade de ocorrência durante sua vida útil, as ações variáveis são classificadas em normais e especiais.

- Ações variáveis normais: sua probabilidade de ocorrência é suficientemente grande para que sejam obrigatoriamente consideradas no projeto de estruturas.

- Ações variáveis especiais: compreendem as ações sísmicas e cargas. As combinações destas ações devem ser especificamente definidas para as situações especiais consideradas.

\subsection{3- Ações excepcionais.}

Consideram-se como excepcionais as ações decorrentes de explosões, choques de veículos, incêndios, enchentes ou sismos excepcionais. 


\section{4- Combinações últimas das ações.}

\subsection{1- Combinações últimas normais.}

Para as combinações últimas normais, o valor da ação de cálculo pode ser apresentado pela seguinte expressão:

$$
F_{d}=\sum_{i=1}^{m} \gamma_{g i} F_{G i, k}+\gamma_{q}\left(F_{Q 1, k}+\sum_{j=2}^{n} \psi_{0 j} F_{Q j, k}\right)
$$

Onde:

- $F_{G i, k}$ : valor característico das ações permanentes,

- $F_{Q 1, k}$ : valor característico da ação variável considerada como ação principal na combinação,

- $F_{Q j, k}$ : valor característico das demais ações variáveis,

- $\Psi_{0 j}$ : fator de combinação que reduz as demais ações variáveis,

- $\gamma_{g i}:$ coeficientes de ponderação das ações permanentes,

- $\gamma_{q}$ : coeficiente de ponderação das ações variáveis.

\subsection{2- Combinações últimas especiais ou de construção.}

Para as combinações últimas especiais ou de construção, o valor da ação de cálculo pode ser apresentado pela seguinte expressão: 


$$
F_{d}=\sum_{i=1}^{m} \gamma_{g i} F_{G i, k}+\gamma_{q}\left(F_{Q 1, k}+\sum_{j=2}^{n} \psi_{0 j, e f} F_{Q j, k}\right)
$$

Sendo:

- $F_{G i, k}$ : valor característico das ações permanentes,

- $F_{Q 1, k}$ : valor característico da ação variável, admitida como ação principal para a situação transitória considerada,

- $\Psi_{0 j, e f}:$ o fator de combinação efetivo de cada uma das demais variáveis que podem agir concomitantemente como ação principal $F_{Q 1}$, durante a situação transitória,

- $\gamma_{g i}$ : coeficientes de ponderação das ações permanentes,

- $\gamma_{q}$ : coeficiente de ponderação das ações variáveis.

O fator $\psi_{0 j, e f}$ é igual ao fator $\psi_{0 j}$ adotado nas combinações normais, salvo quando a ação principal $F_{Q 1}$ tiver um tempo de atuação muito pequeno, neste caso $\Psi_{0 \text { j,ef }}$ pode ser tomado com o correspondente $\Psi_{2 j}$.

\subsection{3- Combinações últimas excepcionais.}

Para as combinações últimas excepcionais, o valor da ação de cálculo pode ser apresentado pela seguinte expressão:

$$
F_{d}=\sum_{i=1}^{m} \gamma_{g i} F_{G i, k}+F_{Q, e x c}+\gamma_{q} \sum_{j=1}^{n} \psi_{0 j, e f} F_{Q j, k}
$$


Onde:

- $F_{Q, e x c}$ : é o valor da ação transitória excepcional, os demais termos já foram definidos nos itens anteriores.

\section{5- Coeficientes de ponderação para combinações últimas.}

\subsection{1- Coeficientes de ponderação para as ações permanentes.}

Os coeficientes de ponderação $\gamma_{g}$ das ações permanentes majoram os valores representativos destas ações que provocam efeitos desfavoráveis, e minoram os valores representativos daquela que provocam efeitos favoráveis.

Para uma estrutura, dada a ação permanente, todas as suas parcelas são ponderadas pelo mesmo coeficiente $\gamma_{g}$, não se admitindo que algumas de suas partes possam ser majoradas e outras minoradas.

Os coeficientes de ponderação $\gamma_{g}$ relativos às ações permanentes diretas, que figuram nas combinações últimas, devem ser tomados com os valores básicos indicados a seguir: 
Tabela 3.1- Valores de $Y_{g}$ para ações permanentes diretas consideradas separadamente. Fonte: NBR 8681 (2003).

\begin{tabular}{|c|c|c|c|}
\hline \multirow[t]{2}{*}{ Combinação. } & \multirow[t]{2}{*}{ Tipo de ação. } & \multicolumn{2}{|c|}{ Efeito. } \\
\hline & & Desfavorável. & Favorável. \\
\hline \multirow{3}{*}{ Normal. } & $\begin{array}{l}\text { Peso próprio de } \\
\text { estrutura metálica. }\end{array}$ & 1,25 & 1,0 \\
\hline & $\begin{array}{l}\text { Peso próprio de } \\
\text { estruturas pré-moldadas. }\end{array}$ & 1,30 & 1,0 \\
\hline & $\begin{array}{l}\text { Peso próprio de } \\
\text { estruturas moldadas } \\
\text { in loco. }\end{array}$ & 1,35 & 1,0 \\
\hline \multirow{3}{*}{$\begin{array}{l}\text { Especial ou de } \\
\text { construção. }\end{array}$} & \begin{tabular}{|l|} 
Peso próprio de \\
estrutura metálica.
\end{tabular} & 1,15 & 1,0 \\
\hline & $\begin{array}{l}\text { Peso próprio de } \\
\text { estruturas pré-moldadas. }\end{array}$ & 1,20 & 1,0 \\
\hline & $\begin{array}{l}\text { Peso próprio de } \\
\text { estruturas moldadas } \\
\text { in loco. }\end{array}$ & 1,25 & 1,0 \\
\hline \multirow{3}{*}{ Excepcional. } & \begin{tabular}{|l|} 
Peso próprio de \\
estrutura metálica.
\end{tabular} & 1,10 & 1,0 \\
\hline & \begin{tabular}{|l|} 
Peso próprio de \\
estruturas pré-moldadas.
\end{tabular} & 1,15 & 1,0 \\
\hline & $\begin{array}{l}\text { Peso próprio de } \\
\text { estruturas moldadas } \\
\text { in loco. }\end{array}$ & 1,15 & 1,0 \\
\hline
\end{tabular}

Tabela 3.2- Valores de $\mathrm{Y}_{\mathrm{g}}$ para ações permanentes diretas agrupadas.

Fonte: NBR 8681 (2003).

\begin{tabular}{|c|c|c|c|}
\hline \multirow[t]{2}{*}{ Combinações. } & \multirow[t]{2}{*}{ Tipos de estrutura. } & \multicolumn{2}{|c|}{ Efeito. } \\
\hline & & Desfavorável. & Favorável. \\
\hline \multirow[t]{2}{*}{ Normal. } & Grandes pontes ${ }^{11}$. & 1,30 & 1,0 \\
\hline & Pontes em geral $^{2)}$. & 1,35 & 1,0 \\
\hline \multirow{2}{*}{$\begin{array}{l}\text { Especial ou de } \\
\text { construção. }\end{array}$} & Grandes pontes ${ }^{1 !}$. & 1,20 & 1,0 \\
\hline & Pontes em geral $^{2)}$. & 1,25 & 1,0 \\
\hline \multirow[t]{2}{*}{ Excepcional. } & Grandes pontes ${ }^{11}$. & 1,10 & 1,0 \\
\hline & Pontes em geral ${ }^{2)}$. & 1,15 & 1,0 \\
\hline
\end{tabular}

\subsection{2- Coeficiente de ponderação para as ações variáveis.}

Os coeficientes de ponderação $\gamma_{q}$ das ações variáveis, majoram os valores representativos destas ações que provocam efeitos desfavoráveis para a segurança da estrutura. 
As ações que provocam efeitos favoráveis não são consideradas nas combinações de ações, admitindo-se que sobre a estrutura atuem apenas as parcelas de ações que produzam efeitos desfavoráveis.

As ações variáveis que tenham parcelas favoráveis e desfavoráveis, que fisicamente não possam atuar separadamente, devem ser consideradas conjuntamente como uma ação única.

Os coeficientes de ponderação $\gamma_{q}$ relativos as ações variáveis que figuram nas combinações últimas, devem ser tomados com os valores básicos indicados na tabela 3.3 (ações consideradas separadamente) ou na tabela 3.4 (ações consideras conjuntamente). O projetista deve escolher uma dessas duas tabelas.

Tabela 3.3- Valores de $\mathrm{Y}_{\mathrm{q}}$ para ações variáveis consideradas separadamente.

Fonte: NBR 8681 (2003).

\begin{tabular}{|c|c|c|}
\hline Combinação. & Tipo de ação. & Coeficiente de ponderação. \\
\hline \multirow{4}{*}{ Normal. } & Ações truncadas ${ }^{1 !}$. & 1,2 \\
\hline & Efeito de temperatura & 1,2 \\
\hline & Ação do vento & 1,4 \\
\hline & Ações variáveis em geral & 1,5 \\
\hline \multirow{4}{*}{$\begin{array}{l}\text { Especial ou } \\
\text { de construção. }\end{array}$} & Ações truncadas ${ }^{1)}$ & 1,1 \\
\hline & Efeito de temperatura & 1,0 \\
\hline & Ação do vento & 1,2 \\
\hline & Ações variáveis em geral & 1,3 \\
\hline Especiais. & Ações variáveis em geral & 1,0 \\
\hline \multicolumn{3}{|c|}{$\begin{array}{l}\text { Ações truncadas são consideradas ações variáveis cuja distribuição de máximos é } \\
\text { truncada por um dispositivo físico de modo que o valor dessa ação não possa } \\
\text { superar o limite correspondente. } \\
\text { O coeficiente de ponderação representado na tabela } 3.3 \text {, é aplicado a esse valor limite. }\end{array}$} \\
\hline
\end{tabular}

Tabela 3.4- Valores de $\gamma_{q}$ para ações variáveis consideradas conjuntamente ${ }^{1)}$.

Fonte: NBR 8681 (2003).

\begin{tabular}{|c|c|c|}
\hline Combinação. & Tipo de estrutura. & Coeficiente de ponderação. \\
\hline Normal. & Pontes & 1,5 \\
\hline $\begin{array}{l}\text { Especial ou } \\
\text { de construção. }\end{array}$ & Pontes \\
\hline \multicolumn{2}{|c|}{ Excepcional. } & Estrutura em geral \\
\hline $\begin{array}{l}{ }^{1} \text { Quando as ações variáveis forem consideradas conjuntamente, o coeficiente de } \\
\text { ponderação representado na tabela 3.4 é aplicado a todas as ações, considerando } \\
\text { também de maneira conjunta as ações permanentes diretas. }\end{array}$ \\
\hline
\end{tabular}




\subsection{3- Coeficiente de ponderação para as ações excepcionais.}

O coeficiente de ponderação $\gamma_{f}$ relativo à ação excepcional que figura nas combinações últimas excepcionais, deve ser tomados como valor básico um $Y_{f}=1,0$.

\section{6- Fatores de combinação e de redução.}

Os fatores de combinação $\Psi_{0}$ estão indicados na tabela 3.5 , juntamente com os fatores de redução $\Psi_{1}$ e $\Psi_{2}$ referentes às combinações de serviço.

Tabela 3.5- Valores de fatores de combinação $\psi_{0}$ e de redução $\psi_{1}$ e $\psi_{2}$ para ações variáveis. Fonte: NBR 8681 (2003).

\begin{tabular}{|l|l|l|l|}
\hline \multicolumn{1}{|c|}{ Ações. } & $\Psi_{0}$ & $\Psi_{1}$ & $\Psi_{2}{ }^{1}$ \\
\hline \multicolumn{1}{|c|}{ Vento. } & & & \\
Pressão dinâmica do vento nas estruturas em geral. & 0,6 & 0,3 & 0 \\
\hline \multicolumn{1}{|c|}{ Temperatura. } & & & \\
Variações uniformes de temperatura em relação à média anual local. & 0,6 & 0,5 & 0,3 \\
\hline \multicolumn{1}{|c|}{ Cargas móveis e seus efeitos dinâmicos. } & & & \\
Passarelas de pedestres. & 0,6 & 0,4 & 0,3 \\
\hline $\begin{array}{l}\text { Pontes rodoviárias. } \\
\text { Pontes ferroviárias não especializadas. }\end{array}$ & 0,7 & 0,5 & 0,3 \\
\hline $\begin{array}{l}\text { Pontes ferroviárias especializadas. } \\
\Psi_{2} \text { o valor zero. }\end{array}$ & 0,8 & 0,7 & 0,5 \\
\hline Vigas de rolamentos de pontes rolantes. & 1,0 & 1,0 & 0,6 \\
\hline
\end{tabular}




\section{7- Fatores de redução para a combinação freqüente, aplicável à verificação}

\section{da fadiga.}

Na falta de um espectro de carga que defina a freqüência de repetição de cada nível de carga, e que permita a aplicação da regra de Palmgren-Miner, a verificação da fadiga pode ser feita para um único nível de carga. Esse nível de carga é definido pela carga freqüente de fadiga $\Psi_{1, \text { fad }} F_{q k}$, à qual corresponde um certo número de ciclos de carga.

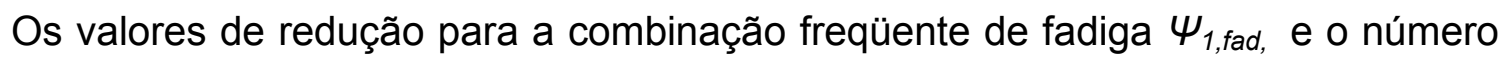
de repetições $(\mathrm{N})$ que possa causar a ruptura por fadiga para a mesma condição de carregamento, são estabelecidos na tabela 3.6.

Tabela 3.6- Valores dos fatores de redução para a combinação freqüente de fadiga para o número de repetições $(N)$ igual a $2 \times 10^{6}$.Fonte: NBR 8681 (2003).

\begin{tabular}{|c|c|}
\hline $\begin{array}{l}\text { Carga móvel e seus efeitos } \\
\text { dinâmicos. }\end{array}$ & $\boldsymbol{\Psi}_{1, \text { fad }}$ \\
\hline Passarelas de pedestres. & 0 \\
\hline \multicolumn{2}{|l|}{ Pontes rodoviárias. } \\
\hline Laje do tabuleiro. & 0,8 \\
\hline Vigas transversais. & 0,7 \\
\hline $\begin{array}{l}\text { Vigas longitudinais }{ }^{1)} \text {. } \\
\text { Vão até } 100 \mathrm{~m} .\end{array}$ & 0,5 \\
\hline Vão de $200 \mathrm{~m}$. & 0,4 \\
\hline Vão $\geq 300 \mathrm{~m}$. & 0,3 \\
\hline Mesa e infraestrutura. & 0 \\
\hline Pontes ferroviárias especializadas. & 1,0 \\
\hline Pontes ferroviárias não especializadas. & 0,8 \\
\hline
\end{tabular}




\section{8- Combinações das ações em serviço.}

Nas combinações de serviço são consideradas todas as ações permanentes, inclusive as deformações impostas permanentes, e as ações variáveis correspondentes a cada um dos tipos de combinações, de acordo com o que é indicado a seguir.

\subsection{1- Combinação quase-permanente de serviço.}

Nas combinações quase-permanentes de serviço, todas as ações variáveis são consideradas com seus valores quase-permanentes $\Psi_{2} F_{Q k}$.

$$
F_{d, u t i l}=\sum_{i=1}^{m} F_{G i, k}+\sum_{j=1}^{n} \psi_{2 j} F_{Q j, k}
$$

\subsection{2- Combinações freqüentes de serviço.}

Nas combinações freqüentes de serviço, a ação variável principal $F_{Q 1}$ é tomada com seu valor freqüente $\Psi_{1} F_{Q 1, k}$ as demais ações variáveis são tomadas com seus valores quase-permanentes $\Psi_{2} F_{Q k}$.

$$
F_{d, u t i l}=\sum_{i=1}^{m} F_{G i, k}+\psi_{1} F_{Q 1, k}+\sum_{j=2}^{n} \psi_{2 j} F_{Q j, k}
$$

\subsection{3- Combinações raras de serviço.}

Nas combinações raras de serviço, a ação variável principal $F_{Q 1}$ é tomada com seu valor característico $F_{Q 1, k}$, as demais ações são tomadas com seus valores freqüentes $\psi_{1} F_{Q k}$. 


$$
F_{d, u t i l}=\sum_{i=1}^{m} F_{G i, k}+F_{Q 1, k}+\sum_{j=2}^{n} \psi_{1 j} F_{Q j, k}
$$

\section{9- Valores a serem considerados na abertura de fissuras.}

Na tabela 3.7 são mostrados os valores máximos permitidos de aberturas de fissuras, de acordo com a sensibilidade das armaduras à corrosão e também as combinações de ações a serem consideradas. Os valores desta tabela são da NBR 7187 (1986) "Projeto e execução de pontes de concreto armado e protendido".

Tabela 3.7- Estados limites de fissuração, em função das condições do meio ambiente e da sensibilidade das armaduras à corrosão. Fonte: NBR 7187 (1986).

\begin{tabular}{|c|c|c|c|c|c|}
\hline \multirow{3}{*}{$\begin{array}{l}\text { Condições } \\
\text { do meio } \\
\text { ambiente. }\end{array}$} & \multirow{3}{*}{$\begin{array}{l}\text { Combinação } \\
\text { de ações. }\end{array}$} & \multicolumn{4}{|c|}{ Sensibilidade das armaduras à corrosão. } \\
\hline & & \multicolumn{2}{|c|}{ Muito sensível. } & \multicolumn{2}{|c|}{ Pouco sensível. } \\
\hline & & Estado limite. & $\mathrm{w}_{\mathrm{k}}(\mathrm{mm})$. & Estado limite. & $\mathrm{w}_{\mathrm{k}}(\mathrm{mm})$. \\
\hline \multirow{2}{*}{$\begin{array}{l}\text { Não } \\
\text { agressivas. }\end{array}$} & Freqüente & Abertura de fissuras. & 0,2 & $\begin{array}{l}\text { Abertura de } \\
\text { fissuras. }\end{array}$ & 0,3 \\
\hline & $\begin{array}{l}\text { Quase } \\
\text { permanece. }\end{array}$ & Abertura de fissuras. & 0,1 & & \\
\hline $\begin{array}{l}\text { Pouco } \\
\text { agressivas. }\end{array}$ & Freqüente. & Abertura de fissuras. & 0,1 & $\begin{array}{l}\text { Abertura de } \\
\text { fissuras. }\end{array}$ & 0,2 \\
\hline \multirow{2}{*}{$\begin{array}{l}\text { Muito } \\
\text { agressivas. }\end{array}$} & Rara. & Formação de fissuras. & & $\begin{array}{l}\text { Abertura de } \\
\text { fissuras. }\end{array}$ & 0,2 \\
\hline & Freqüente. & Descompressão. & & $\begin{array}{l}\text { Abertura de } \\
\text { fissuras. }\end{array}$ & 0,1 \\
\hline
\end{tabular}

Ambientes não agressivos são caracterizados por regiões com baixa umidade relativa durante a maior parte do ano.

Ambientes de poucas agressividades correspondem a locais de intempéries de níveis normais, seja em contato com a água corrente e atmosfera sem grandes concentrações de gases agressivos.

Em se tratando de ambientes muito agressivos, correspondem a locais marinhos e industriais. 
Quanto à sensibilidade de armaduras à corrosão, são consideradas sensíveis as armaduras com diâmetros não superiores a $4 \mathrm{~mm}$, independentes dos tipos de aços.

A NBR 6118 (2002) determina as aberturas de fissuras $\left(w_{k}\right)$, através das seguintes equações:

$$
\begin{gathered}
w_{1}=\frac{\phi_{i} \times \sigma_{s i} \times 3 \sigma_{s i}}{12,5 \times \eta_{i} \times E_{s i} \times f_{c m}} \\
w_{2}=\frac{\phi_{i} \times \sigma_{s i}}{12,5 \times \eta_{i} \times E_{s i}} \times\left(\frac{4}{\rho_{r i}}+45\right)
\end{gathered}
$$

Notas: Adota-se para $w_{k}$ o menor valor entre $w_{1}$ e $w_{2}$

As variáveis envolvidas nas equações são:

- $\&_{\mathrm{i}}$ : diâmetro da barra,

- $\sigma_{\text {si }}$ : tensão da armadura no estádio II,

- $\eta_{i}$ : coeficiente de comformação superficial da barra (para barras passivas $\eta_{i}=2,25$ )

- $\mathrm{E}_{\mathrm{si}}$ : módulo de elasticidade do aço,

- $\rho_{\text {ri }}: A_{s} / A_{c r i}\left(A_{s}\right.$ corresponde a área da barra de aço; $A_{c r i}$ é a área de concreto que envolve a armadura). 


\section{4- SISTEMAS CONSTRUTIVOS - PONTES EM VIGAS DE ALMA CHEIA.}

\section{1- Generalidades.}

A nomenclatura usual empregada em pontes diferencia os elementos estruturais de acordo com as seguintes divisões:

- Superestrutura:

○ Estrutura principal: destinada a vencer os vãos,

- Estrutura secundária: corresponde ao tabuleiro e vigas secundárias que recebem diretamente as cargas do tráfego.

- Aparelhos de apoio: são responsáveis em transmitir as reações de apoio e permitir determinados movimentos da superestrutura.

- Infraestrutura:

- Suporte: são os pilares e encontros de extremidade que possuem a dupla função de suporte e de arrimo do talude,

○ Fundação.

Além desta subdivisão, encontra-se na literatura a seguinte definição:

- Superestrutura: tabuleiro, vigas principais e vigas transversais e longitudinais do tabuleiro, 
- Mesoestrutura: aparelho de apoio, pilar e encontro,

- Infraestrutura: fundação.

Estas definições causam uma certa dúvida, pois os elementos estruturais muitas vezes atuam de maneira conjunta entre si.

Antes do advento da solda, eram utilizados rebites na construção de pontes em vigas metálicas de alma cheia. As mesas eram formadas com a combinação de chapas e cantoneiras, permitindo desta forma a ligação com a alma.

A utilização da solda permitiu uma seção transversal bem mais simplificada, consistindo em uma chapa formando a alma e ligada a esta, através da solda, outras chapas no sentido transversal, consideradas como mesas.

As mesas da viga podem ser constituídas por múltiplas chapas mais esbeltas, ligadas entre si por cordões de solda ou constituída por uma única chapa mais espessa.

Há trinta - quarenta anos atrás, a utilização de chapas espessas para compor a mesa em vigas de grandes dimensões, acarretava problemas referentes à qualidade do aço, pois esta tende a piorar a medida que a espessura da chapa aumente, devido à composição e tamanho dos cristais.

Por esta razão a combinação de chapas mais esbeltas, unidas por cordões de solda era a solução mais indicada. Porém era necessário ficar atento à presença de grandes concentrações de tensões nas regiões de solda.

Nos locais (próximos a mesa) em que as tensões de compressão ou de tração existentes na alma são grandes, pode-se utilizar o recurso de aumentar a espessura da alma nessa região, como é mostrado na figura 4.1. 


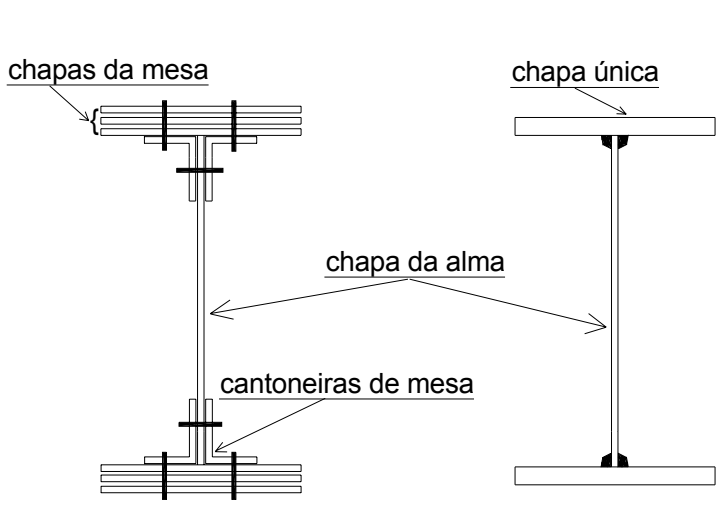

a)

b) chapas múltiplas

de mesa

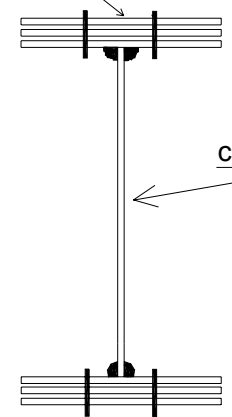

c)

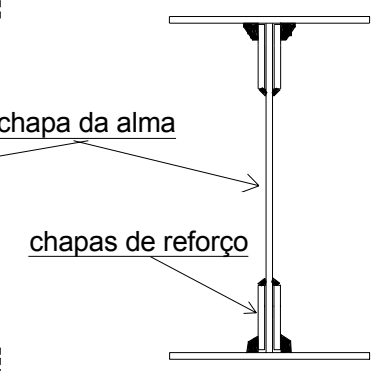

d)

Figura 4.1- Seções transversais típicas de vigas de alma cheia: a) rebitada, b) soldada, c)parte rebitada e parte soldada, d) chapas soldadas. Fonte: O' Connor (1975).

\section{2- Características importantes.}

Podem ser destacadas as principais características das pontes constituídas de vigas de alma cheia como sendo:

- As vigas de alma cheia possuem geometria simples, propiciando custos relativamente mais baixos de fabricação. Em locais de solda, o projeto deve permitir ao máximo o emprego de processos automáticos e semi automáticos,

- Uma das desvantagens seria o uso ineficiente do material localizado na alma. O material empregado neste tipo de viga pode ser maior quando comparado a uma treliça ou a uma estrutura em arco,

- A simplicidade da seção contribui a baixos custos de manutenção,

- Quanto ao dimensionamento da alma, pode-se optar entre uma alma espessa com poucos enrijecedores ou uma alma esbelta com um número maior de enrijecedores transversais. 
- Os momentos e os esforços cortantes variam ao longo do comprimento da viga. É usual variar do mesmo modo a sua altura, seja pelo encurvamento contínuo da mesa inferior ou pelo uso de trechos de altura constantes com mísulas curvas ou retas,

- Pode-se usar aços mais resistentes em regiões com esforços de flexão mais elevados, e conseqüentemente manter a simplicidade do projeto de vigas de altura constantes, todavia esta é uma solução bastante onerosa nos dias de hoje devido ao preço do aço,

- Pode-se utilizar como superestrutura duas vigas principais com espaçamento maior entre elas, juntamente com um sistema auxiliar (transversinas e/ou longarinas) suportando o tabuleiro, ou prever a utilização de vigas principais múltiplas com espaçamentos menores entre elas.

- Vigas retas de alma cheia merecem atenção na flambagem das mesas e alma, e também a estabilidade lateral.

\section{3- Exemplos de estruturas de vigas de alma cheia.}

Na Alemanha foi construída a ponte Wiesbaden-Schierstein (figura 4.2). A superestrutura é composta de vigas de alma cheia que serve de travessia do Rio Reno sendo o vão principal com $205,10 \mathrm{~m}$, seu tabuleiro é ortotrópico e compreende uma faixa de tráfego de $20 \mathrm{~m}$ e dois passeios de $2,00 \mathrm{~m}$.

A altura da viga é variável de 4,45 a $7,45 \mathrm{~m}$, correspondendo às relações vão/altura de 46 a 27,5; relações estas referentes ao vão principal.

A espessura da alma é de $12 \mathrm{~mm}$ que consiste numa relação máxima altura/espessura de 600 .

O espaçamento típico dos enrijecedores longitudinais na região de compressão é de $65,0 \mathrm{~cm}$. Estes enrijecedores estão solidarizados a alma, de maneira que possa 
impedir a flambagem local, provocada por forças concentradas ou de reações de apoio.

Nas bases da alma é soldada uma placa de reforço de $50 \times 2,0 \mathrm{~cm}$, que por sua vez, é soldada nas chapas da mesa e estão ligadas entre si por soldas e rebites.
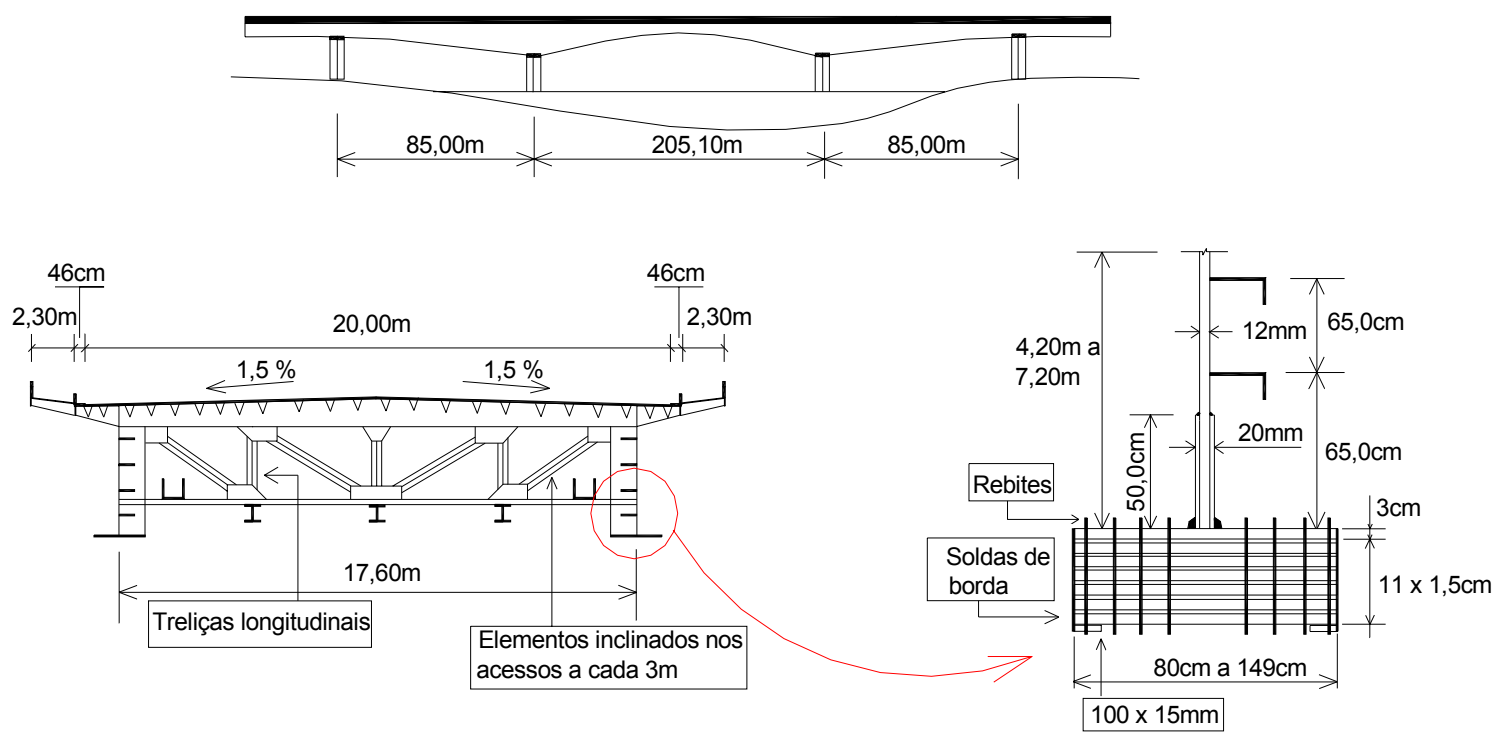

Figura 4.2- Ponte Wiesbaden-Schierstein. (Stahlbau, W. Ernst \& Son-1960).

Outro exemplo de ponte composta de vigas de alma cheia é a ponte sobre o Rio Drau (Áustria). Trata-se de uma ponte esconsa com vãos principais contínuos $58,20 \mathrm{~m} ; 70,10 \mathrm{~m}$ e $58,20 \mathrm{~m}$ (figura 4.3 ).

Para combater os esforços de torção, exigiu um sistema estrutural contendo duas vigas paralelas, um tabuleiro de concreto e contraventamentos inferior e superior. A ponte compreende uma pista de $8,10 \mathrm{~m}$ e um passeio de $1,50 \mathrm{~m}$. O tabuleiro é de concreto moldado in situ com $28 \mathrm{~cm}$ de espessura.

As vigas principais têm altura constante de $3,30 \mathrm{~m}$ correspondendo a uma relação máxima vão/altura de 21,2 . A espessura da alma é de $14 \mathrm{~mm}$ próximo aos apoios e de $10 \mathrm{~mm}$ nas demais regiões, correspondendo às relações altura/espessura de 236 e 330. 
Os enrijecedores transversais estão a 2,40 m nos vãos menores e $2,30 \mathrm{~m}$ no vão principal.

A largura da mesa superior varia de 30 a $51 \mathrm{~cm}$ e a mesa inferior de 60 a $82 \mathrm{~cm}$, as mesas mais espessas foram compostas de três chapas mais finas soldadas entre si.

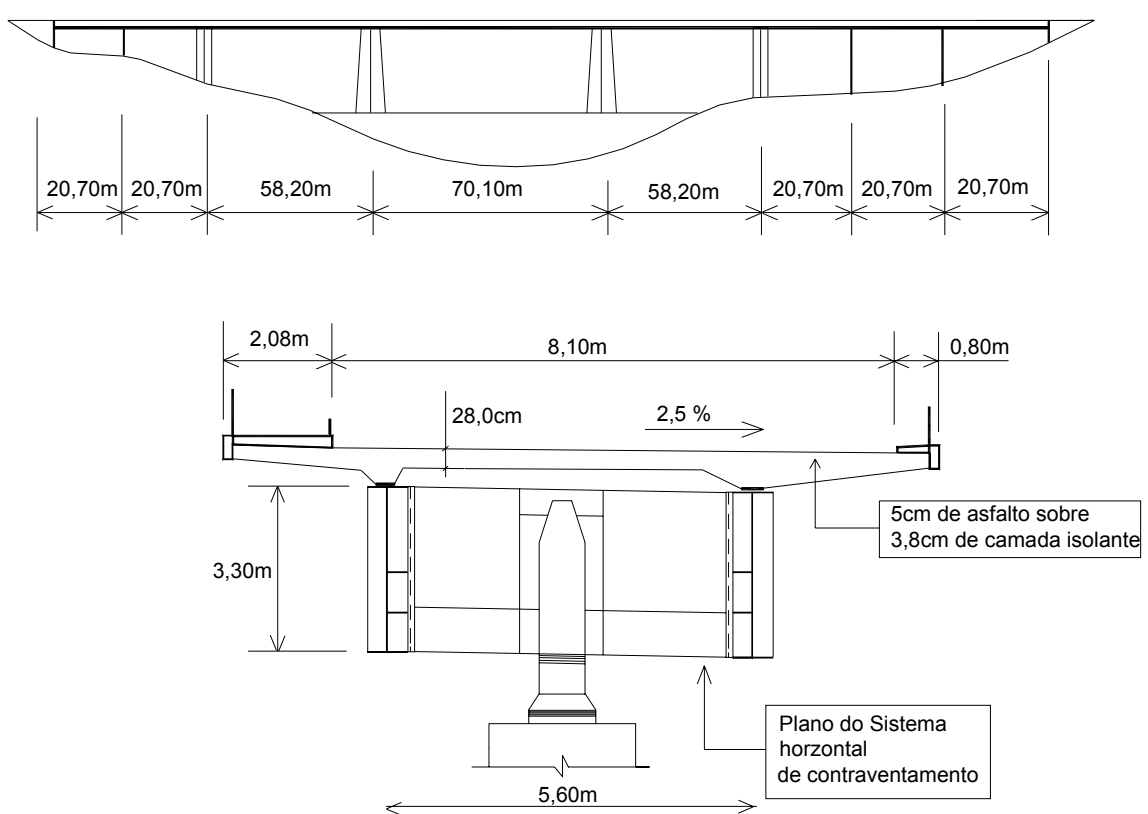

Figura 4.3- Ponte sobre o Rio Drau - Áustria (1967).

\section{4- Disposições construtivas atuais.}

\subsection{1- Generalidades.}

As pontes mistas podem ser adotadas praticamente em todas as tipologias de pontes, sejam pontes em vigas de alma cheia, treliças, estaiadas e arcos, apenas nas pontes pênseis a superestrutura é construída totalmente metálica com $o$ tabuleiro ortotrópico.

As soluções mistas também são utilizadas com sucesso em recuperações e reforços de pontes existentes. 
A competitividade das pontes mistas está no domínio de pequenos e médios vãos. Na Europa, principalmente na França, cerca de 70 a $80 \%$ das pontes com vãos de 60 a 80 metros, são feitas com sistema misto (Lamas/1999).

A razão desta escolha é o emprego dos dois materiais aço e concreto de maneira racional, com o concreto sendo solicitado à compressão e o aço a tração.

Outros fatores importantes seriam a rapidez de montagem, o concreto armado contribuindo com a estabilidade da estrutura e por último a estética.

\subsection{2- Inovações tecnológicas dos sistemas em pontes mistas.}

Podem ser destacados os avanços com relação ao dimensionamento a torção, fadiga, verificação da estabilidade, simplificação dos sistemas de contraventamento e finalmente o aprimoramento das técnicas e métodos de construção e lançamento da estrutura.

As seções transversais mais empregadas são o perfil I e duplo II, como é apresentado na figura 4.4. Os valores usuais da relação altura/vão estão compreendidos entre $1 / 20$ a $1 / 30$, dependendo se as vigas são isostáticas ou hiperestáticas.

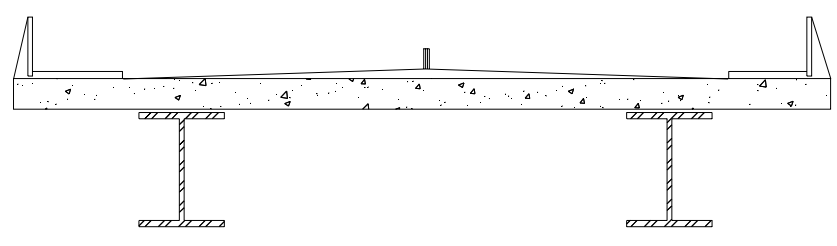

a) Pontes mistas em vigas de alma cheia.

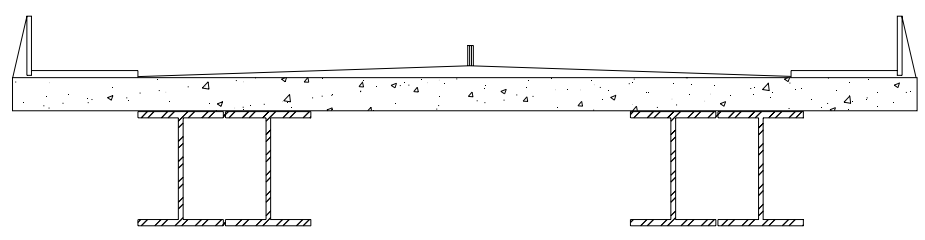

b) Pontes mista em vigas de alma cheia com duplo I.

Figura 4.4- Seções transversais em vigas de alma cheia. Fonte: Lamas (1999). 
A seção transversal teve uma grande evolução, pois antigamente as seções eram compostas de várias vigas metálicas em sua maioria espaçadas de 3 metros, sobre as quais era executada a laje de concreto, e quase sempre formadas de tramos isostáticos de no máximo 30 metros.

Atualmente a seção transversal pode ser composta de duas vigas, com os tabuleiros de largura entre 20 a 22 metros (Lamas/1999). Os vãos das vigas são maiores e quase sempre contínuos.

Segundo Lamas (1999), o emprego de vigas de perfil com duplo II permitiram uma melhora da estabilidade lateral da superestrutura, uma maior eficácia aos esforços de torção, utilização de contraventamentos de 6 a 10 metros e o emprego de tabuleiros de grande largura, reduzindo desta maneira o balanço e o vão central da seção transversal do tabuleiro.

Hoje é possível o uso de chapas espessas para as mesas inferiores, cerca de 150 $\mathrm{mm}$ com aços soldáveis de grãos finos, tornando as pontes de vigas de alma cheia com uma tipologia mais simplificada, e conseqüentemente mais competitivas.

As soluções de vigas de altura variável são bastante utilizadas atualmente, tornando uma solução econômica aliada ao bom funcionamento aos momentos fletores e ao cortante, além de fornecer uma estética agradável.

Quanto ao concreto utilizado no tabuleiro, existe no mercado concreto de alto desempenho com baixa relação água/cimento, proporcionando uma diminuição dos efeitos da retração e fluência. 


\section{5- TABULEIROS DE PONTES.}

\section{1- Generalidades.}

Sobre os tabuleiros incidem as cargas de tráfego, que são transferidas as vigas principais e/ou secundárias, pilares e fundações. Cabe ao tabuleiro, de maneira conjunta com as vigas, a função de resistir aos esforços de torção e de contribuir com a estabilidade da superestrutura.

Podem ser destacados os seguintes tipos de tabuleiro:

- Tabuleiros em placa ortotrópica,

- Tabuleiros de concreto armado moldado in situ,

- Tabuleiros formados com grade de aço,

- Tabuleiros pré-moldados (concreto armado e/ou protendido).

A escolha do tipo de tabuleiro deve seguir os seguintes fatores:

- Durabilidade,

- Resistência à flexão devido a carregamentos verticais,

- Custo,

- Peso próprio. 


\section{2- Tabuleiros em placa ortotrópica.}

Um dos mais conhecidos tabuleiros de pontes é a placa ortotrópica, na qual todos os elementos que pertence à ponte trabalham de maneira solidária entre si, como mostra a figura 5.1.

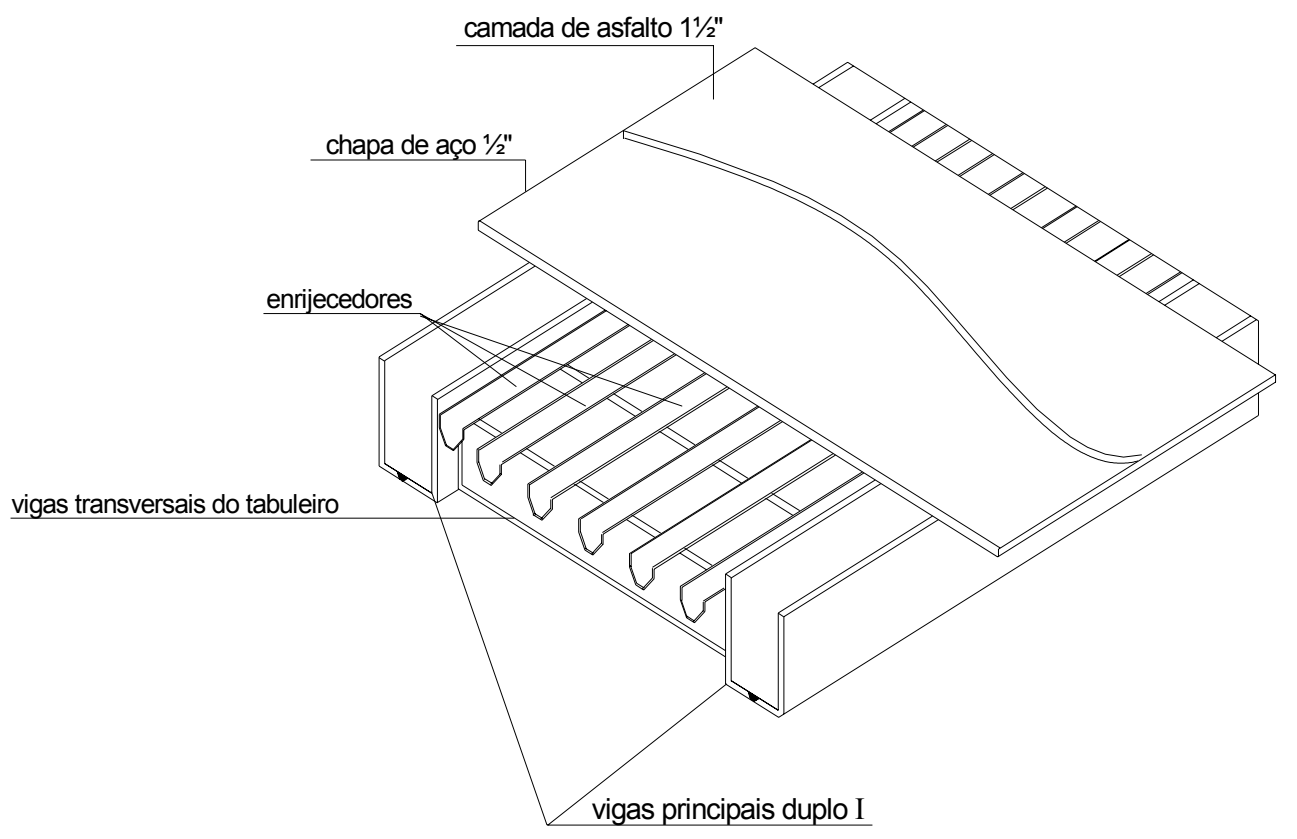

Figura 5.1- Tabuleiros em placa ortotrópica. Fonte: Blodgett (1966).

Usualmente utiliza-se uma chapa de aço de espessura entre $12,5 \mathrm{~mm}$ a $15 \mathrm{~mm}$ sobre toda a extensão da ponte, a mesma serve como mesa superior das vigas principais e transversais do tabuleiro.

Junto à chapa de aço são soldados enrijecedores no sentido longitudinal de maneira que seja aumentada sua rigidez nesta direção, além de contribuir com a resistência a torção.

Tendo uma mesa superior em comum aos três elementos (enrijecedores, vigas principais e transversais), a eficiência ao carregamento pode ser maior.

Sobre esta chapa de aço, geralmente aplica-se uma camada de asfalto em torno de $4 \mathrm{~cm}$ de espessura, em situações a não utilização do concreto sobre a 
superfície do tabuleiro, ocorre concentração de tensões nas ligações em solda entre o enrijecedor e a placa de aço.

Em casos em que seja aplicada uma camada de concreto, a mesma oferece uma melhor distribuição de tensões junto ao tabuleiro eliminando estas concentrações de tensões.

Com o emprego do tabuleiro ortotrópico, basicamente o peso próprio pode ser reduzido à metade quando comparado a outros sistemas estruturais.

Em contrapartida em pontes de pequenos e médios vãos, a utilização deste sistema é inviável economicamente, sendo a solução de pontes de estruturas mistas mais aconselhável.

\subsection{1- Enrijecedores longitudinais.}

Em projetos americanos os enrijecedores mais empregados em placa ortotrópica estão representados na figura 5.2.

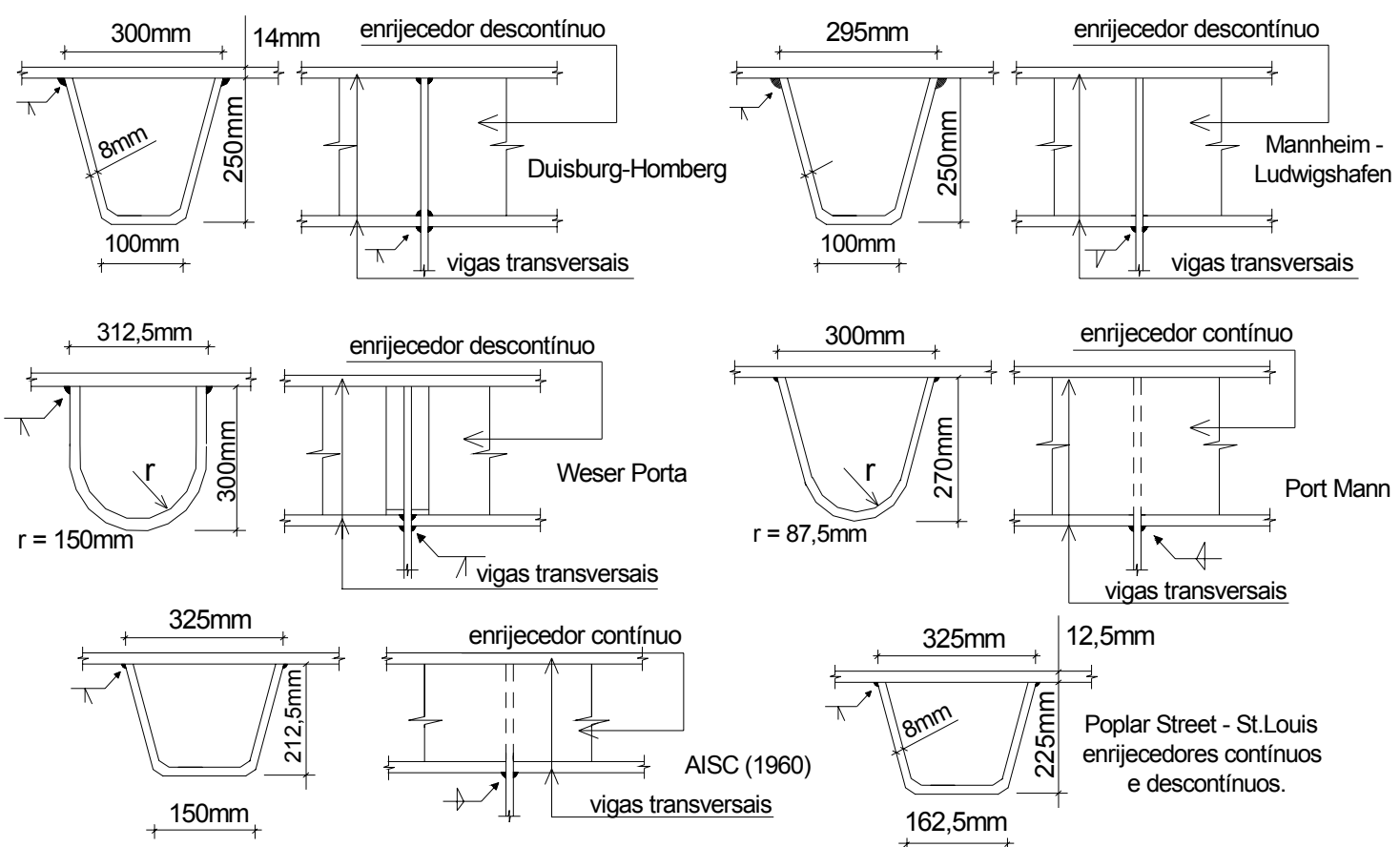

Figura 5.2- Tipos de enrijecedores empregados em tabuleiro ortotrópico. Fonte: Blodgett (1966). 
O detalhe da ligação do enrijecedor com a chapa de aço está mostrado na figura 5.3.

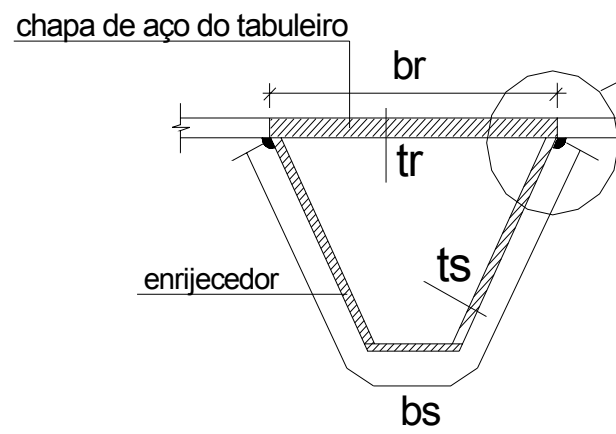

chapa de aço $12,5 \mathrm{~mm}$

$70^{\circ}$

enrijecedor $8 \mathrm{~mm}$

Figura 5.3- Ligação do enrijecedor com a chapa de aço do tabuleiro. Fonte: Blodgett (1966).

Sendo:

- $t_{R}$ : espessura da placa do tabuleiro,

- $t_{s}$ : espessura do enrijecedor,

- $b_{R}$ : largura da placa sem enrijecedor,

- $b_{s}$ : comprimento do enrijecedor.

Outro tipo de enrijecedor é o apresentado na figura 5.4, porém não apresenta a mesma eficiência do que os enrijecedores com seções transversais fechadas, onde estes permitem maiores vãos do tabuleiro ortotrópico, maior eficiência na distribuição transversal das cargas do tráfego e de oferecer maior rigidez à torção.

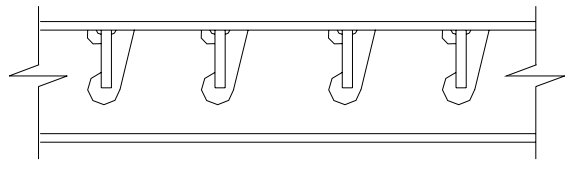

Figura 5.4- Enrijecedor aberto. 


\subsection{2- Posicionamento dos enrijecedores longitudinais junto às vigas transversais do tabuleiro.}

Há duas maneiras de detalhar a interseção dos enrijecedores longitudinais às vigas transversais do tabuleiro, ver figura 5.5 .
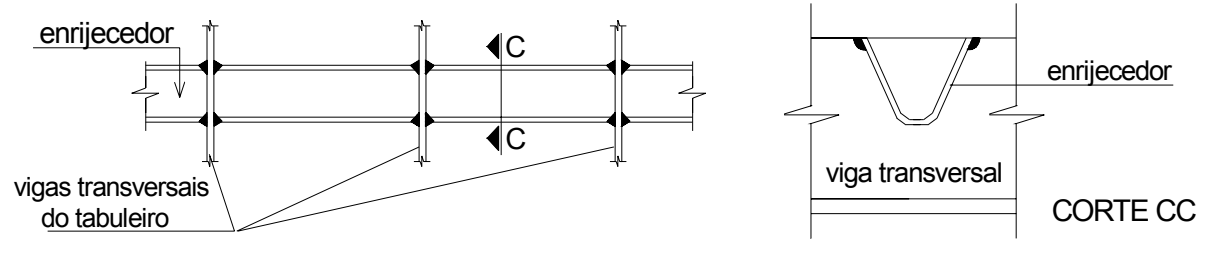

A) Enrijecedor Descontínuo.
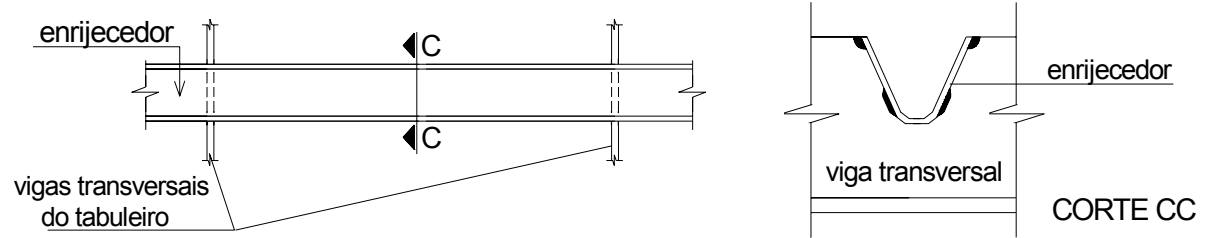

B) Enrijecedor Contínuo.

Figura 5.5- Interseção dos enrijecedores longitudinais com as vigas transversais do tabuleiro.

$\mathrm{Na}$ figura 5.5A, o sistema empregado é bastante comum na Europa. Os enrijecedores não são contínuos, são seccionados, soldados adequadamente e posicionados entre as vigas transversais do tabuleiro.

As envoltórias de tensões aplicadas nos enrijecedores devem ser transferidas através das "teias" formadas pelas vigas transversais do tabuleiro com os enrijecedores.

Este método requer um grande número de solda, sendo duas soldas em cada face da viga por enrijecedor. 
Um método alternativo é mostrado na figura 5.5B, onde o enrijecedor é contínuo e as vigas transversais do tabuleiro são seccionadas adequadamente para a passagem dos enrijecedores.

Neste caso o espaçamento entre os enrijecedores pode ser maior do que o anterior, a solda é aplicada apenas uma vez na viga por enrijecedor, proporcionando uma maior economia de solda.

\section{3- Tabuleiro em concreto armado.}

Muitas pontes são projetadas com tabuleiros de concreto armado, apoiados em vigas. Estes tabuleiros devem ser ancorados às vigas por conectores, fazendo com que o tabuleiro faça parte na resistência aos esforços de flexão.

Esta solução construtiva proporciona economia de aço em torno de $8 \%$ a $30 \%$, contribui no aumento da rigidez da ponte e permite que as vigas de aço tenham alturas menores proporcionando uma melhor estética da superestrutura.

O sistema construtivo apresentado na figura 5.6 é composto de um tabuleiro de concreto armado interligado por conectores às vigas principais, e de um contraventamento para auxiliar na estabilidade e oferecer um aumento de resistência à torção.

A utilização de conectores pode ser qualquer um dos apresentados no item conectores de cisalhamento.

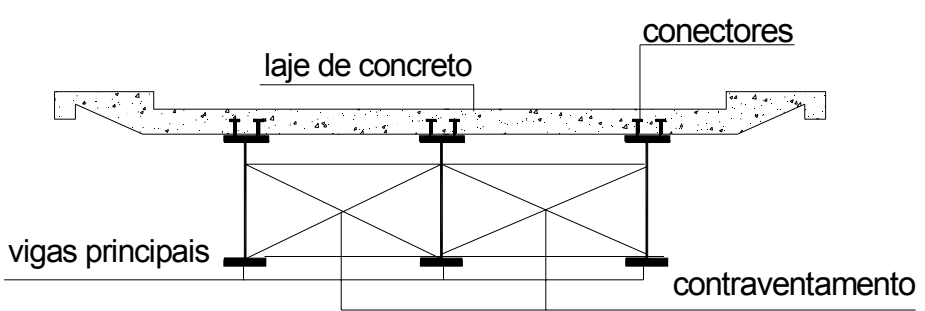

Figura 5.6- Tabuleiro de concreto apoiado em vigas metálicas.

Outro sistema construtivo utilizado como tabuleiro, é quando a laje de concreto apóia-se em um sistema em grelha, como mostra a figura 5.7. 
Este sistema construtivo possui as mesmas particularidades já citadas anteriormente.

vigas longitudinais do tabuleiro

vigas principais

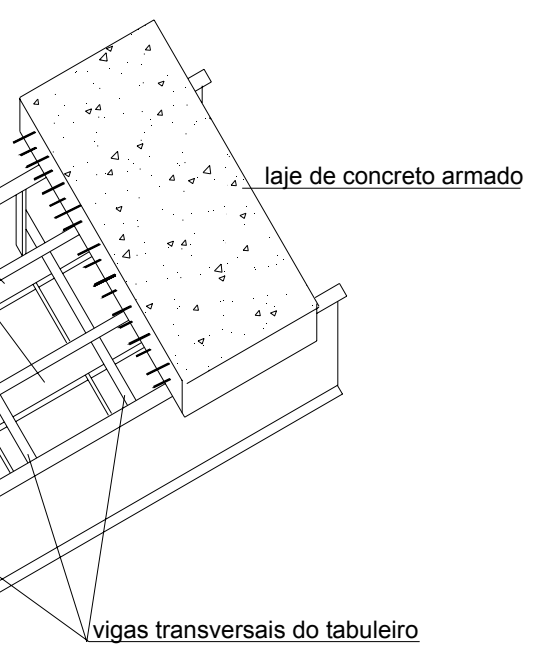

Figura 5.7- Tabuleiro de concreto apoiado em grelha. Fonte: Blodgett (1966).

\section{4- Utilização de grade de aço como tabuleiro.}

Não é comum a utilização da grade de aço como tabuleiro, contudo a mesma proporciona:

a) Redução do peso próprio do tabuleiro,

b) Não há necessidade em se fazer um sistema de drenagem sofisticado,

c) Não são exigidos escoramentos na execução,

d) A grade de aço pode ser instalada facilmente, muitas vezes utiliza-se um concreto leve sobre a mesma com a finalidade de protege-la contra a corrosão. A figura 5.8 mostra um tabuleiro com grade de aço, apoiada nas vigas principais e transversais do tabuleiro. 


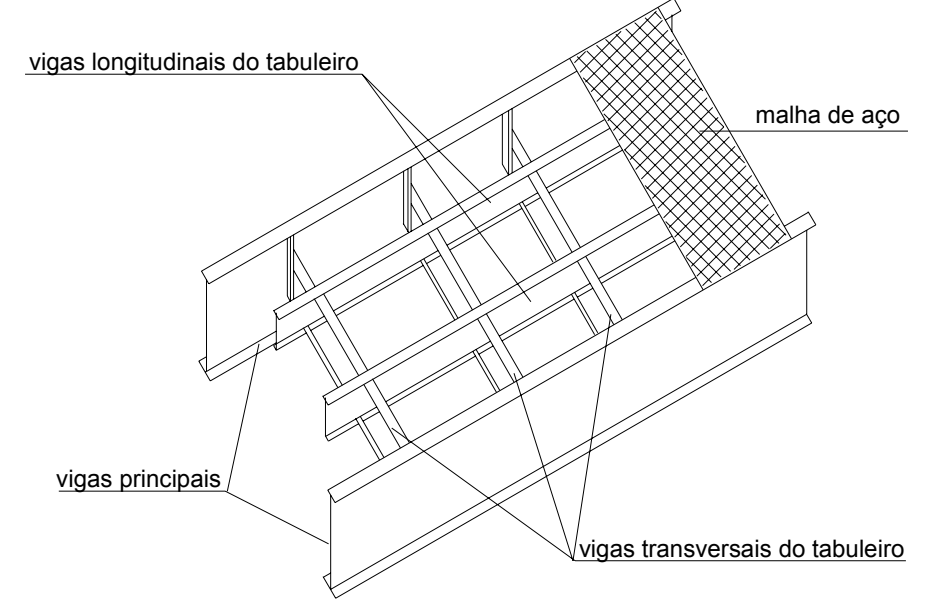

Figura 5.8- Grade de aço aplicada em tabuleiro.

As vigas transversais do tabuleiro são posicionadas abaixo da mesa superior das vigas principais, de maneira que o posicionamento da grade de aço coincida com as mesmas; utiliza-se solda na fixação desta grade com as vigas.

\section{5- Tabuleiro em laje pré-moldada juntamente com o concreto moldado} in situ.

O tabuleiro pode ser construído por elementos pré-moldados, onde os elementos são posicionados longitudinalmente lado a lado, e preenchidos com concreto (figura 5.9).

A figura seguinte mostra a construção deste tipo de tabuleiro, que dispensa a utilização de fôrmas e escoramento, já que as vigas pré-moldadas em seção T invertidas servem como "fôrma" para o concreto moldado in situ. 


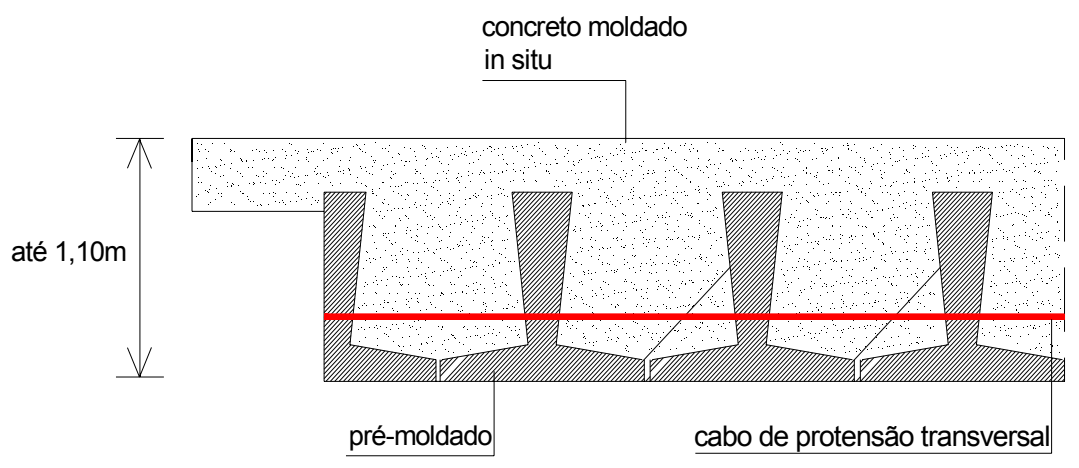

Figura 5.9- Laje maciça - elementos em viga T e concreto moldado in situ.

Fonte: Leonhardt (1977). 


\section{6- CONECTORES DE CISALHAMENTO.}

\section{1- Generalidades.}

O comportamento das estruturas mistas é fundamentado na ação conjunta entre a viga de aço e o concreto armado moldado in loco, pré-moldado e/ou protendido. Para que aconteça essa interação, é necessário desenvolver na interface aço/concreto uma ligação capaz de resistir às tensões tangenciais na superfície de contato entre os dois materiais, impedindo o seu deslocamento relativo.

A aderência natural e o atrito não são levados em consideração no cálculo, portanto se faz necessária a utilização de conectores de cisalhamento para resistir a estes esforços cisalhantes gerados nesta interface, e impedir o deslizamento relativo e a separação da viga de aço com a laje de concreto.

Os conectores são classificados em flexíveis e rígidos e serão mostrados a seguir.

\section{2- Comportamento da ligação aço/concreto ao cisalhamento.}

Ao analisar a deformação de uma viga mista simplesmente apoiada com carregamento na vertical de cima para baixo, nota-se que a superfície superior da viga apresenta tensões de compressão (se encurta), enquanto que a superfície inferior está sujeita a tensões de tração (se alonga).

A ação mista se desenvolve quando os dois elementos estruturais são interconectados de tal forma a se deformarem como se fosse um único elemento. A figura 6.1a e 6.1b mostra o comportamento da viga com e sem interação entre os dois elementos. 
$\mathrm{N}$

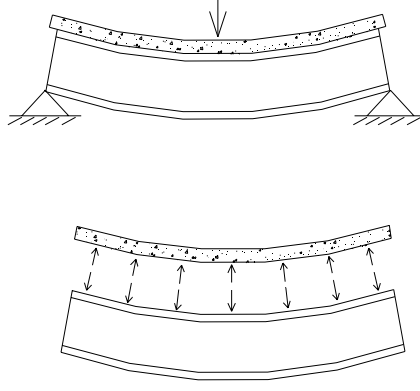

a) vigas fletidas sem ação mista.

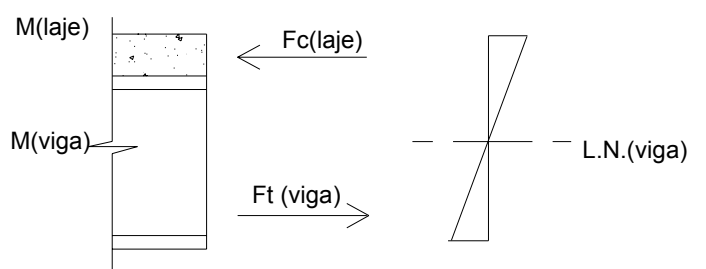

c) interção total.

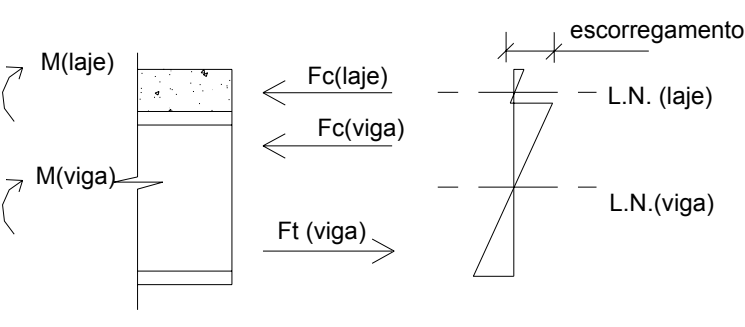

e) interação parcial.
$\mathrm{N}$

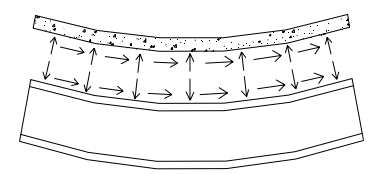

b) vigas fletidas com ação mista.

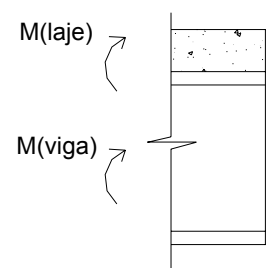

d) nenhuma interação.

escorregamento.

L.N. (laje)

L.N.(viga)

Figura 6.1- Comparação de vigas fletidas com e sem interação e interação parcial.

Fonte: Queiroz (2000)

Quando os dois elementos estiverem interligados por conectores, desenvolvem-se forças que tendem a encurtar a face superior (composta pela laje e mesa superior) e simultaneamente alongar a face inferior, correspondente a mesa inferior da viga. Caso não exista deslizamento relativo entre as duas faces, pode-se considerar o diagrama de deformações apenas com uma linha neutra (figura 6.1c); é definida como interação completa, conhecida também como ação mista total.

Quando a ligação não for suficientemente rígida haverá duas linhas neutras, sua posição depende do grau de interação entre os dois materiais (figura 6.1d, 6.1e). 
O grau de interação entre o aço/concreto depende do número de conectores presentes nesta interface. Se for permitido um pequeno deslizamento relativo entre os dois materiais, surge a interação parcial, conhecida também como ação mista parcial.

Além das forças horizontais existentes na interface laje e viga, os conectores estão sujeitos a cisalhamentos providos de cargas verticais, principalmente nas regiões de apoio que tendem a separar os dois elementos estruturais.

Segundo Johnson (1975) este cisalhamento vertical pode ser desconsiderado, pois a resistência dos conectores é suficiente para resistir a estas ações.

O Eurocoude4 (1996), recomenda que seja considerado $1 / 10$ das forças cisalhantes para as forças de verticais.

\section{3- Tipos de conectores.}

\subsection{1- Conectores tipo pino com cabeça (stud bolts).}

Os conectores tipo pino com cabeça são os mais utilizados, por fornecer uma boa ancoragem com o concreto impedindo o afastamento da laje com a viga, não oferece interferência com a armadura do tabuleiro e sua fixação é bastante rápida e econômica, todavia requer alta energia para que possa ser realizada a soldagem. Seu formato está apresentado na figura 6.2. 


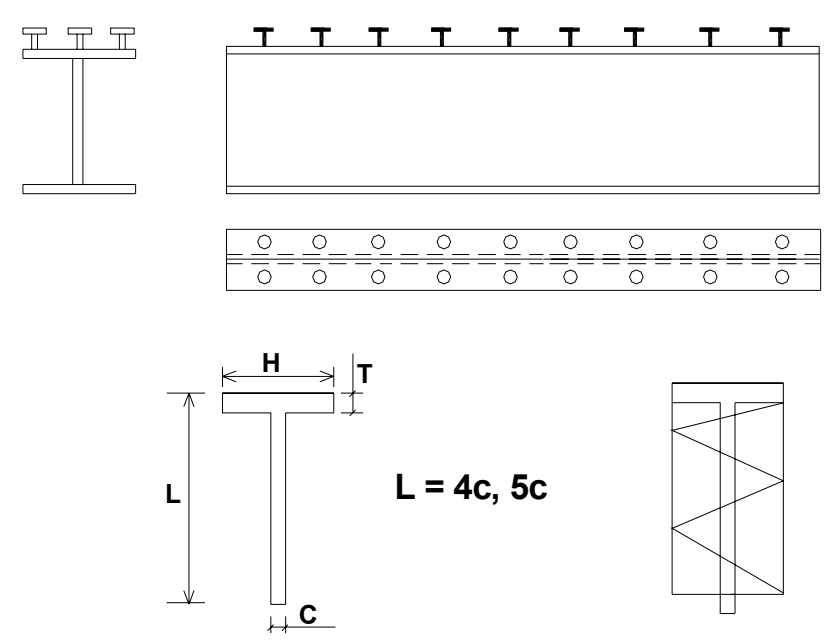

Figura 6.2- Conectores tipo pino com cabeça (stud bolts).

A tabela 6.1 apresenta as dimensões e tolerâncias destes conectores.

Tabela 6.1- Dimensões dos conectores de cisalhamento. Fonte: AWS D1. 1-2000.

\begin{tabular}{|c|c|c|c|c|c|}
\hline \multicolumn{3}{|c|}{$\begin{array}{c}\text { DIÂMETRO } \\
(\mathrm{C})\end{array}$} & \begin{tabular}{l} 
TOLERÂNCIA \\
DE COMPRIMENTO \\
\multicolumn{2}{|c|}{}
\end{tabular} & $\begin{array}{l}\text { DIÂMETRO DA } \\
\text { CABEÇA DO } \\
\text { CONETOR } \\
(\mathrm{H})\end{array}$ & $\begin{array}{l}\text { ALTURA } \\
\text { DA CABEÇA } \\
\text { DO CONECTOR. } \\
(\mathrm{T})\end{array}$ \\
\hline Polegadas & $\mathrm{mm}$ & $\mathrm{mm}$ & $\mathrm{mm}$ & $\mathrm{mm}$ & $\mathrm{mm}$ \\
\hline $5 / 8 "$ & 15,9 & $\begin{array}{l}+0,00 \\
-0,25\end{array}$ & $\pm 1,6$ & $31,7 \pm 0,4$ & 7,1 \\
\hline $3 / 4 "$ & 19,1 & $\begin{array}{l}+0,00 \\
-0,03\end{array}$ & $\pm 1,6$ & $31,7 \pm 0,4$ & 9,5 \\
\hline $7 / 8 "$ & 22,2 & $\begin{array}{l}+0,00 \\
-0,38\end{array}$ & $\pm 1,6$ & $34,9 \pm 0,4$ & 9,5 \\
\hline
\end{tabular}

Existe uma relação entre o diâmetro do conector e a espessura da chapa para que solda utilizada não danifique o material-base, os valores estão mostrados na tabela 6.2 . 
Tabela 6.2- Espessuras mínimas de chapas de aço para solda em arco elétrico do conector.

Fonte: Nelson Stud Welding Process.

\begin{tabular}{|c|c|c|}
\hline \multicolumn{2}{|c|}{ DIÂMETRO DO CONECTOR. } & $\begin{array}{l}\text { ESPESSURA MÍNIMA DO } \\
\text { MATERIAL-BASE. }\end{array}$ \\
\hline Polegadas & $\mathrm{mm}$ & $\mathrm{mm}$ \\
\hline $5 / 8 "$ & 15,9 & 3,75 \\
\hline $3 / 4 "$ & 19,1 & 4,75 \\
\hline $7 / 8 "$ & 22,2 & 6,30 \\
\hline
\end{tabular}

Segundo Dubas (1975) na construção de pontes empregam-se principalmente conectores com diâmetro de 3/4" e 7/8", e para que a resistência total destes sejam alcançadas, a espessura da chapa na qual serão soldados, não deve ser inferior a 40 \% do diâmetro do conector.

De acordo com Dubas (1975), os afastamentos entre os conectores podem ser:

- Sentido longitudinal da viga: espaçamento mínimo: 5d, espaçamento máximo: 50d,

- Sentido transversal à viga: espaçamento mínimo: 4d (d: é o diâmetro do conector).

Na tabela 6.3 temos as propriedades mecânicas dos conectores segundo ASTM A-108.

Tabela 6.3- Propriedades mecânicas requeridas para aços de conectores.

Fonte: AWS D1. 1-2000.

\begin{tabular}{|l|l|}
\hline Resistência à tração. & $415 \mathrm{MPa}$ \\
\hline Limite de escoamento $(0,2 \%$ offset). & $345 \mathrm{MPa}$ \\
\hline Alongamento $(\%$ em $50 \mathrm{~mm})$. & mínimo de $20 \%$ \\
\hline Redução de área. & mínimo de $50 \%$ \\
\hline
\end{tabular}


Os conectores tipo pino com cabeça também podem ser utilizados de maneira conjunta a laje com fôrma de aço incorporada (steel deck). Esta ligação requer mais atenção quando comparado com as lajes maciças, e os principais cuidados a serem tomados são:

- Relação entre a altura do conector e a altura da fôrma,

- Número de conectores dentro de cada nervura,

- Excentricidade, como mostra a figura 6.3.

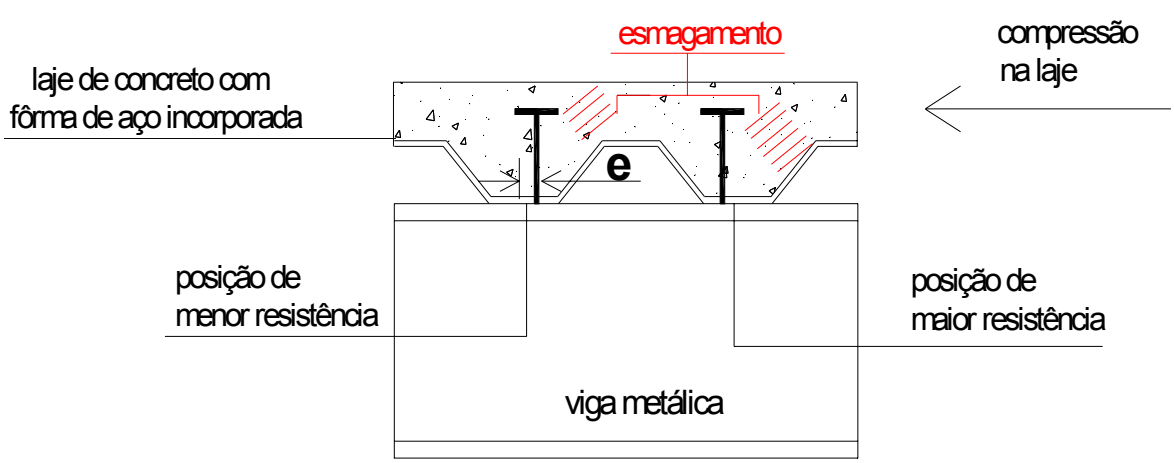

Figura 6.3- Influência da excentricidade.

Estes fatores podem provocar uma redução na resistência nominal dos conectores, conclusões estas baseadas em ensaios (Queiroz/2000).

Para este sistema são feitas recomendações para que os conectores de cisalhamento possam desempenhar adequadamente sua função, e para que sejam válidas as expressões de cálculo das resistências dos conectores e das seções mistas.

A seguir são apresentados os principais cuidados com relação à instalação destes conectores. 
- Os posicionamentos dos conectores em fôrmas de aço devem obedecer às prescrições da figura 6.4,

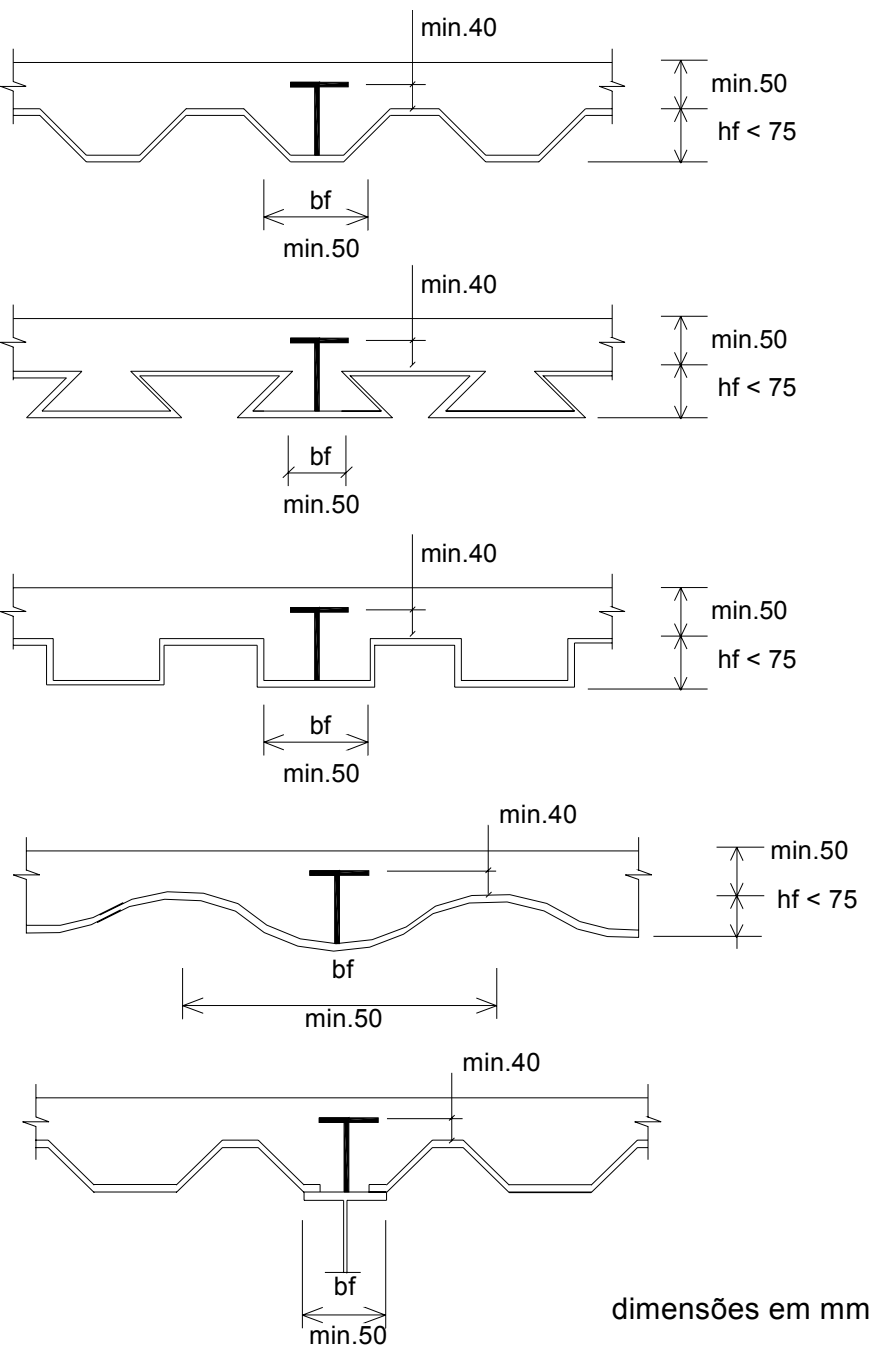

Figura 6.4- Lajes de concreto com fôrma de aço incorporada. Fonte: NBR 8800 (1986).

- A face inferior da cabeça do pino deve estar acima da armadura da laje,

- A espessura da chapa de aço onde são instalados os conectores deve ser $40 \%$ do diâmetro do pino,

- A distância entre a face do conector e a extremidade da chapa não deve ser inferior a $20 \mathrm{~mm}$, 
- A espessura de concreto acima da fôrma de aço deve ser no mínimo $50 \mathrm{~mm}$,

- O comprimento do pino acima da fôrma deve ser no mínimo 40mm,

- O espaçamento entre conectores em lajes de concreto com fôrmas de aço incorporado é de 4x (quatro vezes) o diâmetro, nas direções longitudinais e transversais, e o espaçamento máximo é igual a $8 x$ (oito vezes) a espessura total da laje,

- O posicionamento dos conectores deve ser seguido conforme a figura 6.4.

Notas: Não deve ser aplicada solda, em laje com fôrma de aço incorporada nas seguintes situações:

- Quando a chapa for revestida com pintura,

- Quando a camada de zinco que reveste a pintura for superior a $375 \mathrm{~g} / \mathrm{m}^{2}$,

- Se a fôrma de aço apresentar espessura dupla.

Quando isto ocorrer deve-se soldar os pinos através de furos pré-existentes na fôrma.

Apesar das qualidades apontadas do conector tipo pino com cabeça, quando comparado com o conector Perfobond (desenvolvido na Alemanha por Saul, 1992); o mesmo possui baixa resistência à fadiga.

O conector Perfobond é formado por chapas de aço S23 com 60mm de altura e $12 \mathrm{~mm}$ de espessura, apresentam furos de $30 \mathrm{~mm}$ de diâmetro distanciados entre si de $60 \mathrm{~mm}$.

Sua fixação junto à viga metálica é realizada através de solda e a capacidade resistente é de $1950 \mathrm{kN} / \mathrm{m}$, e comparando sua capacidade resistente a fadiga com os conectores tipo pino com cabeça, equivale a 24 conectores $/ \mathrm{m}$ de $18 \mathrm{~mm}$ ou 19 conectores $/ \mathrm{m}$ de $22 \mathrm{~mm}$.

A figura 6.5 apresenta o formato do conector perfobond. 


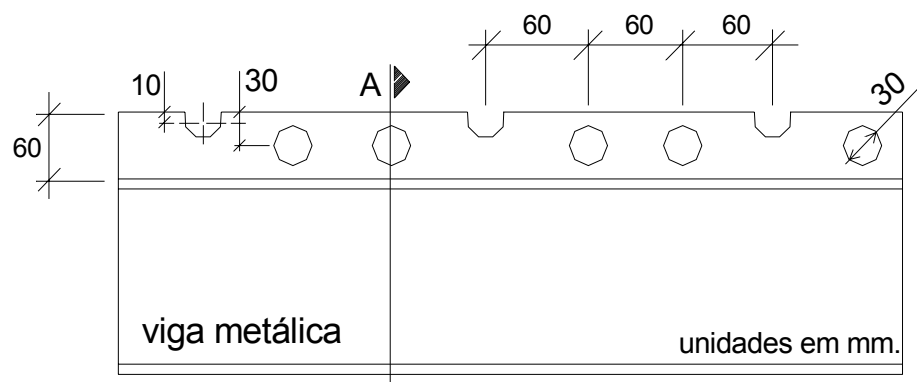

$A \triangleright$

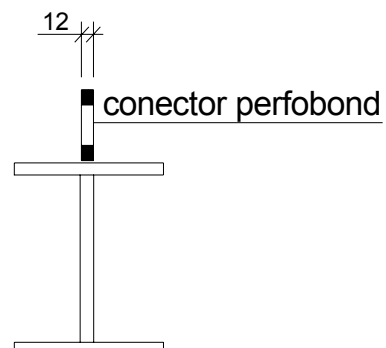

Corte AA

Figura 6.5- Conector Perfobond (Saul/1992).

\subsection{2- Conectores em perfil U laminado.}

Estes conectores são muito utilizados no Brasil e os mais conhecidos são:

$C 3 " \times 4.1 \mathrm{~kg} / \mathrm{m} ; C 4 " \times 5.4 \mathrm{~kg} / \mathrm{m} ; C 5 " \times 6.3 \mathrm{~kg} / \mathrm{m}$

$\mathrm{Na}$ figura 6.6 apresenta o posicionamento destes conectores junto à viga.

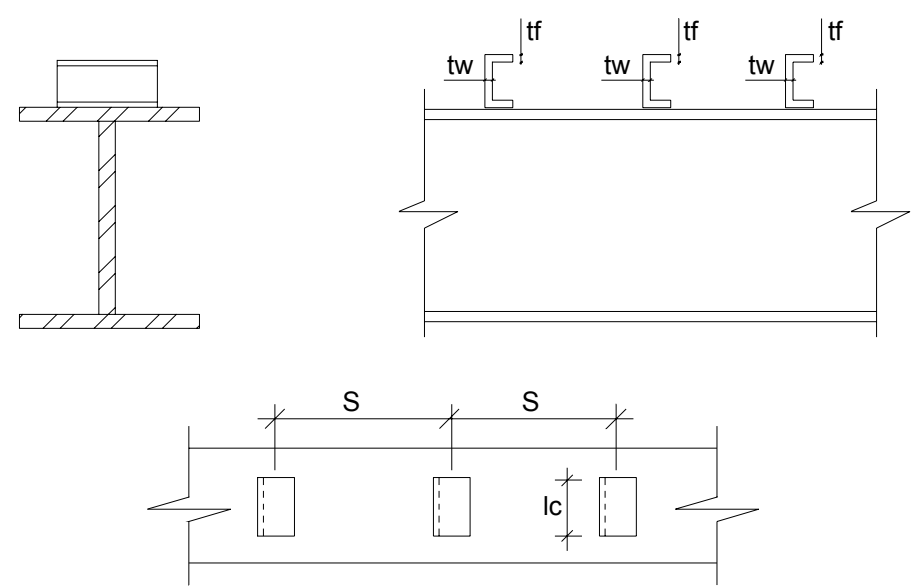

Figura 6.6- Conectores de perfil U laminado.

Notas: Os conectores citados nos itens 6.3 .1 e 6.3.2, são classificados como flexíveis, os mesmos oferecem um comportamento dúctil na ligação aço/concreto. Este comportamento corresponde quando um conector após ter atingido a sua resistência máxima pode continuar a deformar-se, sem que ocorra uma ruptura abrupta, proporcionando que os conectores vizinhos absorvam as forças cisalhantes atuantes, num processo de uniformização da resistência da conexão. 
Esta característica permite espaçar igualmente estes conectores, sem diminuir a resistência máxima da conexão.

Quanto ao dimensionamento dos conectores tipo pino com cabeça e o conector perfil U laminado é apresentado no item 7, com as considerações feitas pela AASHTO (1996).

\subsection{3- Conectores de cisalhamento com características rígidas.}

Podem ser observados na figura 6.7 os conectores com características rígidas, na qual não apresentam as mesmas propriedades do que os conectores com comportamento dúctil.

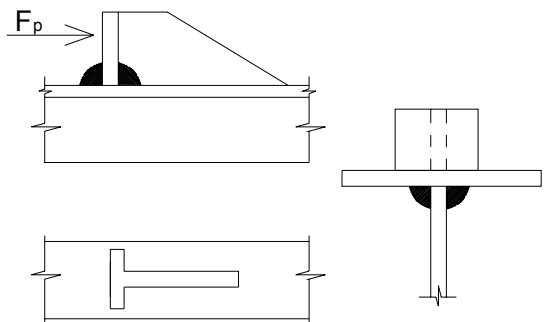

a) perfil $T$ composto de chapa.

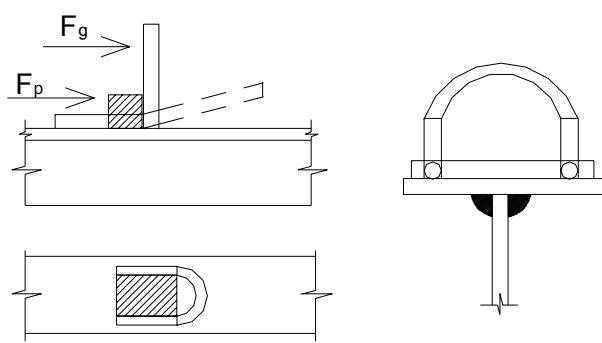

c) perfil em alça com barra chata

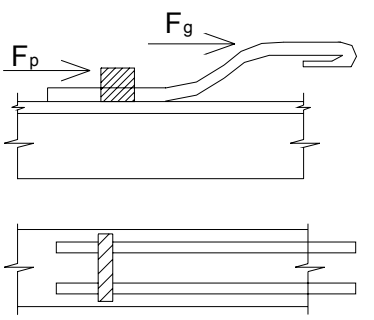

b) plaqueta soldada à mesa combinada com ganchos.

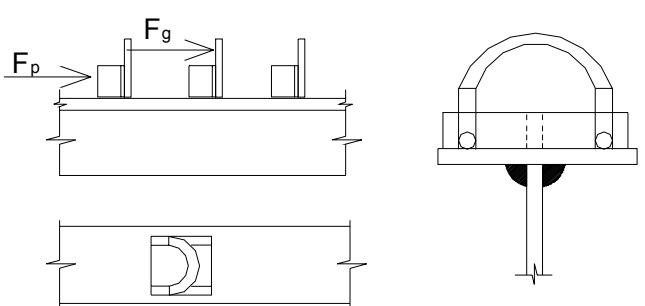

d) perfil T em alça com barra chata.

Figura 6.7- Outros tipos de conectores. Fonte: Eurocode 4 (1996).

A figura 6.7 mostra conectores formados por plaquetas e perfis, soldados à mesa superior da viga de aço. São adicionados a eles ganchos ou alças, destinados a aumentar a resistência do conjunto e de certa forma oferecer uma ductilidade à ligação.

Para o dimensionamento dos conectores com características rígidas, são consideradas duas forças: 
- Contribuição devido à pressão na superfície da plaqueta $\left(F_{p}\right)$,

- Contribuição devido à resistência do gancho e da alça $\left(F_{g}\right)$

A resistência total $\left(F_{\text {conector}}\right)$ do conector, segundo recomendações da Norma alemã (DIN 1078, apud Mason), pode ser traduzida pela fórmula:

$$
F_{\text {conector }}=S_{c} \times \sigma_{c, d}+\mu \times S_{s} \times \sigma_{s}
$$

Onde:

$$
\begin{aligned}
& F_{p}=S_{c} \times \sigma_{c, d} \\
& F_{g}=\mu S_{s} \times \sigma_{s}
\end{aligned}
$$

A tensão admissível à compressão do concreto pode ser calculada pela fórmula.

$$
\sigma_{c, d}=\sigma_{c} \sqrt[3]{\frac{S_{d}}{S_{c}}} \leq \frac{\sigma_{c}}{2}
$$

As variáveis envolvidas nas equações serão:

- $\mathrm{S}_{\mathrm{c}}$ : área projetada da plaqueta,

- $\sigma_{\mathrm{c}, \mathrm{d}}$ : tensão admissível do concreto a compressão,

- $\mathrm{S}_{\mathrm{s}}$ : seção de aço,

- $S_{d}$ : área de espraiamento (figura 6.9), 
- $\sigma_{\mathrm{s}}:$ tensão admissível nos ganchos e alças,

- $\mu$ : fator de redução, o qual deve ser tomado igual a 0,5 para ganchos e 0,7 para o caso de alças,

- $\sigma_{\mathrm{c}}$ : tensão do concreto a compressão.

A figura 6.8 e 6.9 mostra as áreas consideradas nas equações acima.
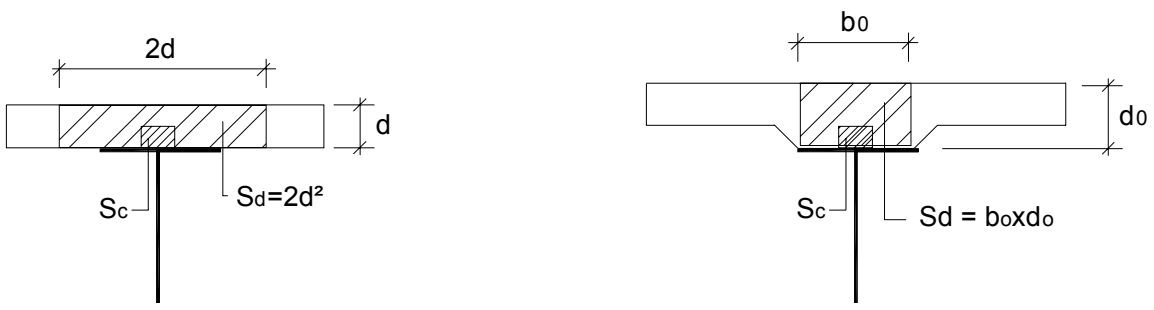

Figura 6.8- Áreas equivalentes. Fonte: Mason (1976).

O espaçamento mínimo obedece o imperativo de se obter uma boa área de espraiamento $S_{d}$, definida na figura 6.9 , exigindo-se $S_{d} \geq 2 S_{c}$, para um ângulo de espraiamento $\alpha=1: 5$.

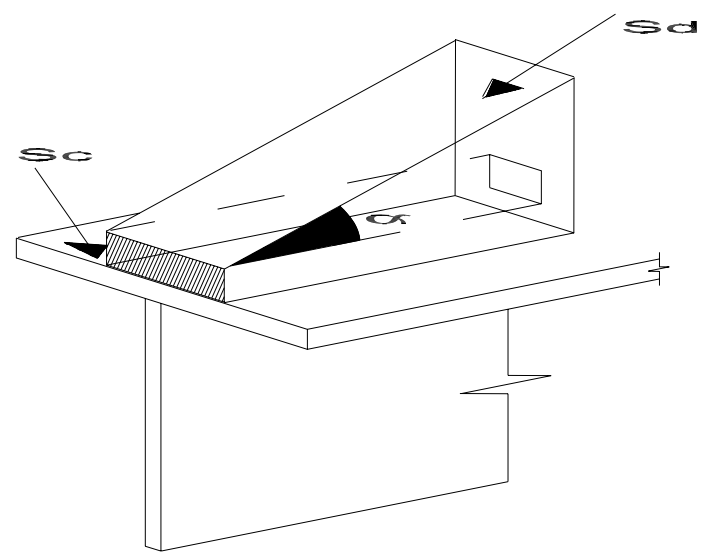

Figura 6.9- Área de espraiamento. Fonte: Mason (1976). 
O espaçamento máximo entre conectores deve estar compreendido entre $2 t_{s} a 3 t_{s}$ $\left(t_{s}=\right.$ espessura da laje), a fim de garantir uma certa uniformidade de distribuição dos esforços.

\subsection{4- Outros sistemas de ligação entre a laje de concreto e a viga de aço.}

Dentre os vários sistemas de ligação, destacam-se os conectores em espiral representados na figura 6.10 .
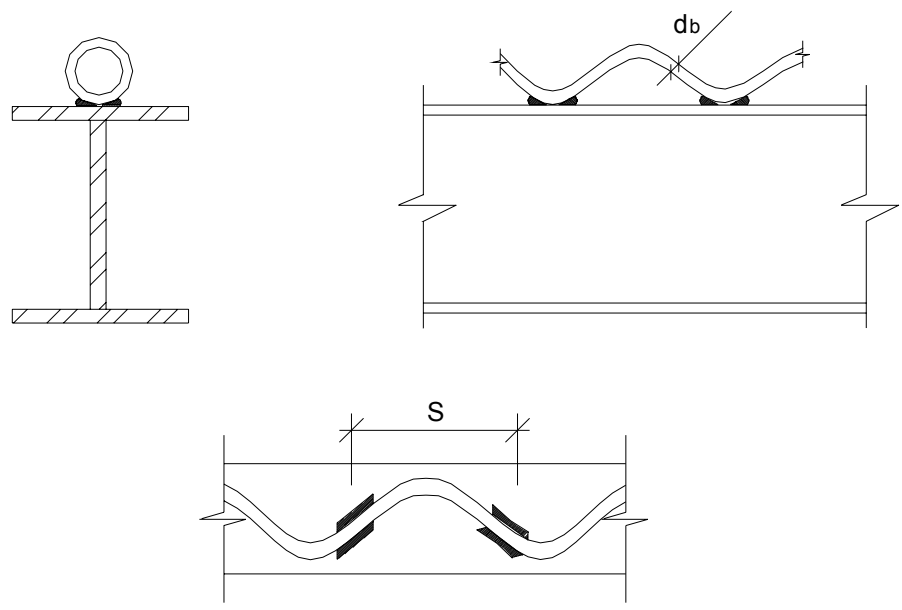

Figura 6.10- Conector em espiral.

A carga admissível correspondente à solicitação estática é apresentada pela equação:

$$
Q_{u}=3840 \times d_{b} \times \sqrt[4]{f_{c k}} \quad \text { (Blodgett) }
$$

As variáveis envolvidas serão:

- $Q_{\mathrm{u}}$ : capacidade do conector,

- $\mathrm{d}_{\mathrm{b}}$ : diâmetro do conector espiral, 
- $\mathrm{f}_{\mathrm{ck}}$ : resistência característica do concreto a compressão.

Outro tipo de conector que vem ganhando popularidade na Europa é o conector da Hilti-HVB (figura 6.11). É solidarizado através de "fixadores a tiro", possuindo vantagem em relação aos demais, de não utilizar energia elétrica para serem instalados.

Conector Hilti HVB

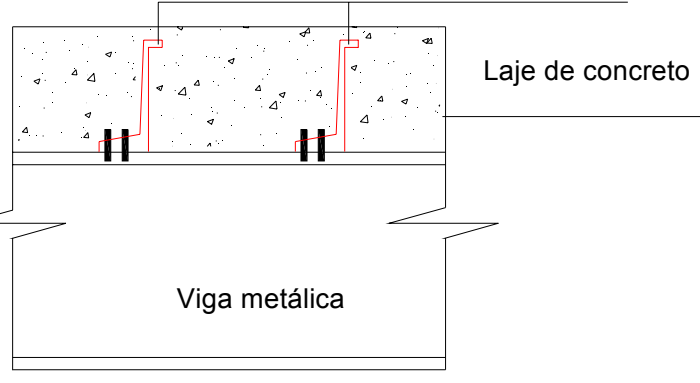

Figura 6.11- Conector da Hilti HVB. 


\section{7- ESTUDO DE VIGAS MISTAS CONSIDERANDO OS EFEITOS DA RETRAÇÃO E FLUÊNCIA.}

\section{1- Generalidades.}

As vigas mistas são constituídas da viga de aço, servindo de sustentação a uma laje de concreto, que estará apoiada na mesa superior e a ela ligada por conectores.

A utilização do tabuleiro de concreto trabalhando de maneira solidária com a viga metálica permite economia e funcionalidade. Um dos problemas a ser resolvido nas pontes com vigas mistas é a determinação das tensões no concreto e no aço, levando em consideração a ligação solidária entre o tabuleiro e as vigas.

Além disso, como o concreto apresenta deformações ao longo do tempo devido aos efeitos da retração e fluência, pode ocorrer uma redistribuição de tensões no aço e no concreto no decorrer do tempo.

O sistema terá uma boa eficiência, quando a linha neutra estiver posicionada de maneira que as tensões de compressão, decorrentes da flexão, sejam resistidas em sua maioria pelo concreto, e o perfil de aço resistindo às tensões de tração.

Há duas possibilidades de construção: sistema escorado e o não escorado. No sistema escorado, toda solicitação será resistida pelo sistema misto, e o escoramento é retirado após o concreto atingir a resistência suficiente $(75 \%$ de sua resistência característica a compressão), para que a ação mista entre os dois materiais possa ser desenvolvida.

Já o sistema não escorado, a viga de aço é dimensionada para resistir seu peso próprio, peso próprio do concreto mais as cargas de construção. O efeito de viga 
mista é utilizado para resistir às cargas móveis, defensas e possíveis manutenções futuras do tabuleiro.

A escolha do processo construtivo, influência as tensões que se desenvolvem em ambos os materiais. Em pontes mistas o processo escorado pode ser utilizado, pelo fato de que a limitação de tensões no perfil metálico pode ser um condicionante em seu dimensionamento.

\section{2- Largura efetiva da laje.}

Em situações em que o efeito "shear lag" se faz presente, as hipóteses de seções planas permanecerem planas, não são obedecidas. Este efeito corresponde a não uniformidade das tensões axiais nas mesas na direção transversal (figura 7.1).

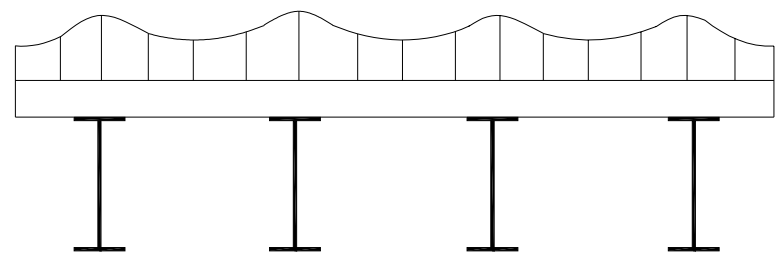

Figura 7.1- Tensões axiais não uniformes nas mesas, efeito "shear lag".

A tensão é maior sobre a viga e decresce a medida que vai se distanciando da sua linha de centro. A largura efetiva pode ser obtida através da figura 7.2. 


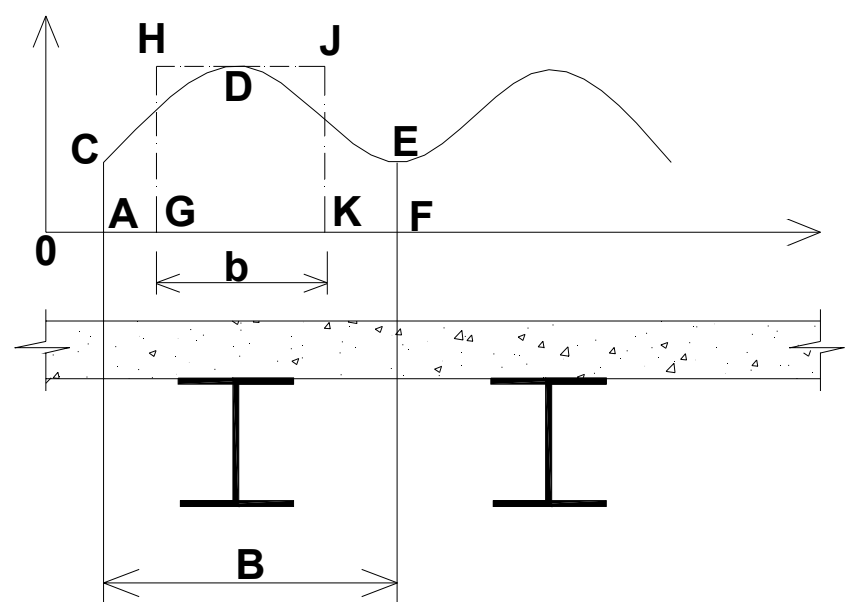

Figura 7.2- Largura efetiva. Fonte: Queiroz (2000).

Desta maneira a contribuição da mesa de concreto não é completa, levando-nos há um conceito de largura efetiva.

Pela figura 7.2, a área GHJK será a mesma do que a área ACDEF e pela teoria da flexão simples pode-se fornecer o valor correto da máxima tensão.

Pela teoria da elasticidade a relação b/B é complexa e depende da relação $B$ com o vão L, o tipo de carregamento, condições de contorno e o posicionamento da seção ao longo do vão.

Portanto a determinação exata da largura efetiva é complexa, porém podem ser utilizados valores pré-determinados como apresentado a seguir.

De acordo com Dubas (1975), admitindo-se as hipóteses de regime elástico onde seções planas permanecem planas, a largura efetiva da laje de concreto que contribui na flexão da viga mista, pode ser mostrada através da figura 7.3 e tabela 7.1 . 


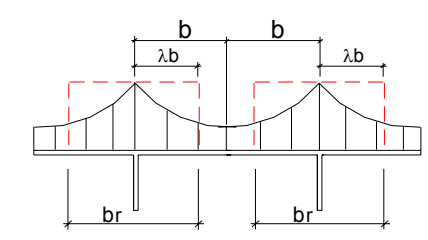

Largura Efetiva: $b r=2 \lambda b$

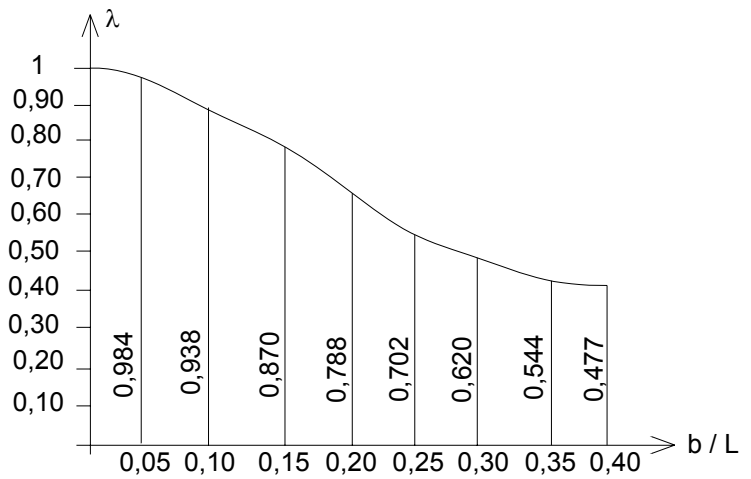

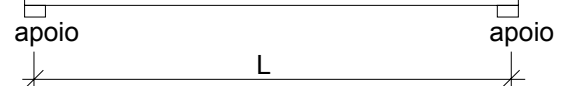

Figura 7.3- Largura efetiva. Fonte: Dubas (1975).

Tabela 7.1- Coeficiente $\lambda$. Fonte: Dubas (1975).

\begin{tabular}{|c|c|c|c|c|c|c|c|c|}
\hline $\mathrm{b} / \mathrm{L}$ & 0,05 & 0,10 & 0,15 & 0,20 & 0,25 & 0,30 & 0,35 & 0,40 \\
\hline$\lambda$ & 0,984 & 0,938 & 0,870 & 0,782 & 0,702 & 0,620 & 0,544 & 0,477 \\
\hline
\end{tabular}

Considerando uma relação $b / L<0,25$, que corresponde a maioria dos casos, os valores $\lambda$ acima representados também podem ser utilizados para a seção representada na figura 7.4 , onde a relação b/L pode ser utilizada entre as vigas adjacentes e no balanço.

A área hachurada representada nesta figura que correspondente ao tabuleiro de concreto, também pode ser considerada como parte integrante à flexão da viga mista. 


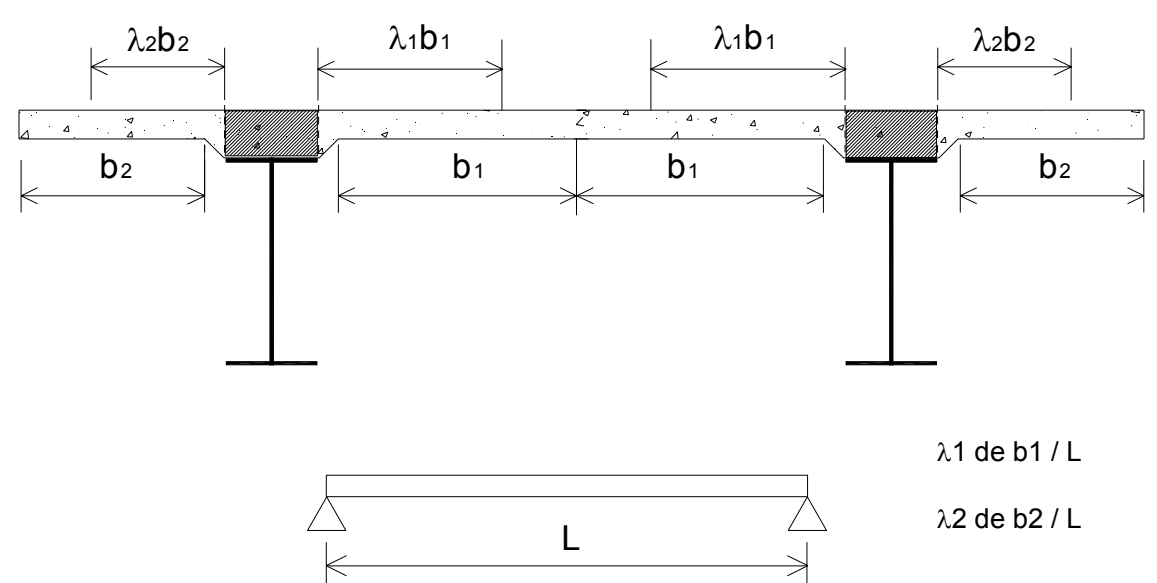

Figura 7.4- Largura efetiva considerando a contribuição das mísulas do tabuleiro.

Fonte: Dubas (1975)

Em vigas contínuas, segundo Dubas (1975), o vão L deve ser substituído pela distância entre seções de momento nulo.

Para o dimensionamento da resistência última de vigas mistas, a largura efetiva pode ser igual a $1 / 3$ do vão ou a distância entre seções correspondente ao momento nulo.

No item 10.38.3 da AASHTO (1996) são recomendados os seguintes valores da largura efetiva:

- Vigas internas:

- 1/4 do vão da viga mista,

- 12 vezes a espessura da laje,

- distância entre os centros das vigas adjacentes. 
- Vigas extremas:

- $1 / 12$ do vão da viga mista,

- 6 vezes a espessura da laje,

- metade da distância entre as vigas adjacentes.

A NBR 8800/1986 estabelece a largura efetiva da laje de concreto da seguinte maneira:

- Vigas internas:

- $1 / 4$ do vão da viga mista,

- 16 vezes a espessura da laje mais a largura da mesa superior da viga de aço,

- a largura da mesa superior da viga de aço mais a média das distâncias livres entre essa mesa e as mesas superiores das vigas adjacentes.

- Vigas extremas:

- $1 / 12$ do vão da viga mista,

- 6 vezes a espessura da laje,

- metade da distância livre entre as mesas superiores da viga considerada e da viga adjacente. 
Quanto ao dimensionamento do tabuleiro, a literatura coloca a disposição vários procedimentos como superfície de influência, gráficos, tabelas, ábacos etc.

\section{3- Interação completa - seções compactas.}

$\mathrm{Na}$ interação completa não é permitido que ocorra deslizamento relativo entre o tabuleiro de concreto e a viga metálica.

O colapso da seção acontece através da plastificação excessiva da viga metálica ou a ruptura do concreto.

A resistência a compressão da laje é estabelecida por $0,85 f_{\mathrm{ck}}$, sendo a área equivalente determinada através da multiplicação da espessura com a largura efetiva, e a resistência a tração do aço é igual a $A_{s} f_{y}$.

A AASHTO (1996) apresenta na figura 7.5 a distribuição de tensões em seções compactas.

b

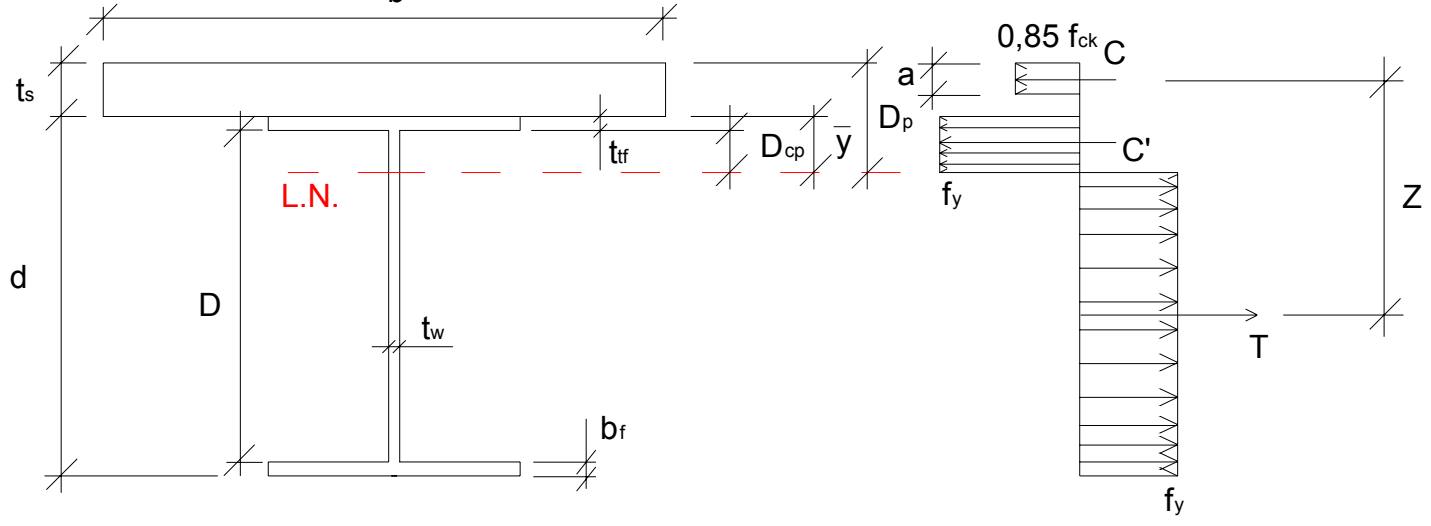

Figura 7.5- Distribuição de tensões em seções compactas. Fonte: AASHTO (1996).

A AASHTO (1996) especifica que nas regiões de momentos positivos, as vigas são compactas quando a alma da seção de aço satisfazer os seguintes requisitos:

$$
\frac{2 \times D_{c p}}{t_{w}} \leq \frac{1600}{\sqrt{f_{y}}} \rightarrow\left[f_{y}\right]=M P a
$$


Sendo:

- $\mathrm{D}_{\mathrm{cp}}=$ altura comprimida da alma referente ao momento de plastificação,

- $f_{y}=$ tensão de escoamento da alma,

- $t_{w}=$ espessura da alma.

Outra condição a ser satisfeita será : $\frac{D_{p}}{D^{\prime}} \leq 5$

$$
\begin{aligned}
& D^{\prime}=\beta \times \frac{\left(d+t_{s}+t_{h}\right)}{7,5} \\
& \left.\beta=0,7-\mathrm{f}_{\mathrm{y}}=350 \mathrm{MPa}\right) \\
& \left.\beta=0,9-\mathrm{f}_{\mathrm{y}}=250 \mathrm{MPa}\right)
\end{aligned}
$$

- $D_{p}$ : corresponde a distância entre o topo da laje e o eixo da L.N. de plastificação,

- d : altura da viga de aço,

- $t_{s}$ : espessura da laje,

- $t_{h}$ : espessura da mísula de concreto sobre a mesa superior da viga de aço.

Com referência a figura 7.5 , o momento resultante de plastificação deve ser determinado da seguinte maneira: 
a) A força de compressão atuante na laje (C), é considerada o menor valor dado pelas equações:

$$
\begin{gathered}
C=0,85 f_{c k} \times b t_{s}+\left(A \times f_{y}\right)_{c} \\
C=\left(A f_{y}\right)_{b f}+\left(A f_{y}\right)_{t f}+\left(A f_{y}\right)_{w}
\end{gathered}
$$

Sendo:

- b : largura efetiva,

- $t_{s}$ : espessura da laje,

- $\left(A_{s} f_{y}\right)_{c}$ : se refere a armadura posicionada na laje de concreto,

- $\left(A_{s} f_{y}\right)_{b f}:$ se refere a mesa inferior da viga de aço,

- $\left(A_{s} f_{y}\right)_{t f}:$ se refere a mesa superior da viga de aço,

- $\quad\left(A_{s} f_{y}\right)_{w}$ : se refere a alma da viga de aço.

b) A altura atuante da tensão aplicada na seção da laje é determinada pela seguinte equação:

$$
a=\frac{C-\left(A f_{y}\right)_{c}}{0,85 f_{c k} b}
$$

c) Quando a L.N. estiver posicionada na seção de aço, a mesma estará sujeita a uma força de compressão dada por: 


$$
C^{\prime}=\frac{\sum\left(A f_{y}\right)_{t f}-C}{2}
$$

d) A localização da L.N., medida a partir do topo da seção de aço deve ser determinada da seguinte maneira:

$$
\begin{gathered}
C^{\prime}<\left(A f_{y}\right)_{t f} \rightarrow \bar{y}=\frac{C^{\prime}}{\left(A f_{y}\right)_{t f}} \times t_{t f} \\
C^{\prime} \geq\left(A f_{y}\right)_{t f} \rightarrow \bar{y}=t_{t f}+\frac{C^{\prime}-\left(A f_{y}\right)_{t f}}{\left(A f_{y}\right)_{w}} \times D
\end{gathered}
$$

Em situações em que a linha neutra esteja localizada na laje de concreto, o seu posicionamento é apresentado pela seguinte relação:

$$
\bar{y}=\frac{\left(A_{s} \times f_{y}\right)_{\text {vigadeaco }}}{0,85 \times f_{c k} \times b}
$$

Sendo:

- $T=\left(A_{s} f_{y}\right)$, força de tração aplicada na viga de aço,

- $\quad C=0,85 f_{c k} b$, força de compressão atuando na laje de concreto.

e) O momento de plastificação é o resultado de todas as forças aplicadas na L.N. multiplicadas pelo braço de alavanca. 
A NBR 8800 classifica perfis compactos em classe1 e 2, que permite a plastificação total da seção mista, e perfis classe 3 que correspondem seções "semi-esbeltas" onde a alma pode sofrer flambagem local em regime inelástico.

Em perfis com chapas esbeltas este conceito não poderá ser empregado, pois teremos a possibilidade de flambagem local no regime elástico (classe 4), e sua resistência última dependerá da máxima tensão de compressão nos elementos que constituem o perfil metálico, e deverá ser calculada pela teoria elástica.

Quando a linha neutra está posicionada na alma, que por sua vez é classificada como esbelta, o cálculo do momento último de plastificação da seção mista consiste em desprezar a região em que a alma está comprimida e também uma altura idêntica só que abaixo da linha neutra.

\section{4- Interação parcial - seções não compactas.}

A interação é considerada parcial, quando a resistência nominal da ligação aço/concreto é inferior a tensão de escoamento da viga de aço e/ou a tensão de ruptura da laje de concreto.

Portanto não é permitido a plastificação da seção, devido ao fato em que o colapso da seção mista ocorre pela insuficiência na conexão.

Neste caso acontece um deslizamento relativo entre o aço e o concreto, apresentando uma descontinuidade no diagrama de tensões (figura 7.6).

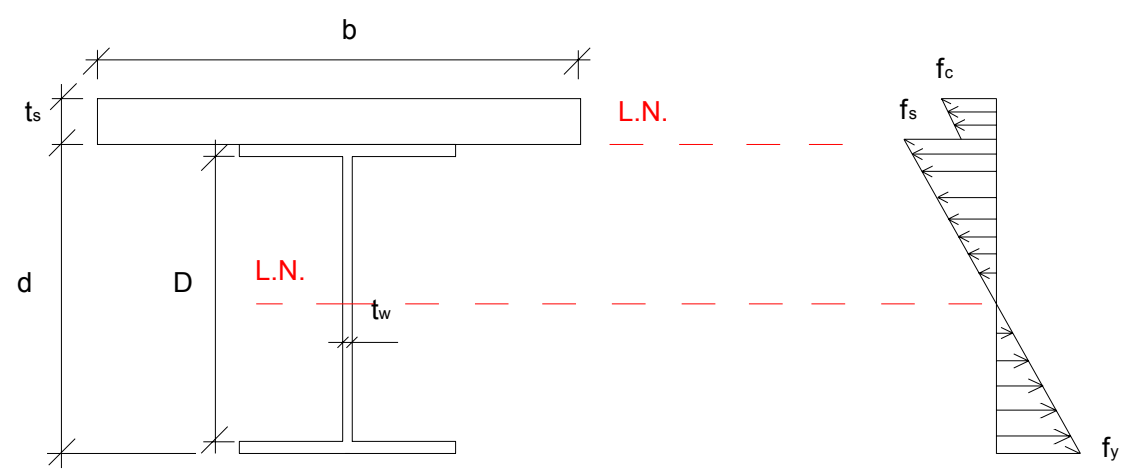

Figura 7.6- Distribuição de tensões em seções não compactas. Fonte: AASHTO (1996). 
A seção apresenta duas linhas neutras, sendo que as suas posições são independentes em função do grau de interação entre os dois materiais.

A interação parcial confere algumas vantagens como por exemplo:

- Redução de 50\% do número de conectores, com redução na resistência em torno de 20\%, uma queda de resistência aceitável segundo Queiroz (2000),

- No sistema de construção não escorado, a seção de aço selecionada para resistir as cargas durante o processo de construção, normalmente não necessita de interação completa para resistir ao carregamento, a não ser que as cargas sejam elevadas,

- O custo unitário de conectores instalados é superior ao custo do perfil de aço, por isto deve-se analisar o número de conectores em um sistema misto,

- A experiência vem demonstrando que os graus de interação da ordem de $70 \%$ a $90 \%$ são bastante interessantes do ponto de vista econômico, segundo Queiroz (2000).

\section{5- Resistência última ao momento fletor em vigas mistas.}

As duas principais maneiras de colapso de vigas mistas são:

- Ruptura por flexão da seção mista (escoamento da viga de aço ou ruptura da laje de concreto), classificada como seção compacta.

- Ruptura da ligação entre aço/concreto (deformação excessiva dos conectores), classificada como seção não compacta. 
O momento resistente $M_{u}$ em seções compactas, nas vigas simplesmente apoiadas (regiões de momentos positivos) é dado por:

$$
\begin{gathered}
D_{p} \leq D^{\prime} \rightarrow M_{u}=M_{p} \\
D^{\prime} \leq D_{p} \leq 5 D^{\prime} \rightarrow M_{u}=\frac{5 M_{p}-0,85 M_{y}}{4}+\frac{0,85 M_{y}-M_{p}}{4} \times\left(\frac{D_{p}}{D^{\prime}}\right)
\end{gathered}
$$

- $M_{p}=C \times z$, momento de plastificação em vigas mistas em regiões de momento positivo.

- $M_{y}=\left(W_{t r}\right)_{i} \times f_{y}$, momento referente ao início de escoamento da mesa tracionada em vigas mistas em regiões de momento positivo.

Onde :

- z: é a distância entre C e T (figura 7.5),

- $\left(\mathrm{W}_{\mathrm{tr}}\right)_{\mathrm{i}}=\mathrm{I}_{\mathrm{v}} / \mathrm{y}_{\mathrm{s}}{ }^{\mathrm{i}}$ momento resistente, referente a seção mista,

- $\mathrm{I}_{\mathrm{v}}$ : momento de inércia da seção mista,

- $y_{s}{ }^{i}$ : distancia correspondente entre a L.N. e a face da mesa tracionada,

- $\mathrm{f}_{\mathrm{y}}$ : tensão de escoamento,

- C : força de compressão atuando na laje de concreto.

A capacidade à flexão de vigas em perfil I designado pela AASHTO (1996), é

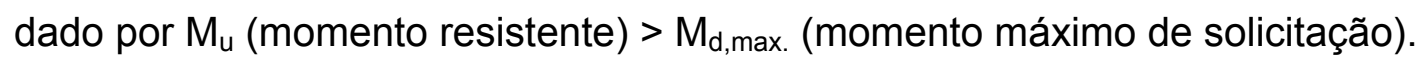




$$
M_{d, \max .}=1,3 \times\left[M_{D L 1}+M_{D L 2}+\frac{5}{3} \times\left(M_{l+I}\right)\right]
$$

(combinação de carregamento Grupo 1. AASHTO/1996).

Notas: Esta combinação apenas é válida para o trem-tipo da AASHTO.

Sendo:

- $\mathrm{M}_{\mathrm{DL} 1}$ : carregamento referente ao peso próprio atuante na viga de aço,

- $\mathrm{M}_{\mathrm{DL} 2}$ : carregamento referente ao peso próprio atuante na viga mista,

- $\mathrm{M}_{\mathrm{L}+\mathrm{I}}$ : carregamento referente a carga móvel mais impacto.

A AASHTO (1996) estabelece uma verificação a compressão da mesa superior da viga de aço (esbeltez da mesa comprimida), limitando-a ao valor:

$$
\frac{b^{\prime}}{t} \leq \frac{160}{\sqrt{\left(\sigma_{D L 1}\right)_{t f}}},\left[\sigma_{\mathrm{DL}}\right]=\mathrm{MPa}
$$

- $b^{\prime}=b_{f} / 2$ - largura da mesa superior,

- $t_{f}$ : espessura da mesa superior,

- $\left(\sigma_{\mathrm{DL}}\right)_{\mathrm{tf}}$ : tensão de compressão na mesa superior, considerando o carregamento referente ao peso próprio da viga de aço mais o peso próprio da laje.

A eq. (7.16) pode ser utilizada em seções compactas e não compactas. 
Em vigas não compactas, a AASHTO (1996) limita a capacidade resistente à flexão como sendo $\left(M_{u}=M_{y}>M_{d, \text { max. }}\right)$, onde $M_{y}$ é o momento de início de escoamento da mesa tracionada.

Também são limitadas as tensões produzidas pelo carregamento aplicado em vigas mistas não compactas, através da seguinte expressão:

$$
0,95 f_{y} \geq \sigma_{D L 1}+\sigma_{D L 2}+\frac{5}{3} \times\left(\sigma_{l+I}\right)
$$

- $\sigma_{L+1:}$ tensão referente ao carregamento da carga móvel,

- $\sigma_{\mathrm{DL} 1}$ : tensão referente ao carregamento do peso próprio atuante na viga de aço,

- $\sigma_{\mathrm{DL} 2}$ : tensão referente ao carregamento do peso próprio atuante na viga mista.

Para finalizar a AASHTO (1996) diferencia construções escoradas e não escoradas, da seguinte maneira:

- Construções não escoradas: quando a estrutura não é provida de escoramento durante a concretagem do tabuleiro, todo o peso próprio estará agindo na viga de aço $1,3 \times\left(\sigma_{D L 1}\right)$, na viga mista teremos um carregamento igual a $1,3 \times\left[\sigma_{\mathrm{DL} 2}+5 / 3 \times\left(\sigma_{\mid++}\right)\right]$, e a soma das tensões atuantes na seção mista é apresentada pela seguinte equação:

$$
f_{y} \geq 1,3 \times\left[\sigma_{D L 1}+\sigma_{D L 2}+\frac{5}{3} \times\left(\sigma_{l+I}\right)\right]
$$


- Construções escoradas: quando a laje permanece escorada até o concreto atingir $75 \%$ de sua resistência característica a compressão, as tensões atuantes na viga mista são iguais a:

$$
f_{y} \geq 1,3 \times\left[\sigma_{D L 2}+\frac{5}{3} \times\left(\sigma_{l+I}\right)\right]
$$

Corresponde ao carregamento referente a carga permanente mais a carga móvel (incluindo impacto), e as tensões serão resistidas pela seção composta.

\section{6- Resistência última ao cisalhamento, referente à seção transversal.}

A força cortante vertical atuante em vigas mistas é resistida praticamente pela alma da viga de aço, desprezando as mesas e a laje de concreto.

Em vigas com perfil I, sem necessidade de utilizar enrijecedores longitudinais, a AASHTO (1996) define a seguinte relação:

$$
\frac{D}{t_{w}} \leq \frac{3042}{\sqrt{f_{y}}},\left[f_{y}\right]=\mathrm{MPa}
$$

Quando não há necessidade de enrijecedores transversais, a AASHTO (1996) determina que a capacidade da alma ao cortante pode ser limitada da seguinte maneira:

$$
\begin{gathered}
V_{u}=c V_{p} \\
V_{p}=0,58 \times D t_{w} f_{y}
\end{gathered}
$$


A constante c é a relação entre a tensão cortante crítica dividida pela tensão cortante de escoamento $c=\frac{\tau_{c r}}{\tau_{y}}$, é determinada da seguinte maneira:

$$
\begin{gathered}
\text { para } \frac{h}{t_{w}}<500 \times \sqrt{\frac{k}{f_{y}}} \rightarrow c=1 \\
\text { para } 500 \times \sqrt{\frac{k}{f_{y}}} \leq \frac{h}{t_{w}} \leq 625 \times \sqrt{\frac{k}{f_{y}}} \rightarrow C=\frac{500 \times \sqrt{k / f_{y}}}{h / t_{w}} \\
\text { para } \frac{h}{t_{w}}>625 \times \sqrt{\frac{k}{f_{y}}} \rightarrow C=\frac{3,1 \times 10^{5} k}{\left(h / t_{w}\right)^{2} \times f_{y}} \\
k=5+\frac{5}{\left(d_{0} / h\right)^{2}}
\end{gathered}
$$

- $k=5$ (ausência de enrijecedores transversais na alma)

As vigas em formato I, com a necessidade de colocar enrijecedores transversais na alma, sua capacidade ao cortante é determinada através da seguinte equação:

$$
\begin{gathered}
V_{u}=V_{p} \times\left[C+\frac{0,87 \times(1-C)}{\sqrt{1+\left(d_{0} / D\right)^{2}}} \rightarrow d_{0} / D<3\right. \\
V_{u}>V_{d, \text { max. }}, V_{d, \text { max. }}=1,3 \times\left[V_{D L 1}+V_{D L 2}+\frac{5}{3} \times\left(V_{L+I}\right)\right]
\end{gathered}
$$


Sendo:

- D : altura da alma,

- $\mathrm{d}_{\mathrm{o}}$ : distância entre os enrijecedores transversais,

- $f_{y}$ : tensão de escoamento da alma,

- $\mathrm{V}_{\mathrm{DL} 1}$ : cortante referente ao carregamento do peso próprio atuante na viga de aço,

- $\mathrm{V}_{\mathrm{DL2}}$ : cortante referente ao carregamento do peso próprio atuante na viga mista,

- $\mathrm{V}_{\mathrm{L}+1}$ : cortante referente ao carregamento da carga móvel atuante na viga mista,

Para construções escoradas $\mathrm{V}_{\mathrm{d} 11}=0$.

As dimensões dos enrijecedores transversais consideradas pela AASHTO (1996) serão:

- $b_{s} / 0,25 b_{f} \rightarrow b_{f}$ : largura da mesa superior,

- $\mathrm{b}_{\mathrm{s}} / 50 \mathrm{~mm}+\mathrm{d} / 30 \rightarrow \mathrm{d}:$ altura da viga,

- $b_{s} / t_{s}[16$,

- $t_{s}$ : espessura do enrijecedor,

- $b_{\mathrm{s}}$ : largura do enrijecedor. 
Outra condição a ser satisfeita com relação ao enrijecedor transversal é a inércia mínima, dada pela seguinte equação:

$$
\begin{gathered}
I=d_{0} t_{w}^{3} J \\
J=2,5 \times\left(\frac{D}{d_{0}}\right)^{2}-2 \geq 0,5
\end{gathered}
$$

Os enrijecedores transversais não serão soldados a mesa tracionada, devido a presença de concentrações de tensões principalmente sobre os efeitos da fadiga. A distância da extremidade do enrijecedor à mesa inferior estará entre $4 t_{w}$ à $6 t_{w}$, a figura 7.7 apresenta mais detalhes.

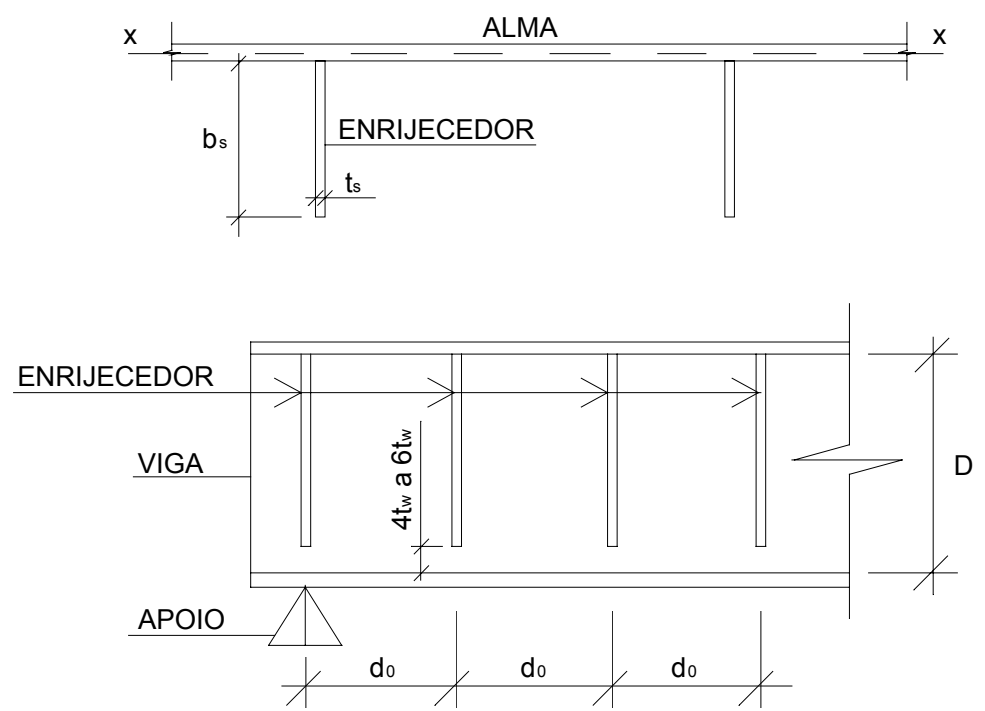

Figura 7.7- Detalhe dos enrijecedores transversais de alma.

Onde:

- I : momento de inércia mínimo do enrijecedor transversal, 
- $\mathrm{J}$ : relação da rigidez de um enrijecedor transversal com a alma,

- $\mathrm{d}_{0}$ : distãncia entre os enrijecedores,

- D : altura da alma,

- $t_{w}$ : espessura da alma.

O espaçamento máximo dos enrijecedores transversais é de $1,5 \mathrm{D}$, enquanto os enrijecedores longitudinais, quando utilizados, o seu posicionamento em relação à mesa comprimida é de $\mathrm{D} / 5$, e sua inércia é determinada da seguinte maneira:

$$
I=D t_{w}^{3} \times\left(2,4 \times \frac{d_{0}^{2}}{D^{2}}-0,13\right)
$$

- D : altura da alma,

- $t_{w}$ : espessura da alma,

- $\mathrm{d}_{0}$ : distância entre os enrijecedores.

A espessura do enrijecedor longitudinal $t_{s}$ será maior a:

$$
t_{s} \geq \frac{b^{\prime} \times \sqrt{\sigma_{s c}}}{2,250}
$$

Onde b’ é a largura do enrijecedor, $\sigma_{\mathrm{sc}}$ é tensão de compressão na mesa superior.

Quando é colocado enrijecedor longitudinal na alma, este não necessita ser contínuo, podendo ser interrompidos nas interseções com os enrijecedores transversais. 


\section{7- Resistência última ao cisalhamento, referente à ligação aço/concreto.}

A resistência ao cisalhamento longitudinal é combatida pelos conectores na junção aço/concreto. Os conectores são colocados sobre a mesa superior e ao longo da viga, e espaçados regularmente ou em intervalos variados.

De acordo com a AASHTO (1996) o cisalhamento longitudinal (q), apresentado na eq. 7.33, é verificado primeiramente à fadiga e depois checado ao estado limite último.

$$
q=Q \times \frac{M_{s}}{I_{V}}=Q \times\left(a_{c} \times b t_{s} / n\right) / I_{v}
$$

Onde:

- $M_{s}$ : momento estático referente à seção a ser ligada, isto é, o tabuleiro de concreto, tomado em relação ao eixo de inércia da viga mista (Figura 7.8),

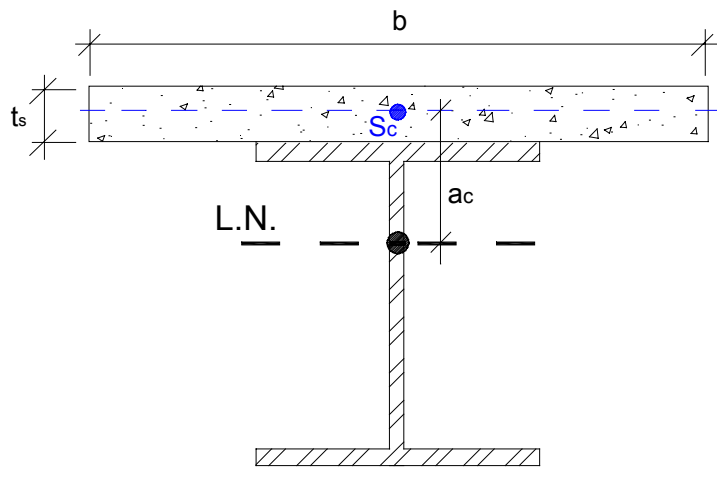

Figura 7.8- Momento estático referente às tensões longitudinais.

- $I_{v}$ : momento de inércia da viga mista considerada em regiões de momentos positivos ou o momento de inércia proveniente da viga de aço incluindo a armadura da laje de concreto em regiões de momento negativo, 
- Q : cortante referente ao carregamento da carga móvel + impacto, mais a cortante provoca pelo carregamento do peso próprio,

- b : largura efetiva,

- $t_{\mathrm{s}}$ : espessura da laje,

- $\mathrm{n}=\mathrm{E}_{\mathrm{c}} / \mathrm{E}_{\mathrm{s}}$ : coeficiente de homogeneização,

- $a_{c}$ : distância entre a L.N. da seção mista com C.G. da laje de concreto.

A força atuante nos conectores pode ser determinada, pela multiplicação das tensões longitudinais cisalhantes uniformemente distribuídas, presentes na superfície de contato entre os dois materiais, pela distância entre os conectores (Figura 7.9).
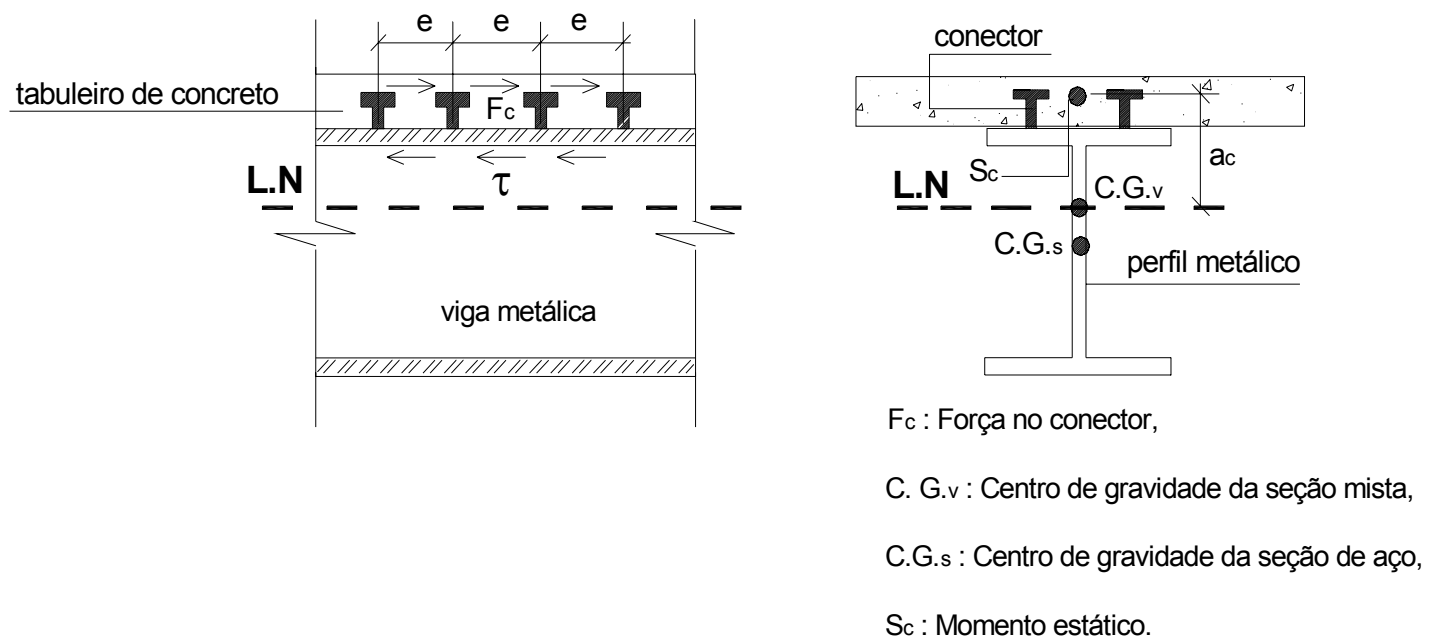

Figura 7.9- Forças transmitidas aos conectores devido as tensões longitudinais cisalhantes.

Segundo a AASHTO, as cargas admissíveis à fadiga em um conector individual, serão apresentadas pelas seguintes expressões: 
- Conector de cisalhamento em perfil U: $Z_{r}=\beta \times l_{c}$

- Conector de cisalhamento tipo pino com cabeça: $Z_{r}=\alpha \times d^{2}$

As variáveis envolvidas são:

- $\mathrm{L}_{\mathrm{c}}$ : comprimento do conector tipo $U$, medido na direção transversal da viga de aço,

- d : diâmetro do conector tipo pino com cabeça,

- $\mathrm{H}$ : altura do conector tipo pino com cabeça,

- $(\mathrm{H} / \mathrm{d}\langle 4)$, garantia de ductilidade.

$$
\begin{gathered}
\alpha: \text { 9,0 para } 1 \times 10^{5} \text { ciclos, } \\
7,3 \text { para } 5 \times 10^{5} \text { ciclos, } \\
\text { 5,4 para } 20 \times 10^{5} \text { ciclos, } \\
\text { 3,8 acima de } 20 \times 10^{5} \text { ciclos. } \\
\beta: 7,00 \text { para } 1 \times 10^{5} \text { ciclos, } \\
5,25 \text { para } 5 \times 10^{5} \text { ciclos, } \\
4,20 \text { para } 20 \times 10^{5} \text { ciclos, } \\
3,7 \text { acima de } 20 \times 10^{5} \text { ciclos. }
\end{gathered}
$$

A quantidade necessária de conectores de cisalhamento, é determinada da seguinte maneira:

$$
n_{c}=\frac{\sum Z_{r}}{q \times s}
$$


Sendo:

- $\Sigma Z_{\mathrm{r}}$ : corresponde a capacidade ao cortante de todos os conectores presentes na seção transversal,

- q: cisalhamento longitudinal determinado pela eq. 7.33.

- s: espaçamento correspondente a uma determinada faixa de solicitação ao cortante.

Após a verificação à fadiga os conectores devem ser checados para o estado limite último. A AASHTO (1996) determina o número de conectores de cisalhamento em uma viga simplesmente apoiada como sendo:

$$
N_{1} \geq \frac{P}{\phi \times Q_{u}}
$$

Onde:

- $\mathrm{N}_{1}$ : número de conectores entre o apoio e o momento máximo positivo,

- $Q_{\mathrm{u}}$ : resistência última do conector de cisalhamento,

- $\phi$ : fator de redução igual a 0,85,

- $P$ : força exercida na laje, definida como $\mathrm{P}_{1}$ e $\mathrm{P}_{2}$,

Nos locais de momento máximo, a força na laje a ser considerada é o menor valor das seguintes equações:

$$
P_{1}=A_{s} \times f_{y}
$$




$$
P_{2}=0,85 \times f_{c k} \times b \times t_{s}
$$

Onde:

- $\mathrm{A}_{\mathrm{s}}$ : área da viga de aço,

- $f_{y}$ : tensão de escoamento do aço,

- $f_{c k}$ : resistência característica do concreto a compressão,

- b: largura efetiva,

- $t_{s}$ : espessura da laje.

A resistência última do conector ao cisalhamento é igual a:

- conector perfil U laminado: $Q_{u}=0,0365 \times\left(t_{f}+0,5 \times t_{w}\right) \times l_{c} \times \sqrt{f_{c k}}$

- conector tipo pino com cabeça: $Q_{u}=3,985 \times 10^{-4} \times d^{2} \times \sqrt{f_{c k}}$

Sendo:

- $t_{f}$ : espessura média da mesa do conector tipo $U$,

- $t_{w}$ : espessura da alma do conector tipo $U$,

- $\mathrm{I}_{\mathrm{c}}$ : comprimento do conector tipo $\mathrm{U}$, medido na direção transversal da viga de aço. 


\section{8- Estado limite de serviço (deslocamentos).}

Em vigas contínuas e simplesmente apoiadas, o deslocamento proveniente da carga móvel + impacto é definido pela seguinte equação:

$$
\delta_{p}=\frac{5 \times p l^{4}}{384 \times E_{s} \times I_{v}}+\frac{F \times l^{3}}{48 \times E_{s} \times I_{v}}+2 \times\left[\frac{F \times b}{12 \times E_{s} \times I_{v}} \times\left(0,75 \times l^{2}-b^{2}\right)\right]
$$

b

$\mathrm{L}$

Quando as vigas não são escoradas durante a concretagem da laje, o deslocamento devido o peso próprio da laje e de outras cargas permanentes adicionais, antes mesmo do concreto atingir $75 \%$ de sua resistência, será determinado com base nas ações aplicadas na viga de aço (AASHTO/1996). Portanto em vigas simplesmente apoiadas a flecha imediata, devido o peso próprio é igual a:

$$
\delta_{\text {imediata }}=\frac{5 \times g l^{4}}{384 \times E_{s} I_{s}}
$$

Quanto ao deslocamento proveniente dos efeitos da retração e fluência em vigas mistas, pode-se definir as seguintes equações:

$$
\delta_{\text {retracao }}=\frac{E_{c} \times \varepsilon_{c s} \times b \times t_{s} \times\left(y_{t} \times t_{s} / 2\right)}{E_{s} \times I_{v}}\left(O^{\prime}\right. \text { CONNOR /1975) (7.44) }
$$


As variáveis presentes nas eqs. $7.42,7.43,7.44$ são:

- $\mathrm{E}_{\mathrm{c}}$ : módulo de elasticidade do concreto,

- $\varepsilon_{c s}$ : coeficiente de retração com valores entre 0,0002 à 0,0005 ,

- $p$ : carga móvel + impacto,

- g : carga permanente,

- b : largura efetiva,

- $t_{s}$ : espessura da laje,

- $y_{t}$ : distância entre o C.G. da viga mista e a interface aço/concreto,

- $\mathrm{E}_{\mathrm{s}}$ : módulo de elasticidade do aço,

- $I_{\mathrm{v}}$ : momento de inércia da viga mista,

- $\mathrm{I}_{\mathrm{s}}$ : momento de inércia da seção de aço.

Quanto a Norma canadense, inicialmente determina-se o momento de inércia efetivo apresentado pela equação:

$$
I_{e f}=I_{s}+0,85 p^{0,25} \times\left(I_{v}-I_{s}\right), \mathrm{p}=1 \text { (interação completa) }
$$

O efeito da fluência é considerado através de uma redução do momento de inércia efetivo em $15 \%$ de seu valor. Portanto em uma viga simplesmente apoiada a determinação da flecha, devido os efeitos da retração e fluência é igual a: 


$$
\delta_{\text {retracao,fluencia }}=\frac{\varepsilon_{c s} \times E_{c} \times A_{c} \times L^{2}}{8 \times E_{s} \times I_{e f}}
$$

- $\mathrm{I}_{\mathrm{ef}}=$ momento de inércia efetivo que leva em consideração a fluência,

Para finalizar, o deslocamento total apresentado em uma viga simplesmente apoiada é igual a:

$$
\delta_{\text {TOTAL }}=\delta_{\text {CARGA MÓVEL }}+\delta_{\text {inicial }}+\delta_{\text {retracao,fluência }}
$$

Os valores limites de deslocamento, impostos pela AASHTO (1996) serão de 1/800 do vão, exceto em pontes urbanas utilizadas por pedestres que será $1 / 1000$ do vão.

\section{9- Efeitos da retração e fluência em vigas mistas.}

\subsection{1- Generalidades.}

Os procedimentos de cálculo das tensões, considerando os efeitos da retração e fluência, foram baseados em DJURIC (1963), posteriormente por Dubas (1975) e Mason (1976).

As tensões na seção mista foram determinadas, admitindo-se um comportamento elástico da mesma e interação completa na ligação entre aço/concreto.

Os efeitos da retração foram combatidos com armaduras posicionadas na laje, enquanto os efeitos da fluência, foram considerados no dimensionamento através da diminuição do módulo de elasticidade do concreto, proporcionando um aumento progressivo do coeficiente de homogeneização. 
A verificação das tensões foi apresentada no tempo $t=0$ quando o carregamento foi aplicado, e no tempo t quando foi levada em consideração a retração e a fluência do concreto.

7.9.2- Efeitos da retração e fluência em vigas mistas, procedimento baseado por Djuric (1963).

\subsubsection{1- Propriedade da seção transversal.}

\subsubsection{1- Para o tempo $\mathrm{t}=0$.}

As notações seguintes são referentes a seção transversal considerando as propriedades do aço e concreto no tempo $t=0$.

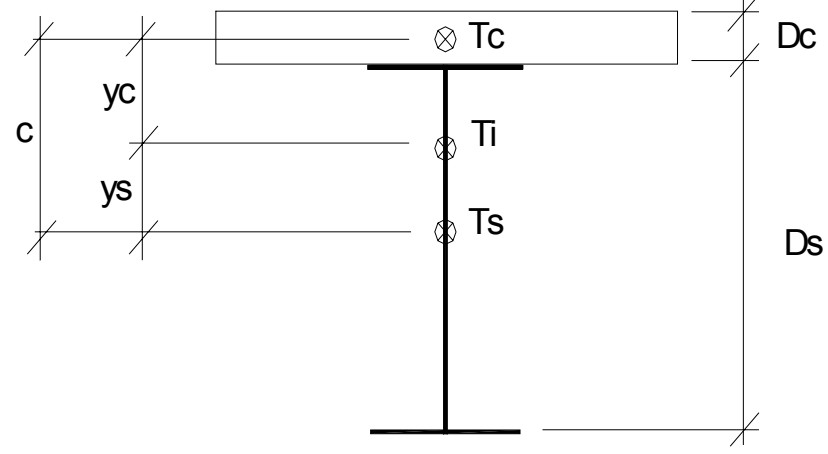

Figura 7.10- Seção transversal $-\mathrm{t}=0$. Fonte: Djuric (1963).

Onde:

Os índices s: aço; c: concreto; i: seção mista e/ou idealizada,

- $\mathrm{T}_{\mathrm{c}}, \mathrm{T}_{\mathrm{s}}, \mathrm{T}_{\mathrm{i}}$ : centro de gravidade,

- $A_{c}, A_{s}$ seção transversal, 
- $\mathrm{I}_{\mathrm{c}}, \mathrm{I}_{\mathrm{s}}$ : momento de inércia,

- $E_{c}, E_{s}$ : módulo de elasticidade,

- $D_{c}, D_{s}$ : largura do concreto e altura total da viga de aço,

- c: distância entre o centro de gravidade da viga de aço e a laje de concreto.

- $E_{r}$ : módulo de elasticidade de referência (usualmente $E_{s}=E_{r}$ ).

Introduzindo também as seguintes notações:

$$
\begin{aligned}
& v_{s}=E_{s} / E_{r} \\
& v_{c}=E_{c} / E_{r} \\
& A_{s}^{r}=v_{s} \times A_{s} \\
& A_{c}^{r}=v_{c} \times A_{c}
\end{aligned}
$$

A área da seção transversal idealizada será dada por:

$$
A_{i}=A_{s}^{r}+A_{c}^{r}
$$

- $y_{s}$ : distância entre $T_{s}$ e $T_{i}$,

- $\mathrm{y}_{\mathrm{c}}$ : distância entre $\mathrm{T}_{\mathrm{c}}$ e $\mathrm{T}_{\mathrm{i}}$,

Satisfazendo as seguintes condições:

$$
A^{r}{ }_{s} \times y_{s}+A_{c}^{r} \times y_{c}=0
$$




$$
\mathrm{y}_{\mathrm{s}}-\mathrm{y}_{\mathrm{c}}=\mathrm{c}
$$

Obtém-se:

$$
\begin{aligned}
& y_{s}=\left(A_{c}^{r} / A_{i}^{r}\right) \times c \\
& y_{c}=\left(A_{s}^{r} / A_{i}^{r}\right) \times c
\end{aligned}
$$

Introduzindo as notações:

$$
\begin{aligned}
& I_{s}{ }^{r}=v_{s} \times I_{s} \\
& I_{r}{ }_{r}=v_{c} \times I_{c}
\end{aligned}
$$

Conseqüentemente obtém-se $\mathrm{I}_{\mathrm{i}}$ (momento de inércia da seção transversal idealizada com o eixo de inércia passando por $\mathrm{T}_{\mathrm{i}}$ ) igual $\mathrm{a}$ :

$$
I_{i}=I_{s}^{r}+A_{s}^{r} \times y_{s}^{2}+I_{c}^{r}+A_{c}^{r} \times y_{c}{ }^{2}=I_{s}^{r}+I_{c}^{r}+\left(c^{2} \times A_{s}^{r} \times A_{c}^{r}\right) / A_{i}
$$

\subsubsection{2- Para o tempo $t$.}

As notações seguintes são referentes a seção transversal da viga mista levando em consideração a retração e fluência. 


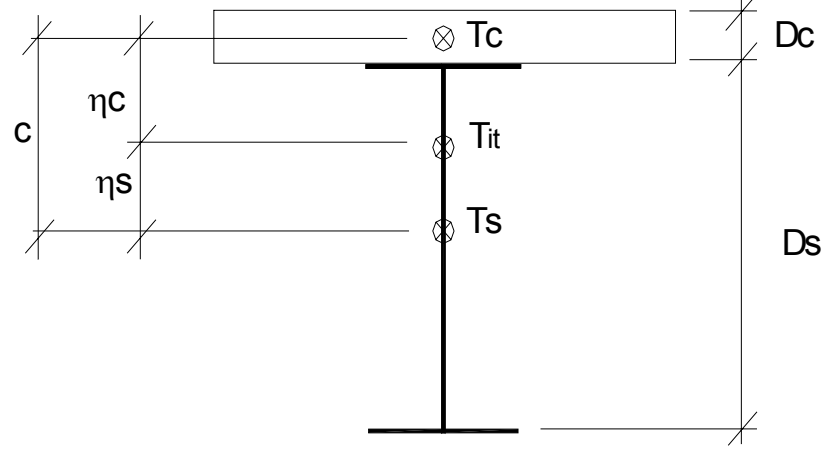

Figura 7.11- Seção transversal no tempo t. Fonte: Djuric (1963).

Sendo:

- $\mathrm{E}_{\mathrm{ct}}$ : módulo de elasticidade efetivo do concreto dado por:

$$
\mathrm{E}_{\mathrm{ct}}=\mathrm{E}_{\mathrm{c}} /\left(1+\xi_{(\mathrm{t}, \mathrm{t}, \mathrm{t})} \times \omega_{(\mathrm{t}:, \mathrm{to})}\right)
$$

- $\omega_{(\mathrm{t}:, \mathrm{to})}$ : coeficiente de fluência,

- $\xi_{(t, t o)}:$ coeficiente de envelhecimento do concreto,

- $\mathrm{E}_{\mathrm{c}}$ : módulo de elasticidade secante do concreto.

- $\mathrm{T}_{\text {it }}$ : centro de gravidade da seção transversal idealizada no tempo $\mathrm{t}$.

A equação 7.60 procura ajustar o módulo de elasticidade do concreto para o tempo $t$, considerando o envelhecimento do concreto. Os valores de $\xi_{(\mathrm{t}: \text {, to) }}$ estão apresentados na tabela 7.2 . 
Tabela 7.2- Valores do coeficiente de envelhecimento $\xi\left(t_{\text {. }}, t_{0}\right)$. Fonte: Bazant (1972).

\begin{tabular}{|c|c|c|c|c|c|}
\hline \multirow{2}{*}{\begin{tabular}{|l|} 
\\
$\left(t:-t_{0}\right)$
\end{tabular}} & \multirow[b]{2}{*}{$\omega(\mathrm{t}:, 7)$} & \multicolumn{4}{|c|}{ Valores de $\xi\left(\mathrm{t}_{\mathrm{f}}, \mathrm{t}_{0}\right)$} \\
\hline & & $t_{0}=10$ & $t_{0}=10^{2}$ & $t_{0}=10^{3}$ & $t_{0}=10^{4}$ \\
\hline \multirow{4}{*}{10 dias } & 0.5 & 0.525 & 0.804 & 0.811 & 0.809 \\
\hline & 1.5 & 0.720 & 0.826 & 0.825 & 0.820 \\
\hline & 2.5 & 0.774 & 0.842 & 0.837 & 0.830 \\
\hline & 3.5 & 0.806 & 0.856 & 0.848 & 0.839 \\
\hline \multirow{4}{*}{$10^{2}$ dias } & 0.5 & 0.505 & 0.888 & 0.916 & 0.915 \\
\hline & 1.5 & 0.739 & 0.919 & 0.932 & 0.928 \\
\hline & 2.5 & 0.804 & 0.935 & 0.943 & 0.938 \\
\hline & 3.5 & 0.839 & 0.946 & 0.951 & 0.946 \\
\hline \multirow{4}{*}{$10^{3}$} & 0.5 & 0.511 & 0.912 & 0.973 & 0.981 \\
\hline & 1.5 & 0.732 & 0.943 & 0.981 & 0.985 \\
\hline & 2.5 & 0.795 & 0.956 & 0.985 & 0.988 \\
\hline & 3.5 & 0.830 & 0.964 & 0.987 & 0.990 \\
\hline \multirow{4}{*}{$10^{4}$} & 0.5 & 0.461 & 0.887 & 0.956 & 0.965 \\
\hline & 1.5 & 0.702 & 0.924 & 0.966 & 0.972 \\
\hline & 2.5 & 0.770 & 0.940 & 0.972 & 0.976 \\
\hline & 3.5 & 0.808 & 0.950 & 0.977 & 0.980 \\
\hline
\end{tabular}

Introduzindo outras notações como:

$$
\begin{aligned}
& v_{c t}=E_{c t} / E_{r} \\
& A_{c t}^{r}=v_{c t} \times A_{c} \\
& A_{i t}=A_{s}^{r}+A_{c t}^{r}
\end{aligned}
$$

Definindo para:

$$
\eta_{\mathrm{s}}=\left(\mathrm{A}_{\mathrm{ct}}^{\mathrm{r}} / \mathrm{A}_{\mathrm{it}}\right) \times \mathrm{c}
$$

(distância entre $T_{s} T_{i t}$ )

$$
\eta_{c}=\left(A_{s}^{r} / A_{i t}\right) \times c
$$

(distância entre $T_{c} T_{i t}$ ) 
Usando a notação:

$$
I_{c t}^{r}=v_{c t} \times I_{c}
$$

O momento de inércia da seção transversal idealizada no tempo t é dado por:

$$
I_{i t}=I_{s}^{r}+A_{s}^{r} \times \eta_{s}{ }^{2}+I_{c t}^{r}+A_{c t}^{r} \times \eta_{c}{ }^{2}=I_{s}^{r}+I_{c t}^{r}+\left(c^{2} \times A_{s}^{r} \times A_{c t}^{r}\right) / A_{i t}
$$

\subsubsection{2- Distribuição de tensões.}

\subsubsection{1- Para o tempo $\mathrm{t}=0$.}

Inicialmente considera-se a deformação por escorregamento, que resulta em um deslizamento entre o aço e concreto.

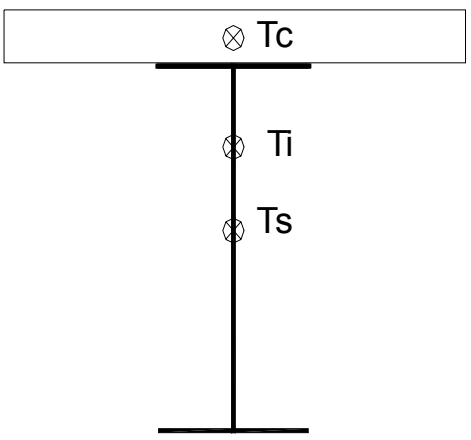

$\varepsilon k$

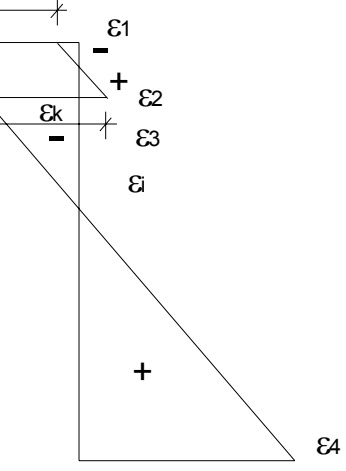

Figura 7.12- Deformações na seção composta no tempo $t$ = 0. Fonte: Djuric (1963).

A deformação em um ponto qualquer é determinada em função do centro de gravidade da seção transversal idealizada.

$$
\varepsilon_{s}=\varepsilon_{i}+k \times y
$$


7- Estudos de vigas mistas considerando os efeitos da retração e fluência. 113

$$
\varepsilon_{c}=\varepsilon_{i}+k \times y+\varepsilon_{k}
$$

As tensões serão dadas através das equações:

$$
\begin{gathered}
\sigma_{s}=E_{s} \times \varepsilon_{s}=E_{s} \times\left(\varepsilon_{i}+K \times y\right) \\
\sigma_{c}=E_{c} \times \varepsilon_{c}=E_{c} \times\left(\varepsilon_{i}+K \times y\right)+E_{c} \times \varepsilon_{k}
\end{gathered}
$$

Fazendo o equilíbrio de equações:

$$
\begin{gathered}
\int_{s} \sigma_{s} \times d A+\int_{c} \sigma_{c} \times d A=N \\
\int_{s} \sigma_{s} \times y \times d A+\int_{c} \sigma_{c} \times y \times d A=M
\end{gathered}
$$

Com as eq. 7.52 e 7.59 e levando em consideração:

$$
\begin{aligned}
& \int_{s} d A=A_{s}, \int_{s} y \times d A=A_{s} \times y_{s} \\
& \int_{s} y^{2} \times d A=I_{s}+A_{s} \times y_{s}^{2} \\
& \int_{c} d A=A_{c}, \int_{c} y \times d A=A_{c} \times y_{c} \\
& \int_{c} y^{2} \times d A=I_{c}+A_{c} \times y_{c}^{2}
\end{aligned}
$$


De 7.72 e 7.73 tem-se:

$$
\begin{array}{r}
E_{r} \times A_{i} \times \varepsilon_{i}=N-\sigma_{k} \times A_{c} \\
E_{r} \times I_{i} \times k_{i}=M-\sigma_{k} \times A_{c} \times y_{c}
\end{array}
$$

Usando a notação:

$$
N_{k}=\sigma_{k} \times A_{c}
$$

Onde:

$$
\sigma_{k}=E_{c} \times \varepsilon_{k}
$$

Considerando:

$$
N^{*}=N-N_{k}, M^{*}=M-N_{k} \times y_{c}
$$

De 7.78 e 7.79 pode-se obter:

$$
\begin{gathered}
\varepsilon_{i}=\frac{N^{*}}{E_{r} \times A_{i}} \\
k=\frac{M^{*}}{E_{r} \times I_{i}}
\end{gathered}
$$

Finalmente de 7.70 e 7.71 determinam-se as tensões aplicadas na laje de concreto e na viga de aço. 


$$
\begin{gathered}
\sigma_{s o}=v_{s} \times\left(\frac{N^{*}}{A_{i}}+\frac{M^{*}}{I_{i}} \times y\right) \\
\sigma_{c o}=v_{c} \times\left(\frac{N^{*}}{A_{i}}+\frac{M^{*}}{I_{i}} \times y\right)+\sigma_{k}
\end{gathered}
$$

As forças internas referentes a laje de concreto e a viga de aço são dadas pelas seguintes equações:

$$
\begin{gathered}
M_{s o}=M^{*} \times \frac{I_{s}^{r}}{I_{i}} \rightarrow N_{s o}=N^{*} \times \frac{A_{s}^{r}}{A_{i}}+M^{*} \times \frac{A_{s}^{r} \times y_{s}}{I_{i}} \\
M_{c o}=M^{*} \times \frac{I_{c}^{r}}{I_{i}} \rightarrow N_{c o}=N^{*} \times \frac{A_{c}^{r}}{A_{i}}+M^{*} \times \frac{A_{c}^{r} \times y_{c}}{I_{i}}+N_{k}
\end{gathered}
$$

\subsubsection{2- Para o tempo t.}

Deformações no tempo $t$ em determinados pontos da seção transversal seja no aço ou no concreto, são determinados em relação ao centro de gravidade da seção transversal idealizada.

$$
\begin{gathered}
\varepsilon_{s}=\varepsilon_{i t}+k_{t} \times \eta \\
\varepsilon_{c}=\varepsilon_{i t}+k_{t} \times \eta+\varepsilon_{t k}
\end{gathered}
$$

Onde $\varepsilon_{k t}$ é a deformação por deslizamento no tempo t. 
As tensões no aço serão determinadas de acordo com o comportamento elástico, e nesta fase são considerados os efeitos da retração e da fluência de acordo com a expressão:

$$
\sigma_{c}=E_{c t} \times\left(\varepsilon_{c}-\varepsilon_{s h}\right)-\rho \times \sigma_{c o}
$$

Onde:

- $\sigma_{\mathrm{c}}$ : tensão no concreto no tempo $\mathrm{t}$,

- $\sigma_{c o}$ : tensão no concreto no tempo $t=0$,

- $\varepsilon_{\mathrm{c}}$ : deformação total no concreto no tempo $\mathrm{t}$,

- $\varepsilon_{\text {sh }}$ : deformação por retração.

$$
\begin{aligned}
& E_{c t}=\frac{E_{c}}{1+\chi_{(t \infty, t o} \times \varphi_{(t \infty, t o)}} \\
& \rho=\frac{\left(1-\chi_{(t \infty, t o)}\right) \times \varphi_{(t \infty, t o)}}{1+\chi_{(t \infty, t o)} \times \varphi_{(t \infty, t o)}}
\end{aligned}
$$

Sendo:

- $\mathrm{E}_{\mathrm{ct}}$ : módulo de elasticidade efetivo do concreto,

- $\mathrm{E}_{\mathrm{c}}$ : módulo de elasticidade secante do concreto,

- $\omega_{(\mathrm{t}:, \mathrm{to})}$ : coeficiente de fluência,

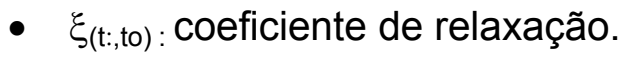


As tensões serão dadas através das seguintes equações:

$$
\begin{gathered}
\sigma_{s}=E_{s} \times \varepsilon_{s}=E_{s} \times\left(\varepsilon_{i t}+K_{t} \times y\right) \\
\sigma_{c}=E_{c t} \times\left(\varepsilon_{i t}+K_{t} \times \eta\right)-\rho \times \sigma_{c o}-E_{c t} \times \varepsilon_{s h}+E_{c t} \times \varepsilon_{k t}
\end{gathered}
$$

Onde $\sigma_{c o}$ é a tensão referente ao tempo $t=0$.

Com a mudança do centro de gravidade de $T_{i}$ para $T_{i t}$, o momento na seção será dado por:

$$
M^{\prime}=M+N \times\left(\eta_{s}-y_{s}\right)
$$

Fazendo o equilíbrio de equações:

$$
\begin{gathered}
\int_{s} \sigma_{s} \times d A+\int_{c} \sigma_{c} \times d A=N \\
\int_{s} \sigma_{s} \times \eta \times d A+\int_{c} \sigma_{c} \times \eta \times d A=M^{\prime}
\end{gathered}
$$

Similar ao processo no tempo $\mathrm{t}=0$, portanto:

$$
\begin{gathered}
E_{r} \times A_{i t} \times \varepsilon_{i t}=N+\rho \times N_{c t=0}+N_{s h}-N_{k t} \\
E_{r} \times I_{i t} \times k_{t}=M^{\prime}+\rho \times\left(M_{c t=0}+N_{c t=0} \times \eta_{c}\right)+N_{s h} \times \eta_{c}-N_{k t} \times \eta
\end{gathered}
$$

Onde: 


$$
\begin{gathered}
\int_{c} \sigma_{c o} \times d A=N_{c o} \\
\int_{c} \sigma_{c o} \times \eta \times d A=M_{c o}+N_{c o} \times \eta_{c} \\
N_{s h}=E_{c t} \times \varepsilon_{s h} \times A_{c} \\
N_{k t}=\sigma_{k t} \times A_{c} \\
\sigma_{k t}=E_{c t} \times \varepsilon_{k t}
\end{gathered}
$$

Considera-se a seguinte notação:

$$
\begin{gathered}
N_{t}^{*}=N+\rho \times N_{c o}+N_{s h}-N_{k t} \\
M^{*}=M^{\prime}+\rho \times\left(M_{c o}+N_{c o} \times \eta_{c}\right)+N_{s h} \times \eta_{c}-N_{k t} \times \eta_{c}
\end{gathered}
$$

De 7.99, obtém-se:

$$
\begin{aligned}
& \varepsilon_{i t}=\frac{N_{t}^{*}}{E_{r} \times A_{i t}} \\
& k_{t}=\frac{M_{t}^{*}}{E_{r} \times I_{i t}}
\end{aligned}
$$

Finalmente das eqs. 7.94 e 7.95 , as tensões são obtidas. 


$$
\begin{gathered}
\sigma_{s}=v_{s} \times\left(\frac{N_{t}^{*}}{A_{i t}}+\frac{M_{t}^{*}}{I_{i t}} \times \eta\right) \\
\sigma_{c}=v_{c t} \times\left(\frac{N_{t}^{*}}{A_{i t}}+\frac{M_{t}^{*}}{I_{i t}} \times \eta\right)-\rho \times \sigma_{c o}-E_{c t} \times \varepsilon_{s h}+\sigma_{k t}
\end{gathered}
$$

Caso seja considerado interação completa na ligação entre aço/concreto, as deformações por deslizamento $\left(\varepsilon_{\mathrm{k}}, \varepsilon_{\mathrm{kt}}\right)$ presentes nas expressões $7.85 ; 7.86 ; 7.110$ e 7.111, são considerados iguais a zero.

7.9.3- Determinação dos formulários das tensões em seções mistas, segundo Dubas (1975) e Mason (1976).

Os formulários desenvolvidos por Dubas (1975) e Mason (1976) à determinação das tensões na seção mista, foram admitidos que as grandezas geométricas da seção fossem iguais a:

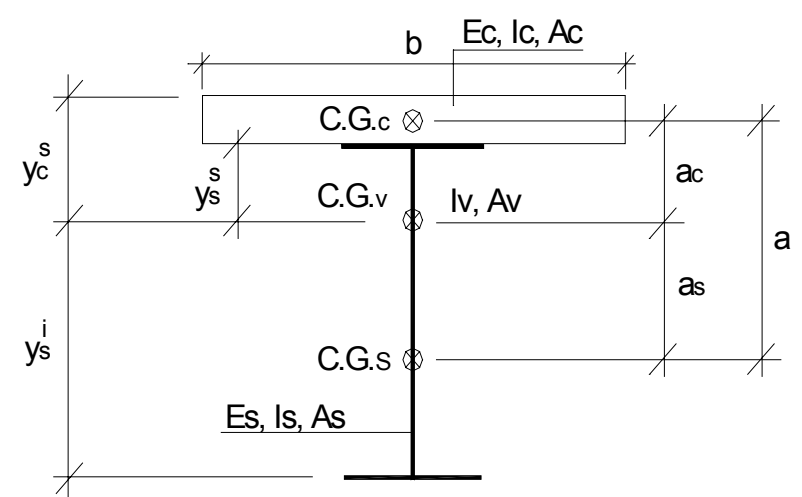

Figura 7.13- Grandezas geométricas das seções no caso de flexão simples. Fonte: Dubas (1975) e Mason (1976).

As variáveis envolvidas são: 
- $A_{c}$ : área de concreto,

- $\mathrm{I}_{\mathrm{c}}$ : momento de inércia da seção do concreto em relação ao seu baricentro,

- $A_{s}$ : área da seção de aço,

- $\mathrm{I}_{\mathrm{s}}$ : momento de inércia da seção de aço,

- $I_{v}:$ momento de inércia da viga mista,

- y : distância de um ponto qualquer da seção ao centro de gravidade da seção mista,

- a : distância entre os centros de gravidade das seções de concreto e de aço,

- $a_{c}$ : distância do centro de gravidade da seção de concreto ao centro de gravidade da seção mista,

- $a_{s}$ : distância do centro de gravidade da seção de aço ao centro de gravidade da seção mista,

- C.G.v : centro de gravidade da seção mista,

- C.G. c : centro de gravidade da seção de concreto,

- C.G.s : centro de gravidade da seção de aço,

- $E_{s}, E_{c}$ : módulo de elasticidade do aço e concreto. 
Ao considerar a seção mista, devemos determinar o coeficiente de equivalência mecânica $n=E_{s} / E_{c}$.

No cálculo das tensões devido à ação do momento fletor, foram admitidas as hipóteses de seções planas permaneçam planas, e que não aconteça deslizamento relativo entre as seções de concreto e do aço.

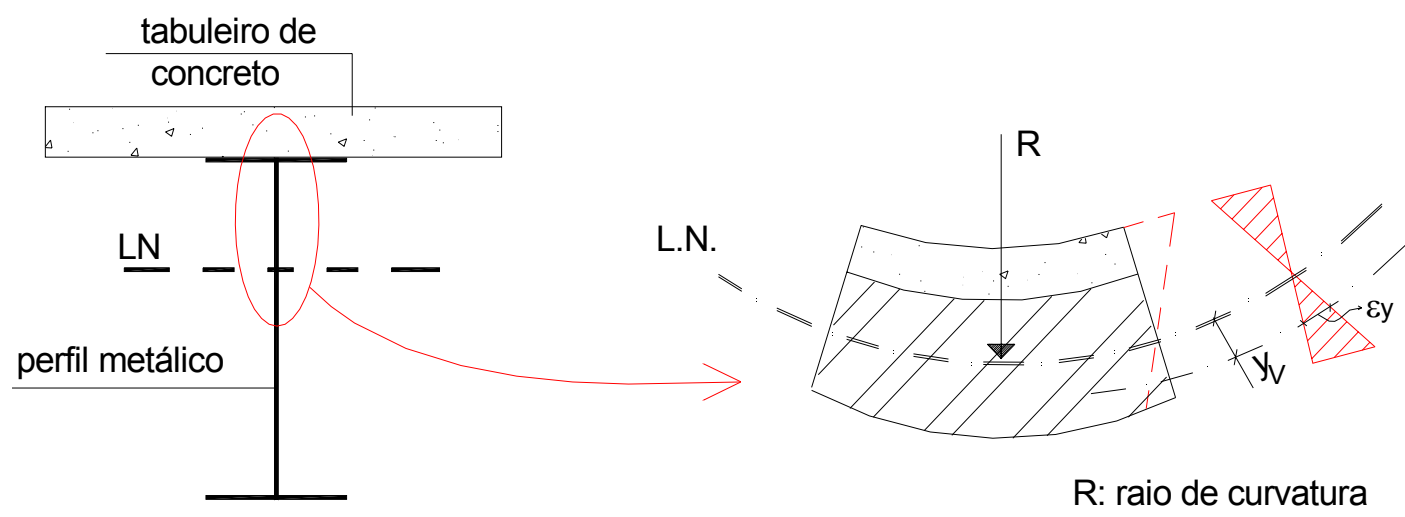

Figura 7.14- Seções planas permanecem planas. Fonte: Mason (1976).

O alongamento de uma fibra genérica, representado na figura 7.14 , pode ser determinado pela seguinte equação:

$$
\varepsilon_{y}=\frac{y_{V}}{R}
$$

As tensões encontradas no concreto e no aço serão:

$$
\begin{gathered}
n \times \sigma_{c}=\frac{y_{V}}{R} \times E_{s} \\
\sigma_{s}=\frac{y_{V}}{R} \times E_{s}
\end{gathered}
$$

A condição que determina a posição da linha neutra é dada por: 


$$
\int_{A c} \sigma_{c} d A_{c}+\int_{A s} \sigma_{s} d A_{s}=0
$$

Substituindo nas equações acima.

$$
\frac{1}{n} \int_{A c} y_{V} d A_{c}+\int_{A s} y_{V} d A_{s}=0
$$

Desta maneira as distâncias $\mathrm{a}_{\mathrm{c}} \mathrm{e} \mathrm{a}_{\mathrm{s}}$ serão dadas por:

$$
\begin{aligned}
& a_{s}=\frac{\frac{1}{n} \times A_{c}}{\frac{1}{n} \times A_{c}+A_{s}} \times a \\
& a_{c}=\frac{A_{s}}{\frac{1}{n} \times A_{c}+A_{s}} \times a
\end{aligned}
$$

O momento fletor na seção é relacionado com as tensões através da seguinte expressão:

$$
M=\int_{A c} y_{V} \sigma_{c} d A_{c}+\int_{A s} y_{V} \sigma_{s} d A_{s} \rightarrow M=\frac{E_{s}}{R} \times I_{v}
$$

Sendo:

$$
I_{v}=\frac{1}{n} \times \int_{A c} y_{V}^{2} d A_{c}+\int_{A s} y_{V}^{2} d A_{s}
$$


Este é o momento de inércia da seção mista em relação à linha neutra, na qual a área de concreto é reduzida na proporção 1/n. Em virtude deste fato, concluí-se que:

$$
I_{v}=I_{s}+A_{s} \times a^{2}{ }_{s}+\frac{1}{n} \times\left[I_{c}+A_{c} \times a^{2}{ }_{c}\right]
$$

As tensões nos dois materiais em relação ao momento fletor são dadas por:

$$
\begin{aligned}
& \sigma_{c}=\frac{M \times y}{n I_{v}} \\
& \sigma_{s}=\frac{M \times y}{I_{v}}
\end{aligned}
$$

Se a seção estiver sendo solicitada pelo momento fletor $M$ e por uma força normal $\mathrm{N}$, conduzirá às seguintes tensões:

$$
\begin{gathered}
\sigma_{s}=\frac{N}{A_{v}}+\frac{M}{I_{v}} y \\
\sigma_{c}=\frac{1}{n} \times\left(\frac{N}{A_{v}}+\frac{M}{I_{v}} \times y\right)
\end{gathered}
$$

A área da seção transversal mista é dada por:

$$
A_{v}=\frac{1}{n} \times A_{c}+A_{s}
$$




$$
n=\frac{E_{s}}{E_{c}}
$$

Os momentos resistentes são:

$$
\begin{gathered}
W_{c}^{s}=\frac{I_{v}}{y_{c}^{s}} \\
W_{s}^{s, i}=\frac{I_{v}}{y_{s}^{s, i}}
\end{gathered}
$$

Portanto as fórmulas gerais são apresentadas por:

$$
\begin{gathered}
\sigma_{s}^{s, i}=\frac{N}{A_{v}}+\frac{M}{W_{s}^{s, i}} \\
\sigma_{c}^{s}=\frac{1}{n} \times\left(\frac{N}{A_{v}}+\frac{M}{W_{c}^{s}}\right)
\end{gathered}
$$

7.9.4- Considerações a serem feitas na diferença de temperatura entre aço/concreto em vigas simplesmente apoiadas.

Considera-se que a ligação entre o aço/concreto seja suprida por uma variação de temperatura $\Delta \mathrm{T}$, de maneira que ocorra uma deformação unitária $6 \alpha \Delta \mathrm{T}$.

A força $F_{c}$ aplicada no centro de gravidade da seção de concreto, capaz de produzir o mesmo efeito, é representada pela seguinte equação:

$$
F_{c}=N_{c, \Delta T}= \pm \alpha_{T} \times \Delta T \times E_{c} \times A_{c}
$$


A força desenvolvida no conector (figura 7.9), devido às tensões longitudinais cisalhantes provenientes da variação de temperatura é igual a:

$$
F_{\text {conector }, \Delta T}=N_{c, \Delta T} \times e=\left[ \pm \alpha_{T} \times \Delta T \times E_{c} \times A_{c}\right] \times e
$$

Na figura 7.15 tem-se a distribuição de tensões em virtude do $\Delta T$.

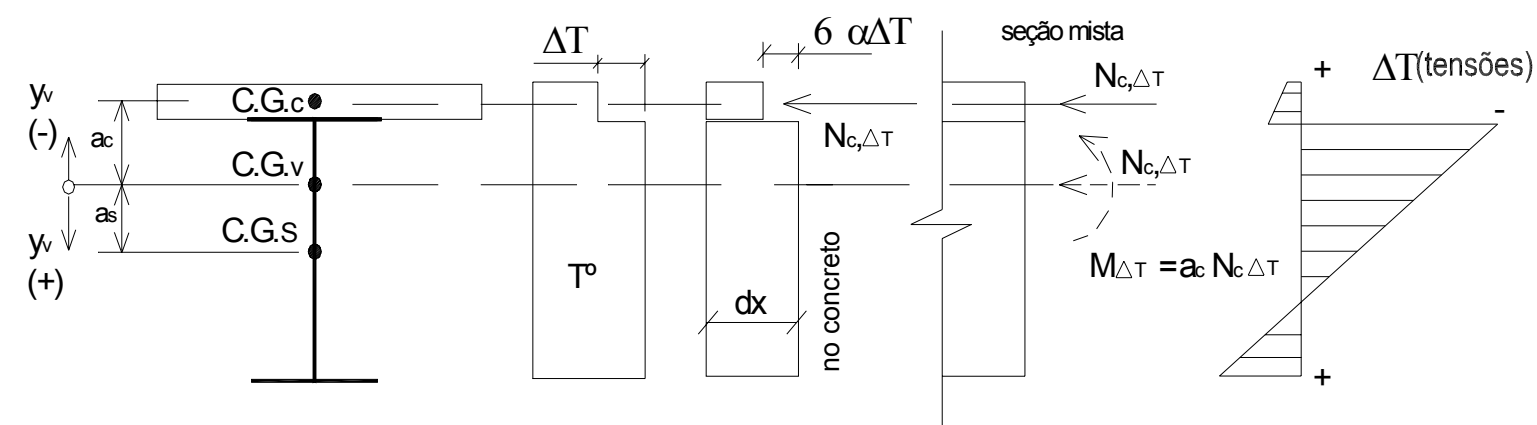

Figura 7.15- Distribuição de tensões devido a variação de temperatura nas seções mistas.

Fonte: Dubas (1975).

Ao considerar a ligação exercida pelos conectores à laje como interação completa, tudo acontece como se a força fosse aplicada na seção mista, localizada no centro de gravidade da seção de concreto.

Ao transferir $N_{c, \Delta T}$ para o centro de gravidade da seção mista, deve ser acrescentado o momento, dado por:

$$
\mathrm{M}_{\Delta \mathrm{T}}=6 \mathrm{~F}_{\mathrm{c}} 3 \mathrm{a}_{\mathrm{c}}
$$

Portanto as tensões devido a variação de temperatura, equivalem a uma solicitação flexo-compressão.

As tensões atuantes na seção mista, devido a variação de temperatura, são obtidas através das equações: 


$$
\begin{gathered}
\sigma_{s}=\alpha_{T} \times \Delta T \times E_{s} \times \frac{A_{c} / n}{A_{v}}\left(1-\frac{a_{c} \times A_{v}}{I_{v}} \times y\right) \\
\sigma_{c}=\alpha_{T} \times \Delta T \times E_{s} \times \frac{A_{s}}{n \times A_{v}}\left(1+\frac{a_{s} \times A_{v}}{I_{v}} \times y\right)
\end{gathered}
$$

O momento $\mathrm{M}_{\Delta \mathrm{T}}$ aplicado na seção mista é dado por:

$$
N_{c, \Delta T}: M_{\Delta T}=N_{c \Delta T} \times a_{c}= \pm \alpha_{T} \times \Delta T \times E_{c} \times A_{c} \times a_{c}
$$

\subsection{5- Efeitos da retração em vigas mistas, de acordo com Dubas (1975) e Mason (1976).}

A distribuição de tensões devido a retração está mostrada na figura 7.16. A deformação da laje é impedida pela viga metálica e a situação final pode ser processada em três estágios.

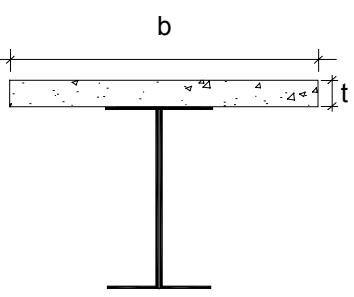

a) Seção transversal.

Ec $\times \varepsilon c s$

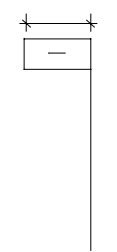

d) tensões devidas ao item b)

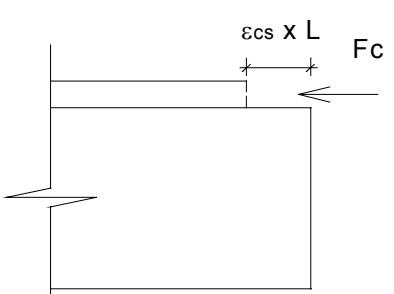

b) Força externa aplicada à laje.

$\sigma c$

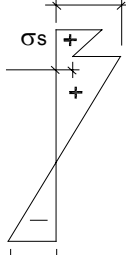

e) tensões devidas ao item c).

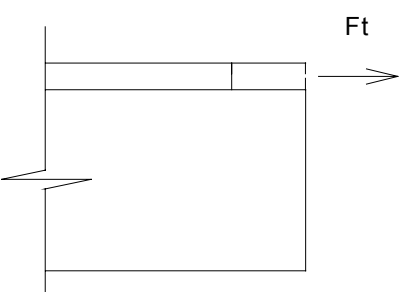

c) Força aplicada na seção mista.

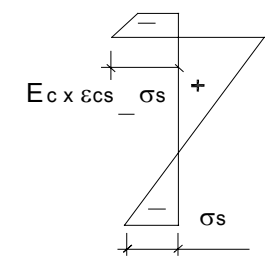

f) Tensões finais.

Figura 7.16- Tensões devido aos efeitos da retração em viga mista. Fonte: O'CONNOR (1975). 
a) $\bigcirc$ valor do encurtamento da laje é igual a $\varepsilon_{c s} L$, onde $\varepsilon_{c s}$ é o coeficiente de retração e $L$ o comprimento da laje.

b) A laje pode retornar ao comprimento original através de uma força $F_{t}$ aplicada no centro de gravidade da laje, produzindo tensões uniformes de tração igual a $E_{c} . \varepsilon_{c s} \times$ bt. Sendo $E_{c}$ o módulo de elasticidade do concreto; $b$ a largura efetiva; $t a$ espessura da laje.

c) A situação final é a soma dos dois estágios representados na figura $7.16 \mathrm{~d}$, $7.16 \mathrm{e}$.

De acordo com Mason (1976), o efeito da retração pode ser assimilado ao de uma queda de temperatura, porém a mesma é influenciada pela deformação lenta e a expressão que define o coeficiente de homogeneização é dada por:

$$
\mathrm{n}_{r}=\mathrm{n}\left(1+0,52 \varphi\left(\mathrm{t}_{\infty}, \mathrm{t}_{0}\right)\right)
$$

Isto equivale a dizer, que o efeito da deformação lenta na retração pode ser levado em consideração no dimensionamento, através da expressão que relaciona os módulos de elasticidade secante do concreto $\left(E_{c}\right)$ e o módulo de elasticidade efetivo do concreto $\left(E_{c t}\right)$.

$$
E_{c t}=\frac{E_{c}}{1+0,52 \times \varphi_{(t \infty, t o)}}
$$

A determinação das tensões com o valor do coeficiente de equivalência mecânica modificado, pode ser aplicando nas equações 7.130; 7.131.

A força atuante na laje de concreto devido às tensões longitudinais cisalhantes de retração mostradas na figura $7.16 f$ é igual a: 


$$
F_{c, r}=\varepsilon_{c s} \times E_{c t} \times A_{c}
$$

As forças de cisalhamento longitudinais, devidas a variação de temperatura e a retração, são resistidas pelos conectores na interface aço/concreto, porém estas forças provocam tensões de tração na laje e devem ser resistidas por armaduras colocadas transversalmente à viga.

A determinação desta armadura pode ser realizada através do modelo de treliça de Mörch, análogo ao cálculo de estribos em estrutura de concreto armado.

$\mathrm{Na}$ figura 7.17 apresenta as forças concentradas ( $\left.F_{\text {conectores }}\right)$ atuantes nos conectores, e espraiam-se lateralmente através de bielas de compressão no concreto. A forças de tração $\left(F_{t}\right)$, são combatidas pelas armaduras colocadas na laje entre os conectores.

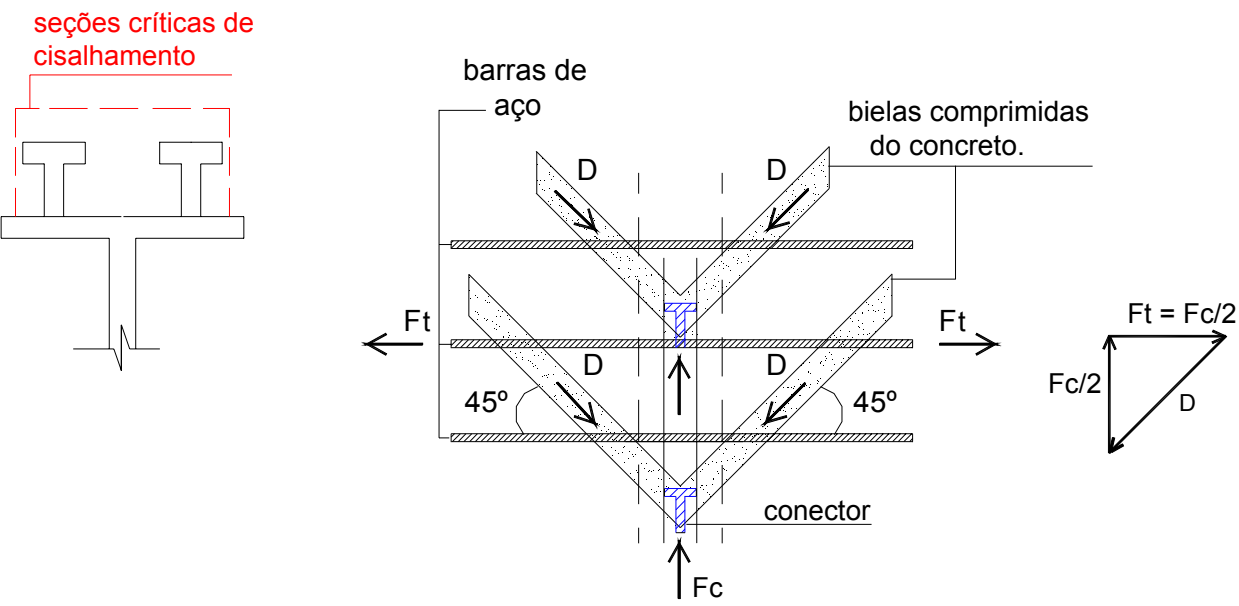

Figura 7.17- Esforços de tração transmitidos pelos conectores à laje de concreto.

Fonte: Dubas (1975).

Próximos aos apoios atuam na laje forças concentradas ( $F_{\text {resultante); são }}$ transferidas por cisalhamento à superfície de contato entre os dois materiais.

Essa transferência como mostra a figura 7.18, requer uma força vertical para baixo que equilibre a força concentrada de cisalhamento. 


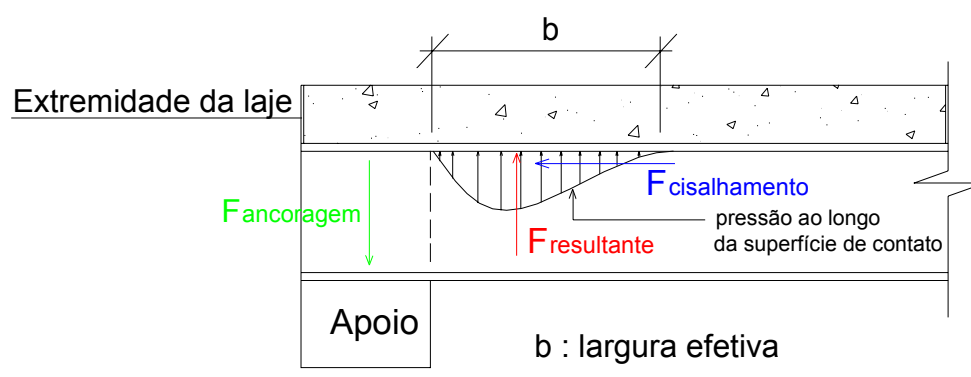

Figura 7.18- Forças de retração próximas à extremidade do tabuleiro.

Fonte: O' CONNOR (1975).

Estas forças possuem valores relativamente grandes e atuam ao longo de um comprimento igual a largura efetiva da laje do tabuleiro. Este efeito de empenamento na extremidade da laje deve ser combatido com utilização de conectores.

\subsection{6- Efeitos da fluência em vigas mistas, considerações feitas por Dubas (1975) e Mason (1976).}

Segundo Mason (1976) o efeito da deformação lenta proporciona uma diminuição do módulo de elasticidade do concreto e uma transferência de esforços do concreto para o aço.

Esta transferência ocorre lentamente com a diminuição de tensão no concreto e aumento de tensão na seção de aço.

A relação entre módulo de elasticidade secante do concreto $\left(E_{c}\right)$ com módulo de elasticidade efetivo $\left(E_{c t}\right)$ é apresentada pela seguinte equação.

$$
E_{c t}=\frac{E_{c}}{1+1,1 \times \varphi_{(t o, t o)}}
$$

O coeficiente de equivalência mecânica, devido os efeitos da fluência, é dado pela expressão: 


$$
\mathrm{n}_{f}=\mathrm{n}\left(1+1,1 \times \varphi\left(\mathrm{t}_{\infty}, \mathrm{t}_{0}\right)\right.
$$

A redistribuição de tensões na viga mista devido a fluência é apresentada pela figura 7.19.
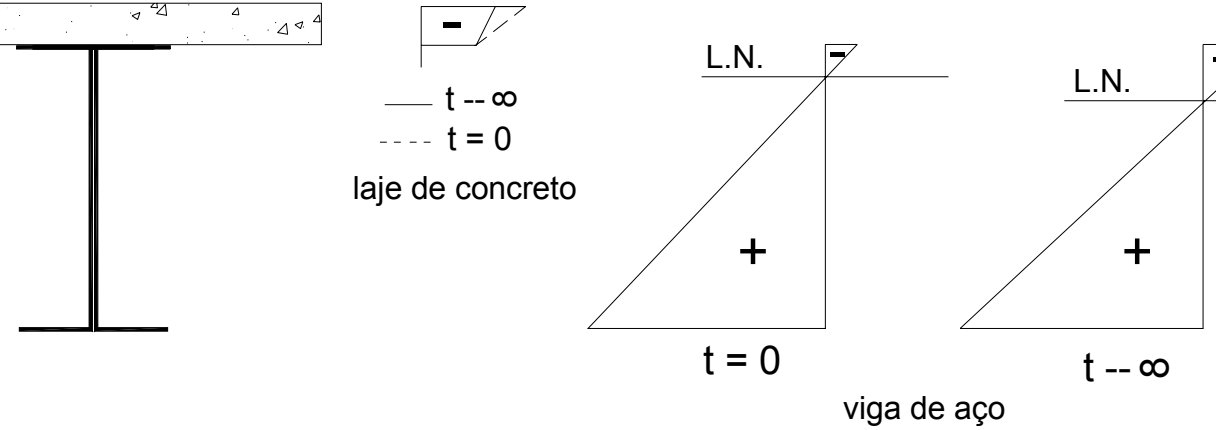

Figura 7.19- Redistribuição de tensões devido aos efeitos da fluência em vigas mistas.

Fonte: Dubas (1975).

Ao analisar a figura 7.19 pode ser concluído:

- Solicitações a flexão:

- concreto: apreciavelmente menor,

- mesa superior da viga de aço: aumento considerável,

- mesa inferior da viga de aço : ligeiramente maior.

Para levar em consideração o efeito da deformação lenta, basta fazer os cálculos das tensões com o valor do coeficiente de equivalência mecânica modificado, aplicando-o nas equações 7.130; 7.131.

Notas: A AASHTO (1996) especifica que as tensões produzidas pelo o efeito da fluência em projeto de vigas mistas serão determinadas, considerando um aumento no coeficiente de homogeneização em três vezes $(3 x)$ o seu valor inicial. 


\subsection{0- Exemplo numérico - Verificação das tensões.}

Realizou-se a verificação de tensões na seção transversal (figura 7.20), referente as Notas de aula: Pontes Metálicas, do Professor Dr. Maximiliano Malite da EESC - USP São Carlos.

Corresponde a viga central da ponte, simplesmente apoiada com um vão livre de $20 \mathrm{~m}$.

As características da seção estão mostradas a seguir como também o momento fletor máximo atuante na viga mista.

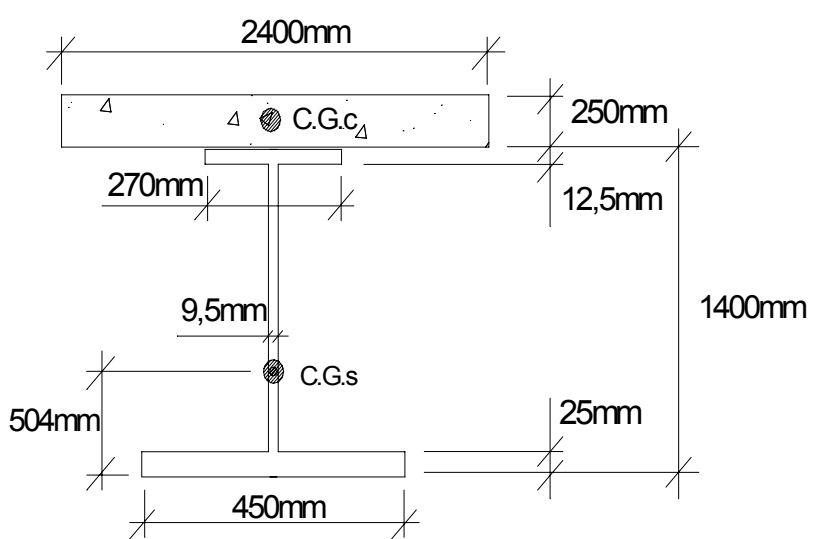

Figura 7.20- Seção transversal.

Inicialmente o cálculo das tensões foi realizado nos tempos $t=0$ e $t=$ : com os formulários apresentados por Djuric (1963), depois foram utilizados os métodos aplicados por Mason (1976), e no final os resultados foram confrontados.

As características da seção transversal são dadas pelos seguintes valores:

- $\mathrm{E}_{\mathrm{s}}=205000 \mathrm{MPa}$,

- $A_{\mathrm{s}}=276 \mathrm{~cm}^{2}$,

- $\mathrm{I}_{\mathrm{s}}=792171 \mathrm{~cm}^{4}$,

- $\mathrm{f}_{\mathrm{ck}}=25 \mathrm{MPa}-\mathrm{E}_{\mathrm{ci}}=5600 \times 25^{1 / 2}=28000 \mathrm{MPa}, \mathrm{E}_{\mathrm{c}}=0,85 \times \mathrm{E}_{\mathrm{ci}}=23800 \mathrm{MPa}$,

- $\mathrm{A}_{\mathrm{c}}=6000 \mathrm{~cm}^{2}$, 
- $\mathrm{I}_{\mathrm{C}}=312500 \mathrm{~cm}^{4}$,

- $\mathrm{D}_{\mathrm{s}}=140 \mathrm{~cm}$,

- $\mathrm{D}_{\mathrm{c}}=25 \mathrm{~cm}$,

- $c=102,1 \mathrm{~cm}$,

- $\omega\left(\mathrm{t}_{0}, \mathrm{t}_{\mathrm{t}}\right)=3$ (umidade relativa $75 \% \mathrm{t}_{0}=5$ dias) NBR $6118(2002)$,

- $\varepsilon_{\mathrm{cs}}=0,00023 \mathrm{~m} / \mathrm{m}$ (umidade relativa de $75 \% \mathrm{t}_{0}=5$ dias) NBR 6118 (2002),

- $\mathrm{M}_{\mathrm{g}}=1270 \mathrm{kNm}$ (carga permanente),

- $\mathrm{M}_{\mathrm{p}}=2624 \mathrm{kNm}$ (carga móvel),

- $\mathrm{M}_{\mathrm{d}}=\mathrm{M}_{\mathrm{g}}+\mathrm{M}_{\mathrm{p}}=3894 \mathrm{kNm}$.

7.10.1- Propriedades da seção para $t=0$, segundo Djuric (1963).

As propriedades da viga mista serão dadas por:

$v_{s}=\frac{E_{s}}{E_{r}}=1, E_{r}=E_{s}, v_{c}=\frac{E_{c}}{E_{r}}=\frac{23800}{205000}=0,116$

$A_{s}^{r}=v_{s} \times A_{s}=276 \mathrm{~cm}^{2}$

$A_{c}^{r}=v_{c} \times A_{c}=0,116 \times 6000=696 \mathrm{~cm}^{2}$

$A_{i}=A_{s}^{r}+A_{c}^{r}=276+696=972 \mathrm{~cm}^{2}$

$y_{s}=\frac{A_{c}^{r}}{A_{i}} \times c=\frac{696}{972} \times 102,1=73,1 \mathrm{~cm}$

(Distância entre o C.G. da viga de aço com o C.G. da viga mista). 
$y_{c}=\frac{A_{s}^{r}}{A_{i}} \times c=\frac{276}{972} \times 102,1=29 \mathrm{~cm}$

(Distância entre o C.G. da laje de concreto com o C.G. da viga mista).

$I_{s}^{r}=v_{s} \times I_{s}=1 \times 792171=792171 \mathrm{~cm}^{4}$

$I_{c}^{r}=v_{c} \times I_{c}=0,116 \times 312500=36250 \mathrm{~cm}^{4}$

$I_{i}=I_{s}^{r}+I_{c}^{r}+\frac{c^{2} \times A_{s}^{r} \times A_{c}^{r}}{A_{i}}=792171+36250+\frac{102,1^{2} \times 276 \times 696}{972}=2888593,287 \mathrm{~cm}^{4}$

\subsection{2- Verificação se a seção é compacta (AASHTO/1996).}

$$
\frac{2 D_{c p}}{t_{w}} \leq \frac{1600}{\sqrt{f_{y}}} \rightarrow \frac{2 \times 15,25}{0,95}=32,10 \leq \frac{1600}{\sqrt{350}}=85,52, \text { tudo certo! }
$$

$$
\frac{D_{p}}{D^{\prime}} \leq 5 \rightarrow \frac{41,5}{0,7 \times \frac{(140+25)}{7,5}}=2,69 \leq 5 \text {, tudo certo! }
$$

7.10.3- Verificação das tensões na seção para $t=0$, segundo Djuric (1963).

$$
N^{*}=N-N_{k} \rightarrow N_{k}=\sigma_{k} \times A_{c} \rightarrow \sigma_{k}=E_{c} \times \varepsilon_{k} \rightarrow \varepsilon_{k}=0 \therefore N_{k}=0
$$

(interação completa)

$$
\begin{aligned}
& \mathrm{N}=0 \rightarrow \mathrm{N}^{*}=0 . \\
& M^{*}=M-N_{k} \times y_{c} \\
& M^{*}=M=3894 k N m
\end{aligned}
$$




$$
\begin{aligned}
& \sigma_{s o}^{\text {sup }}=v_{s} \times\left(\frac{N^{*}}{A_{i}}+\frac{M^{*}}{I_{i}} \times y\right)=1 \times\left(\frac{M}{I_{i}} \times y\right)=1 \times\left[\frac{3894}{0,028885} \times(0,165)\right]=22243,03 \mathrm{kN} / \mathrm{m}^{2}=-22,24 \mathrm{MPa} \\
& \sigma_{s o}^{\text {inf }}=v_{s} \times\left(\frac{N^{*}}{A_{i}}+\frac{M^{*}}{I_{i}} \times y\right)=1 \times\left(\frac{M}{I_{i}} \times y\right)=1 \times\left[\frac{3894}{0,028885} \times(1,235)\right]=166485,72 \mathrm{kN} / \mathrm{m}^{2}=166,48 \mathrm{MPa} \\
& \sigma_{c o}^{\text {sup }}=v_{c} \times\left(\frac{N^{*}}{A_{i}}+\frac{M^{*}}{I_{i}} \times y\right)+\sigma_{k} \rightarrow \sigma_{k}=E_{c} \times \varepsilon_{k} \rightarrow \varepsilon_{k}=0 \therefore \sigma_{k}=0
\end{aligned}
$$

(interação completa)

$$
\sigma_{c o}^{\text {sup }}=v_{c} \times\left(\frac{N^{*}}{A_{i}}+\frac{M^{*}}{I_{i}} \times y\right)+\sigma_{k}=0,116 \times\left[\frac{3894}{0,028885} \times 0,415\right]=6489,57 \mathrm{kN} / \mathrm{m}^{2}=-6,49 \mathrm{MPa}
$$

As tensões atuantes na laje e na viga de aço estão representadas na figura abaixo:

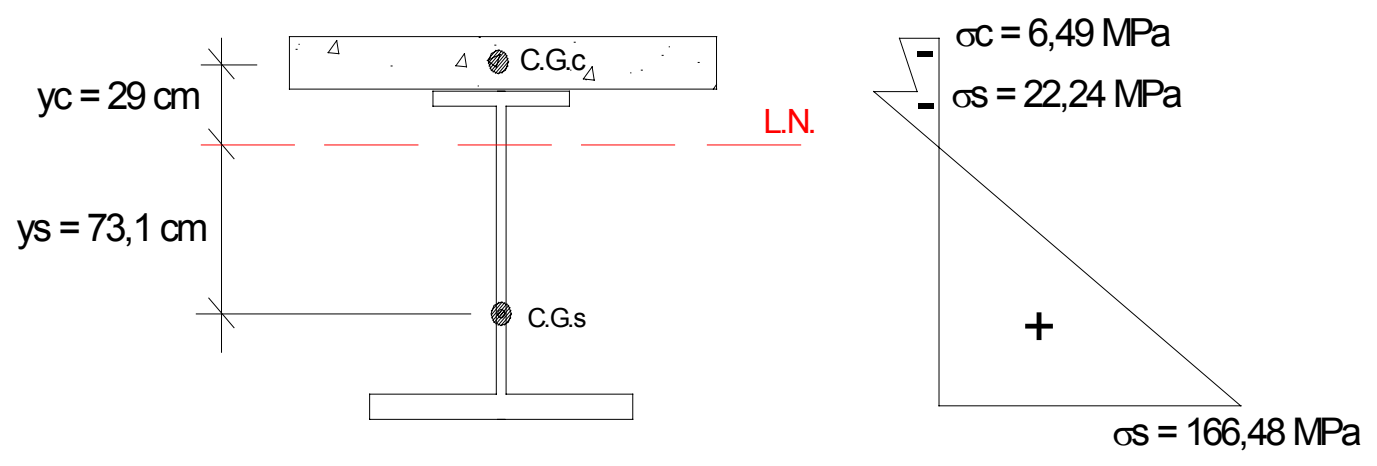

Figura 7.21 - Distribuição de tensões no tempo $t=0$.

7.10.4- Propriedades da seção para $t=$ :, segundo Djuric (1963).

$E_{c t}=\frac{E_{c}}{1+\chi_{(t \infty, t o)} \times \varphi_{(t \infty, t o)}}=\frac{23800}{1+0,8 \times 3}=7000 \mathrm{MPa}$

Os valores do coeficiente de envelhecimento do concreto $\xi_{\text {(t:, to), foram }}$ apresentados na tabela 7.2 pág. 111 . 
$v_{c t}=\frac{E_{c t}}{E_{r}}=\frac{7000}{205000}=0,0341, E_{r}=E_{s}$

$A_{c t}^{r}=v_{c t} \times A_{c}=0,0341 \times 6000=205 \mathrm{~cm}^{2}$

$A_{i t}=A_{s}^{r}+A_{c t}^{r}=276+205=481 \mathrm{~cm}^{2}$

$\eta_{s}=\frac{A_{c t}^{r}}{A_{i t}} \times c=\frac{205}{481} \times 102,1=43,5 \mathrm{~cm}$

(Distância entre o C.G. da viga de aço com o C.G. da viga mista).

$\eta_{c}=\frac{A_{s}^{r}}{A_{i t}} \times c=\frac{276}{481} \times 102,1=58,6 \mathrm{~cm}$

(Distância entre o C.G. da laje de concreto com o C.G. da viga mista).

$I_{c t}^{r}=v_{c t} \times I_{c}=0,0341 \times 312500=10656,25 \mathrm{~cm}^{4}$

$I_{i t}=I_{s}^{r}+I_{c t}^{r}+\frac{c^{2} \times A_{s}^{r} \times A_{c t}^{r}}{A_{i t}}=792171+10656,25+\frac{102,1^{2} \times 276 \times 205}{481}=2029049,95 \mathrm{~cm}^{4}$

7.10.5- Verificação se a seção é compacta, (AASHTO /1996).

$\frac{2 D_{c p}}{t_{w}} \leq \frac{1600}{\sqrt{f_{y}}} \rightarrow \frac{2 \times 44,85}{0,95}=94,42 \leq \frac{1600}{\sqrt{350}}=85,52$ não atende!

Aumenta-se a espessura da alma, fazendo com que ela tenha $12,5 \mathrm{~mm}$ de espessura.

Portanto a relação $2 D_{c p} / t_{w}=(2 \times 44,85) / 1,25=71,76 \leq 85,52$, tudo certo! 


$$
\frac{D_{p}}{D^{\prime}} \leq 5 \rightarrow \frac{71,1}{0,7 \times \frac{(140+25)}{7,5}}=4,62 \leq 5, \text { tudo certo! }
$$

7.10.6- Verificação das tensões na seção para t = :, segundo Djuric (1963).

$$
\begin{aligned}
& M^{\prime}=M+N\left(\eta_{s}-y_{s}\right) \rightarrow N=0, M^{\prime}=3894 \mathrm{kNm} \\
& N_{s h}=E_{c t} \times \varepsilon_{s h} \times A_{c}=7000000 \times 0,00023 \times 0,6=966 \mathrm{kN} \\
& N_{t}^{*}=N+\rho \times N_{c o}+N_{s h}-N_{k t} \\
& N_{k t}=\sigma_{k t} \times A_{c} \\
& \sigma_{k t}=E_{c t} \times \varepsilon_{k t} \rightarrow \varepsilon_{k t}=0,(\text { interação completa }) \rightarrow N_{k t}=0 \\
& N_{c o}=N^{*} \times \frac{A_{c}^{r}}{A_{i}}+M^{*} \times \frac{A_{c}^{r}}{I_{i}}+N_{k}=3894 \times \frac{0,0696 \times 0,29}{0,028885}=2721 \mathrm{kN} \rightarrow N^{*}=N_{k}=0 \\
& M_{t}^{*}=3894+0,176 \times(49+2721 \times 0,59)+966 \times 0,59=4755 \mathrm{kNm} \\
& M_{c o}^{*}=M^{\prime}+\rho \times\left(M_{c o}+N_{c o} \times \eta_{c}\right)+N_{s h} \times \eta_{c}-N_{k t} \times \eta_{c} \\
& \left.N_{t}^{*}=N+\rho \times N_{c o}^{r}+N_{s h}-N_{k t} \rightarrow N_{t}^{*}=0,176 \times 2721+966=1444,90 \mathrm{kN} \rightarrow N_{(t o, t o)}\right) \times \varphi_{(t o, t o)}=\frac{(1-0,8) \times 3}{1+0,8 \times 3}=0,176 \\
& 1+\chi_{(t o, t o)} \times \varphi_{(t o o, t o)} \\
& I_{i}
\end{aligned}
$$




$$
\begin{aligned}
& \sigma_{s}^{\text {sup }}=v_{s} \times\left(\frac{N_{t}^{*}}{A_{i t}}+\frac{M_{t}^{*}}{I_{i t}} \times \eta\right)=1 \times\left(\frac{1445}{0,0481}+\frac{4775}{0,0202905} \times 0,46\right)=138294,21 \mathrm{kN} / \mathrm{m}^{2}=-138,29 \mathrm{MPa} \\
& \sigma_{s}^{\text {inf }}=v_{s} \times\left(\frac{N_{t}^{*}}{A_{i t}}+\frac{M_{t}^{*}}{I_{i t}} \times \eta\right)=1 \times\left(\frac{1445}{0,0481}+\frac{4755}{0,0202905} \times 0,939\right)=250092,59 \mathrm{kN} / \mathrm{m}^{2}=250,10 \mathrm{MPa} \\
& \sigma_{c}^{\text {sup }}=v_{c t} \times\left(\frac{N_{t}^{*}}{A_{i t}}+\frac{M_{t}^{*}}{I_{i t}} \times \eta\right)-\rho \times \sigma_{c o}^{\text {sup }}+E_{c t} \times \varepsilon_{s h}+\sigma_{k t} \rightarrow \sigma_{k t}=E_{c t} \times \varepsilon_{k t} \rightarrow \varepsilon_{k t}=0 \therefore \sigma_{k t}=0 \\
& \quad \text { (interação completa) } \\
& \sigma_{c}^{\text {sup }}=0,0341 \times\left(\frac{1445}{0,0481}+\frac{4775}{0,0202905} \times 0,71\right)-0,176 \times(-6489)-7000000 \times(0,00023)=6254,10 \mathrm{kN} / \mathrm{m}^{2}=-6,25 \mathrm{MPa}
\end{aligned}
$$

As tensões atuantes na seção mista estão apresentadas na figura 7.22.

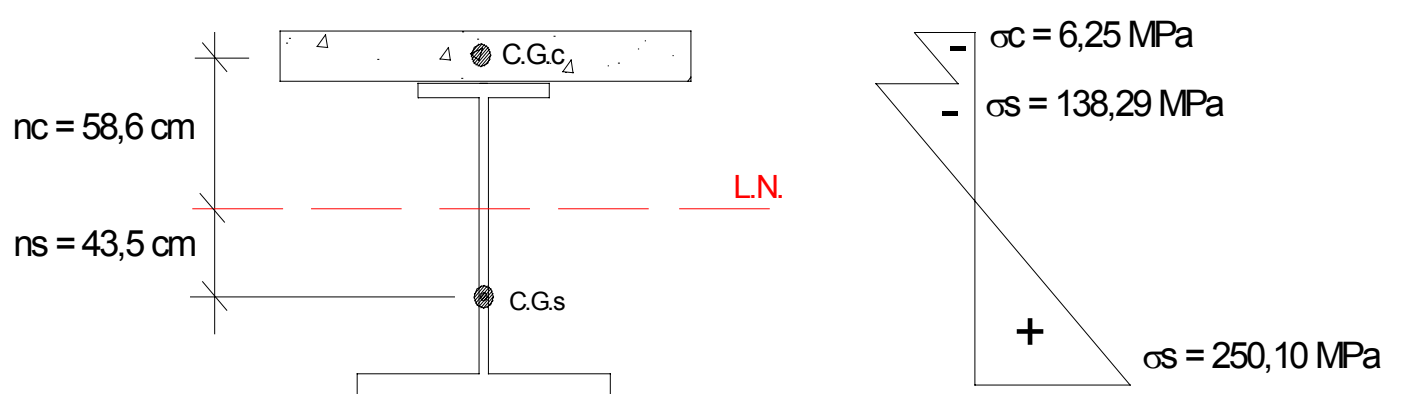

Figura 7.22- Distribuição de tensões no tempo $t=$ :.

O resumo das tensões é apresentado na tabela 7.3.

Tabela 7.3- Resumo das tensões, procedimento referente a Djuric (1963).

\begin{tabular}{|c|c|c|}
\hline Tensões. & $\mathrm{t}=0$ & $\mathrm{t}=:$ \\
\hline$\sigma_{c}^{\text {sup }}$ & $-6,49 \mathrm{MPa}$ & $-6,25 \mathrm{MPa}$ \\
\hline$\sigma_{s}^{\text {sup }}$ & $-22,24 \mathrm{MPa}$ & $-138,29 \mathrm{MPa}$ \\
\hline$\sigma_{s}^{\text {inf }}$ & $166,48 \mathrm{MPa}$ & $250,10 \mathrm{MPa}$ \\
\hline
\end{tabular}




\subsection{7- Verificação das tensões, segundo Mason (1976).}

Considerando o exemplo anterior, com as mesmas características e o mesmo carregamento, a determinação das tensões será feita com os formulários propostos por Mason (1976).

\subsubsection{1- Características da seção.}

\subsubsection{1- Estágio inicial.}

$n=E_{s} / E_{c}=205000 / 23800=8,6$, considera $n=9$.

$a_{s}=\frac{\frac{1}{n} \times A_{c}}{\frac{1}{n} \times A_{c}+A_{s}} \times a=\frac{\frac{1}{9} \times 6000}{\frac{1}{9} \times 6000+276} \times 102,1=72,2 \mathrm{~cm}$

$a_{c}=\frac{A_{s}}{\frac{1}{n} \times A_{c}+A_{s}} \times a=\frac{276}{\frac{1}{9} \times 6000+276} \times 102,1=29,9 \mathrm{~cm}$

$A_{v}=\frac{1}{n} \times A_{c}+A_{s}=\frac{1}{9} \times 6000+276=942,67 \mathrm{~cm}^{2}$

$I_{v}=I_{s}+A_{s} \times a^{2}{ }_{s}+\frac{1}{n} \times\left[I_{c}+A_{c} \times a^{2}{ }_{c}\right]=792171+276 \times 72,2^{2}+\frac{1}{9}\left(312500+6000 \times 29,9^{2}\right)=2861643,69 \mathrm{~cm}^{4}$

$y_{c}^{s}=42,4 \mathrm{~cm} \quad \rightarrow \quad W_{c}^{s}=\frac{I_{v}}{y_{c}^{s}}=\frac{2861643,69}{42,4}=67502,74 \mathrm{~cm}^{3}$

$y_{s}^{s}=17,4 \mathrm{~cm} \quad \rightarrow \quad W_{s}^{s}=\frac{I_{v}}{y_{s}^{s}}=\frac{2861643,69}{17,4}=164528,47 \mathrm{~cm}^{3}$ 


$$
y_{s}^{i}=122,61 \mathrm{~cm} \quad \rightarrow \quad W_{s}^{i}=\frac{I_{v}}{y_{s}^{i}}=\frac{2861643,69}{122,61}=23339,97 \mathrm{~cm}^{3}
$$

\subsubsection{2- Estágio final, considerando os efeitos da retração e fluência.}

\section{a) Retração.}

$$
\begin{aligned}
& n_{r}=n \times(1+0,52 \varphi)=9 \times(1+0,52 \times 3)=23,04 \\
& a_{s}=\frac{\frac{1}{n} \times A_{c}}{\frac{1}{n} \times A_{c}+A_{s}} \times a=\frac{\frac{1}{23,04} \times 6000}{\frac{1}{23,04} \times 6000+276} \times 102,1=49,6 \mathrm{~cm} \\
& a_{c}=\frac{A_{s}}{\frac{1}{n} \times A_{c}+A_{s}} \times a=\frac{276}{\frac{1}{23,04} \times 6000+276} \times 102,1=52,5 \mathrm{~cm} \\
& A_{v}=\frac{1}{n} \times A_{c}+A_{s}=\frac{1}{23,04} \times 6000+276=536,42 \mathrm{~cm}^{2} \\
& I_{v}=I_{s}+A_{s} \times a^{2} s+\frac{1}{n} \times\left[I_{c}+A_{c} \times a^{2} c\right]=792171+276 \times 49,6^{2}+\frac{1}{23,04} \times\left(312500+6000 \times 52,5^{2}\right)=2202511,38 m^{4} \\
& y_{c}^{s}=65 \mathrm{~cm} \quad \rightarrow \quad W_{c}^{s}=\frac{I_{v}}{y_{c}^{s}}=\frac{2202511,38}{65}=33867,60 \mathrm{~cm}^{3} \\
& y_{s}^{s}=40 \mathrm{~cm} \quad \rightarrow \quad W_{s}^{s}=\frac{I_{v}}{y_{s}^{s}}=\frac{2202511,38}{40}=55017,40 \mathrm{~cm}^{3}
\end{aligned}
$$




$$
y_{s}^{i}=99,97 \mathrm{~cm} \quad \rightarrow \quad W_{s}^{i}=\frac{I_{v}}{y_{s}^{i}}=\frac{2202511,38}{99,97}=22032,38 \mathrm{~cm}^{3}
$$

\section{b) Fluência.}

$$
n_{f}=n \times(1+1,1 \varphi)=9 \times(1+1,1 \times 3)=38,7
$$

$a_{s}=\frac{\frac{1}{n} \times A_{c}}{\frac{1}{n} \times A_{c}+A_{s}} \times a=\frac{\frac{1}{38,7} \times 6000}{\frac{1}{38,7} \times 6000+276} \times 102,1=36,7 \mathrm{~cm}$

$a_{c}=\frac{A_{s}}{\frac{1}{n} \times A_{c}+A_{s}} \times a=\frac{276}{\frac{1}{38,7} \times 6000+276} \times 102,1=65,4 \mathrm{~cm}$

$A_{v}=\frac{1}{n} \times A_{c}+A_{s}=\frac{1}{38,7} \times 6000+276=431,04 \mathrm{~cm}^{2}$

$I_{v}=I_{s}+A_{s} \times a_{s}^{2}+\frac{1}{n} \times\left[I_{c}+A_{c} \times a_{c}^{2}\right]=792171+276 \times 36,7^{2}+\frac{1}{38,7} \times\left(312500+6000 \times 65,4^{2}\right)=1835112,91 \mathrm{~cm}^{4}$

$$
y_{c}^{s}=77,9 \mathrm{~cm} \rightarrow W_{c}^{s}=\frac{I_{v}}{y_{c}^{s}}=\frac{1835112,91}{77,9}=23564,55 \mathrm{~cm}^{3}
$$

$$
y_{s}^{s}=52,9 \mathrm{~cm} \quad \rightarrow \quad W_{s}^{s}=\frac{I_{v}}{y_{s}^{s}}=\frac{1835112,91}{52,9}=34705,97 \mathrm{~cm}^{3}
$$

$$
y_{s}^{i}=87,1 \mathrm{~cm} \quad \rightarrow \quad W_{s}^{i}=\frac{I_{v}}{y_{s}^{i}}=\frac{1835112,91}{87,1}=21063,23 \mathrm{~cm}^{3}
$$


7.10.7.2- Determinação das tensões na seção, segundo Mason (1976).

a) Para $\mathbf{t}=\mathbf{0}$

$\sigma_{c}^{\text {sup }}=\frac{1}{n} \times\left(\frac{M_{d}}{W_{c}^{s}}\right)=\frac{1}{9} \times\left(\frac{3894}{0,06750}\right)=6409,88 \mathrm{kN} / \mathrm{m}^{2}=-6,41 \mathrm{MPa}$

$\sigma_{s}^{\text {sup }}=\frac{M_{d}}{W_{s}^{s}}=\frac{3894}{0,16453}=23667,42 \mathrm{kN} / \mathrm{m}^{2}=-23,67 \mathrm{MPa}$

$\sigma_{s}^{\mathrm{inf}}=\frac{M_{d}}{W_{s}^{i}}=\frac{3894}{0,023340}=166838,05 \mathrm{kN} / \mathrm{m}^{2}=166,84 \mathrm{MPa}$

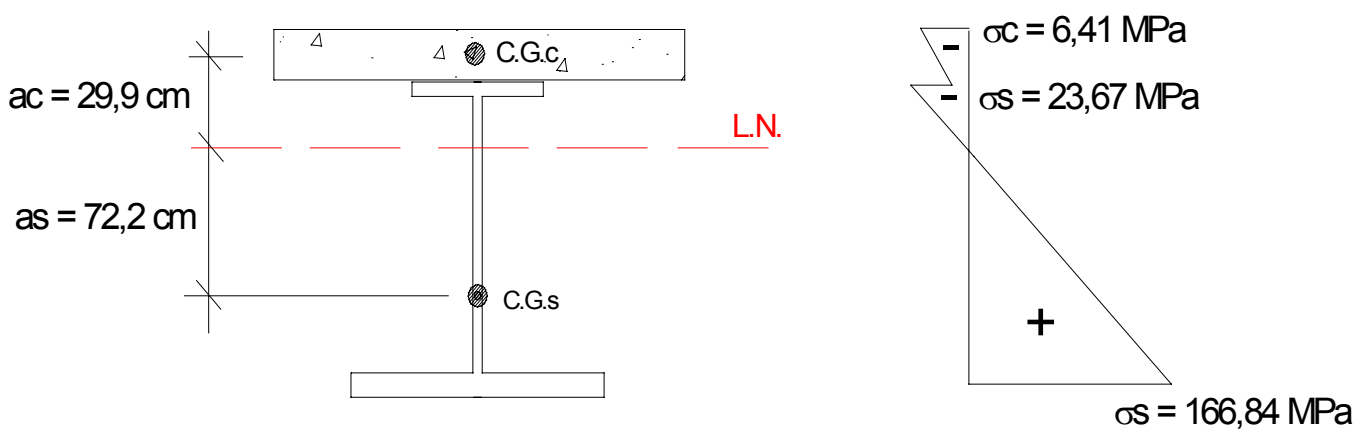

Figura 7.23- Distribuição de tensões no tempo $t=0$.

b) Para $\mathbf{t}=$ :.

b-1) Considerando o efeito da retração.

$E_{c t}=\frac{E_{c}}{1+0,52 \times \varphi}=\frac{23800}{1+0,52 \times 3}=9296,875 \mathrm{MPa}$ 


$$
\begin{aligned}
& F_{c, r}=\varepsilon_{c s} \times E_{c} \times A_{c}=0,00023 \times 92968750 \times 0,6=1282,97 \mathrm{kN} \\
& \sigma_{c}^{\text {sup }}=\frac{1}{n_{r}} \times\left(\frac{F_{c, r}}{A_{v}}+\frac{M_{d}}{W_{c}^{s}}\right)=\frac{1}{23,04} \times\left(\frac{1282,97}{0,0536}+\frac{3894}{0,033868}\right)=6029,16 \mathrm{kN} / \mathrm{m}^{2}=-6,03 \mathrm{MPa} \\
& \sigma_{s}^{\text {sup }}=\frac{F_{c, r}}{A_{v}}+\frac{M_{c, r}+M_{d}}{W_{s}^{s}}=\frac{1282,97}{0,0536}+\frac{673,56+3894}{0,055017}=106956,89 \mathrm{kN} / \mathrm{m}^{2}=-106,96 \mathrm{MPa} \\
& \sigma_{s}^{\text {inf }}=\frac{F_{c, r}}{A_{v}}+\frac{M_{c, r}+M_{d}}{W_{s}^{i}}=\frac{1282,97}{0,0536}+\frac{673,56+3894}{0,022032}=231250,82 \mathrm{kN} / \mathrm{m}^{2}=231,25 \mathrm{MPa} \\
& \text { ac }=52,5 \mathrm{~cm} \\
& \text { as }=49,6 \mathrm{~cm} \\
& \text { C.G.c }
\end{aligned}
$$
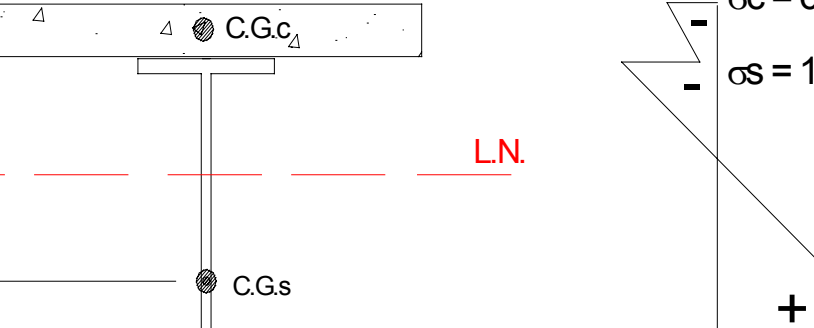

b-2) Considerando o efeito da fluência.

$$
\begin{aligned}
& \sigma_{c}^{\text {sup }}=\frac{1}{n_{r}} \times\left(\frac{M_{d}}{W_{c}^{s}}\right)=\frac{1}{38,7} \times\left(\frac{3894}{0,023564}\right)=4270,08 \mathrm{kN} / \mathrm{m}^{2}=-4,27 \mathrm{MPa} \\
& \sigma_{s}^{\text {sup }}=\frac{M_{d}}{W_{s}^{s}}=\frac{3894}{0,034706}=112199,62 \mathrm{kN} / \mathrm{m}^{2}=-112,20 \mathrm{MPa} \\
& \sigma_{s}^{\text {inf }}=\frac{M_{d}}{W_{s}^{i}}=\frac{3894}{0,021063}=184873,95 \mathrm{kN} / \mathrm{m}^{2}=184,87 \mathrm{MPa}
\end{aligned}
$$




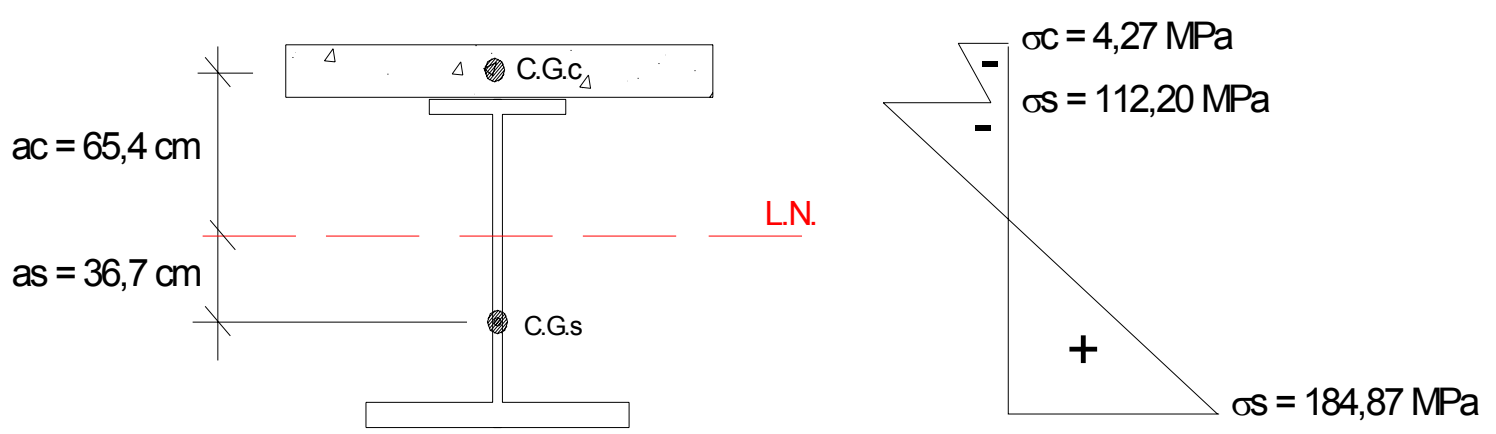

Figura 7.25- Distribuição de tensões devido a fluência para $t=:$.

A tabela 7.4 apresenta o resumo das tensões obtidas pelo formulário de Mason (1976).

Tabela 7.4- Resumo das tensões pelo formulário de Mason.

\begin{tabular}{|c|c|c|c|c|}
\hline Tensões. & $\mathrm{t}=0$ & Retração. & Fluência. & Tensões criticas. \\
\hline$\sigma_{c}^{\text {sup }}$ & $-6,41 \mathrm{MPa}$ & $-6,03 \mathrm{MPa}$ & $-4,27 \mathrm{MPa}$ & $-6,41 \mathrm{MPa}$ \\
\hline$\sigma_{s}^{\text {sup }}$ & $-23,67 \mathrm{MPa}$ & $-106,96 \mathrm{MPa}$ & $-112,20 \mathrm{MPa}$ & $-112,20 \mathrm{MPa}$ \\
\hline$\sigma_{s}^{\text {inf }}$ & $166,84 \mathrm{MPa}$ & $231,25 \mathrm{MPa}$ & $184,87 \mathrm{MPa}$ & $231,25 \mathrm{MPa}$ \\
\hline
\end{tabular}

\subsection{8- Comparação de resultados entre os dois métodos, Mason e Djuric.}

Na tabela 7.5 estão os resultados das tensões no tempo $t=0 \mathrm{e} t=:$ dos dois métodos utilizados.

Tabela 7.5- Comparação das tensões obtidas pelos métodos de Mason e Djuric.

\begin{tabular}{|c|c|c|c|c|}
\hline Tensões. & $\begin{array}{c}\text { Djuric } \\
\mathrm{t}=0 .\end{array}$ & $\begin{array}{c}\text { Mason }- \text { Dubas } \\
\mathrm{t}=0 .\end{array}$ & $\begin{array}{c}\text { Djuric } \\
\mathrm{t}=: .\end{array}$ & $\begin{array}{c}\text { Mason } \\
\mathrm{t}=: .\end{array}$ \\
\hline$\sigma_{c}^{\text {sup }}$ & $-6,49 \mathrm{MPa}$ & $-6,41 \mathrm{MPa}$ & $-6,25 \mathrm{MPa}$ & $-6,03 \mathrm{MPa}$ \\
\hline$\sigma_{s}^{\text {sup }}$ & $-22,24 \mathrm{MPa}$ & $-23,67 \mathrm{MPa}$ & $-138,29 \mathrm{MPa}$ & $-112,20 \mathrm{MPa}$ \\
\hline$\sigma_{s}^{\text {inf }}$ & $166,48 \mathrm{MPa}$ & $166,84 \mathrm{MPa}$ & $250,10 \mathrm{MPa}$ & $231,25 \mathrm{MPa}$ \\
\hline
\end{tabular}




\subsection{9- Determinação do deslocamento.}

A determinação do deslocamento teve como base as Notas de aula: Pontes Metálicas do Prof. Dr. Maximiliano Malite. EESC USP São Carlos, o carregamento permanente e variável foram todos retirados destas notas de aula.

O sistema construtivo utilizado foi a construção não escorada, o deslocamento devido a carga permanente é determinado com base em ações aplicadas na viga de aço, portanto a flecha imediata devido o peso próprio em vigas simplesmente apoiadas é igual a:

$20,4 \mathrm{kN} / \mathrm{m}$

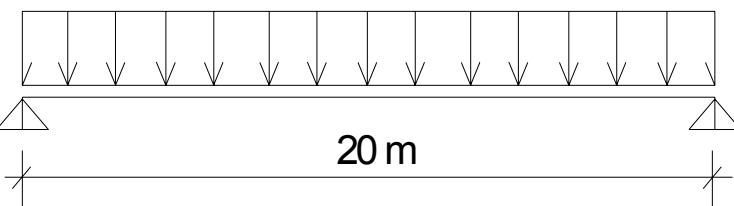

Figura 7.26- Carregamento permanente. Fonte: Notas de aula, Pontes Metálicas.

O valor da flecha imediata é igual a:

$\delta_{i}=\frac{5 \times g \times l^{4}}{384 \times E_{s} I_{s}}=\frac{5 \times 20,4 \times 20^{4}}{384 \times 205000000 \times 0,00792171}=2,671 \times 10^{-2} \mathrm{~m}=2,62 \mathrm{~cm}$

Outra verificação é com relação a flecha decorrente a carga móvel, onde o carregamento é mostrado na figura 7.27. 


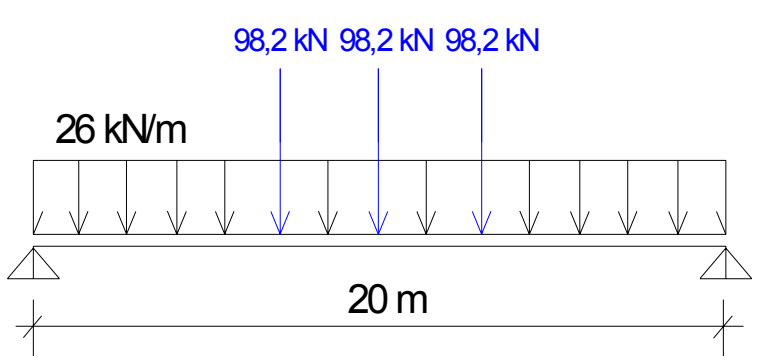

Figura 7.27- Carregamento referente a carga móvel.

Fonte: Notas de aula. Pontes Metálicas.

O valor da flecha devido a carga móvel é igual a:

$$
\begin{aligned}
& \delta_{p}=\frac{5 \times p \times l^{4}}{384 \times E_{s} I_{v}}+\frac{F \times l^{3}}{48 \times E_{s} \times I_{v}}+2 \times\left[\frac{F \times b}{12 \times E_{s} \times I_{v}} \times\left(0,75 \times l^{2}-b^{2}\right)\right] \\
& \delta_{p}=\frac{5 \times 26 \times 20^{4}}{384 \times 205000000 \times 0,029}+\frac{98,2 \times 20^{3}}{48 \times 205000000 \times 0,029}+2 \times\left[\frac{98,2 \times 10}{12 \times 205000000 \times 0,029} \times\left(0,75 \times 20^{2}-10^{2}\right)\right] \\
& \delta_{p}=17,439 \times 10^{-3} \mathrm{~m}=1,74 \mathrm{~cm}
\end{aligned}
$$

Quanto a determinação da flecha decorrente aos efeitos da retração e fluência do concreto, a Norma canadense estabelece de início a determinação do momento de inércia efetivo que é igual a:

$I_{e f}=0,85 \times\left[I_{s}+0,85 \times 1^{0,25} \times\left(I_{v}-I_{s}\right)\right]=0,85 \times\left[792171+0,85 \times(2888594-792171)=2188011 \mathrm{~cm}^{4}\right.$

Após a determinação do momento de inércia efetivo calcula-se a flecha através da equação:

$\delta_{r, f}=\frac{\varepsilon_{c s} \times E_{c} \times A_{c} \times l^{2}}{8 \times E_{s} \times I_{e f}}=\frac{0,00023 \times 23800000 \times 0,6 \times 20^{2}}{8 \times 205000000 \times 0,026409014}=3,0333 \times 10^{-2} \mathrm{~m}=3,03 \mathrm{~cm}$ 
Finalmente o deslocamento total da viga mista é a soma das três parcelas e o valor total é igual a:

$\delta_{\text {total }}=\delta_{i}+\delta_{p}+\delta_{r, f}=2,62+1,74+3,03=7,39 \mathrm{~cm}$ 


\section{8- CONCLUSÕES E RECOMENDAÇÕES.}

Todas as solicitações que forem aplicadas antes da ligação aço/concreto agem somente sobre as vigas de aço. Como o aço da estrutura mista não sofre deformação lenta sob temperaturas normais estas tensões não sofrem alterações. Após sua ligação com o tabuleiro de concreto, a laje ao se deformar devido os efeitos da retração e da fluência, ocorre uma redistribuição de tensões no tabuleiro e nas vigas e aço além de proporcionar um aumento do deslocamento.

Cargas aplicadas após a solidarização entre aço/concreto devem ser resistidas pela viga mista, enquanto as tensões totais na viga de aço são obtidas pela superposição das tensões que ocorreram antes e após a esta solidarização.

As cargas atuantes nas vigas são apresentadas da seguinte maneira:

- Peso próprio da estrutura de aço: $\mathrm{g}_{1}$,

- Peso próprio da laje de concreto: $g_{2}$,

- Fôrmas: $g_{3}$,

- Cargas restantes: $g_{4}$,

- Cargas móveis: q.

Notas: A fôrma utilizada durante a concretagem da laje (viga metálica $+g_{3}$ ) e retirada após o endurecimento do concreto (estrutura mista - $\mathrm{g}_{3}$ ). Seu peso próprio pode ser desprezado quando a laje for executada em pequenos trechos.

Cargas restantes são entendidas como cargas permanentes que são introduzidas na estrutura após a ligação da laje de concreto com a viga de aço, como por exemplo: revestimentos, defensas, tubulações e lastro (pontes ferroviárias). 
As ações a serem consideradas nas vigas mistas, estão representadas de maneira esquemática na figura 8.1. As tensões são formadas devido as diferentes solicitações, com os seus correspondentes coeficientes de equivalência mecânica.

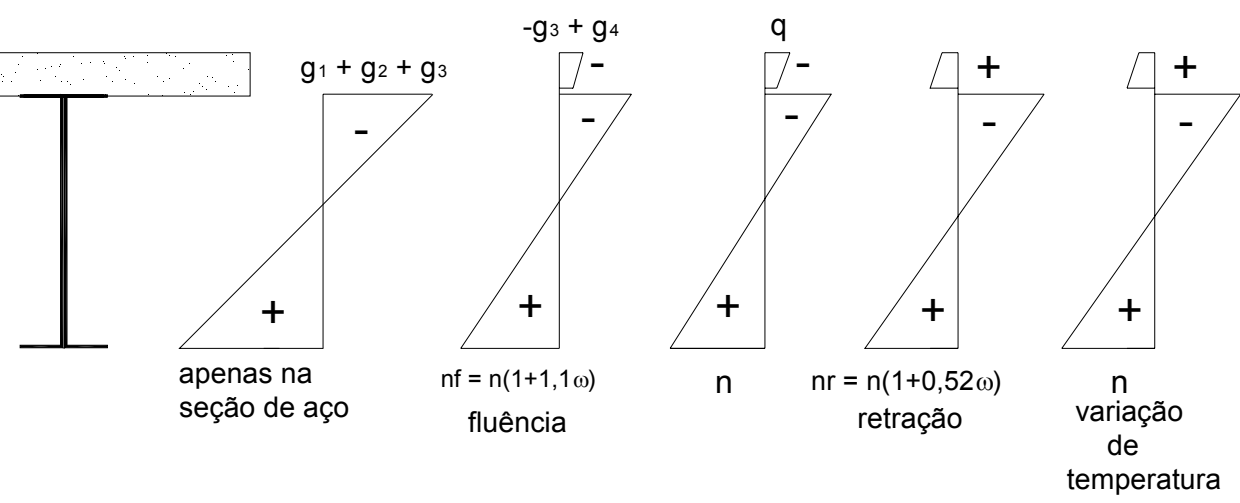

Figura 8.1- Diferentes solicitações em vigas mistas. Fonte: Dubas (1975).

Os efeitos da fluência foram considerados no dimensionamento através da diminuição do módulo de elasticidade do concreto, proporcionando um aumento progressivo do coeficiente de homogeneização.

Para amenizar estes efeitos nas vigas mistas isostáticas, pode ser utilizado o artifício de colocar apoios intermediários, no instante da concretagem da laje (figura 8.2).

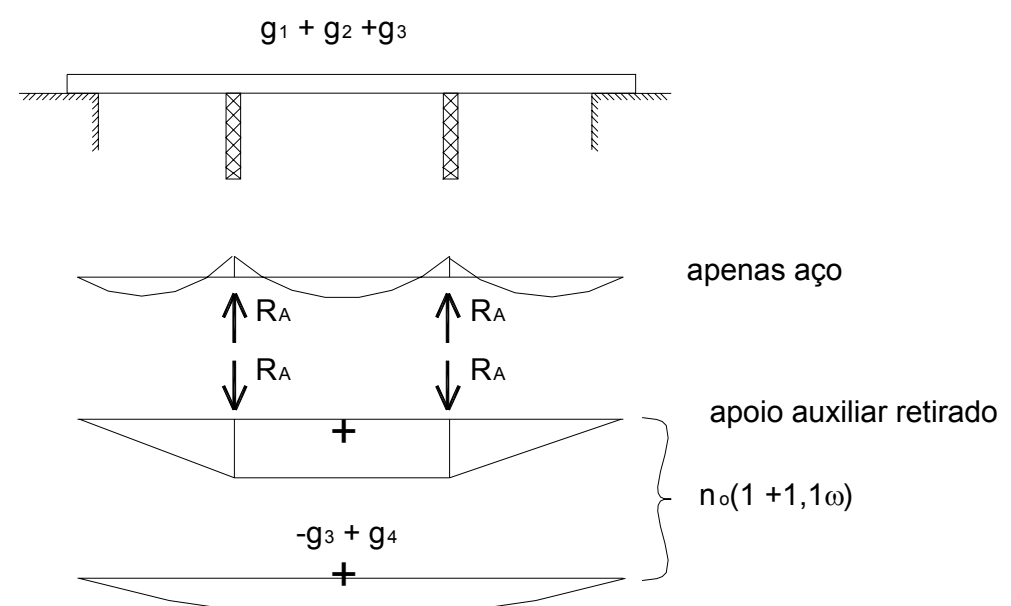

Figura 8.2- Vigas de aço com apoios adicionais. 
Os apoios intermediários podem ser retirados no instante em que os efeitos da fluência tendem a diminuir, geralmente após 60 dias (Tabela 2.2, NBR 6118/2002 página 13).

Neste momento também já se estabeleceu uma ação conjunta entre a laje de concreto e a viga metálica e conseqüentemente um aumento da rigidez da seção mista.

Porém esta alternativa pode ser muito onerosa, portanto outra maneira de coibir a fluência é de pré-encurvar a viga de aço antes da concretagem do tabuleiro. Isto é realizado com o uso de escoramentos intermediários, que são posicionados à viga de maneira que seja dada uma contraflecha.

Com isso são introduzidos pré-esforços na viga, de maneira que a mesa inferior adquira uma tensão de compressão como se uma protensão fosse realizada, semelhante às estruturas de concreto.

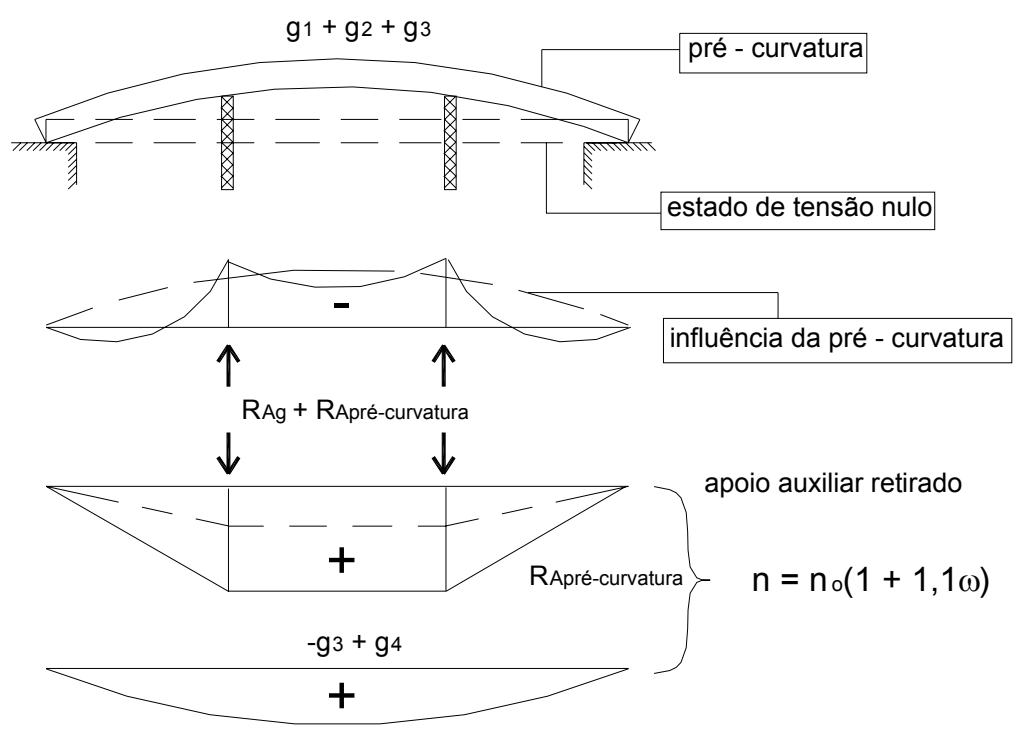

Figura 8.3- Vigas de aço pré-encurvadas. Fonte: Dubas (1975). 
Na figura 8.3, é mostrado que os momentos negativos apenas solicitam a viga de aço, enquanto os momentos positivos solicitam a viga mista, de maneira que as tensões de compressão estejam presentes na mesa inferior, as de tração na mesa superior e compressão na laje de concreto.

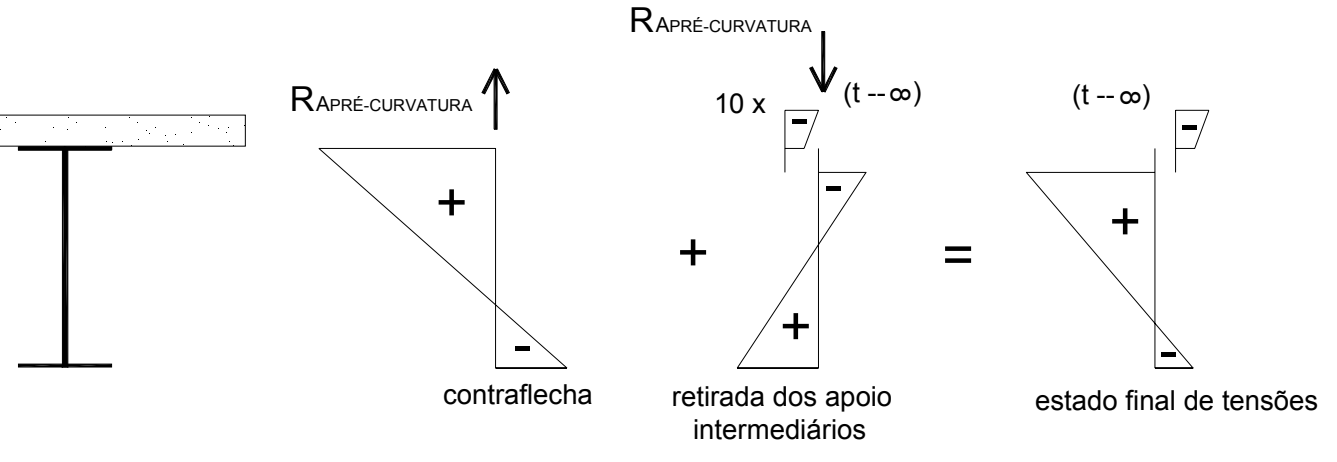

Figura 8.4- Estado de tensões em vigas pré-encurvadas. Fonte: Dubas (1975).

De acordo com Dubas (1975), após a superposição com os outros carregamentos obtém-se na viga de aço, tensões menores que as obtidas no sistema adotado da figura 8.2, proporcionando menores seções transversais.

Os apoios intermediários apresentados na figura 8.2 e 8.3, podem ser substituídos por tirantes provisórios (figura 8.5), também tornando possível um préencurvamento da viga de aço antes da concretagem da laje. 


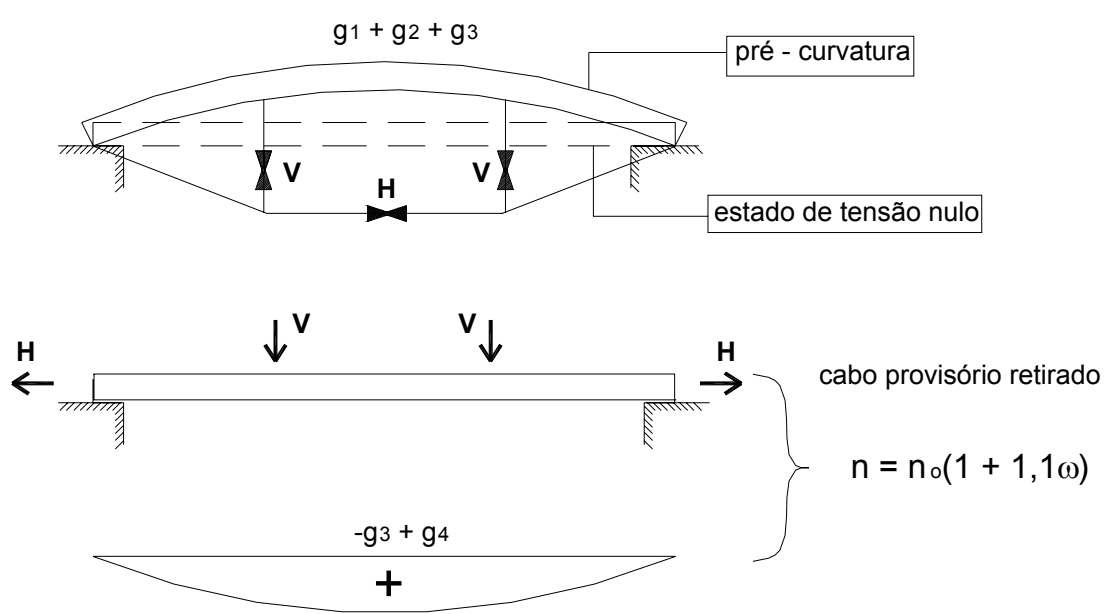

Figura 8.5- Vigas de aço pré-encurvadas através de cabos provisórios. Fonte: Dubas (1975).

O acréscimo de tensões de compressão no concreto, não é via de regra inconveniente. Como a estrutura mista é mais rígida do que a viga de aço, ao retirar os escoramentos intermediários e/ou os cabos provisórios, as deformações produzidas geralmente serão menores do que as obtidas no pré-encurvamento. Esta diferença de deformações deve ser levada em consideração ao se fixar a contraflecha da viga, e seu valor pode ser igual a flecha imediata $+50 \%$ da flecha devido ao carregamento variável.

Quanto aos efeitos da retração que causam forças de cisalhamento longitudinal, são resistidas pelos conectores, porém estes efeitos provocam tensões de tração na laje e serão combatidos por armaduras colocadas transversalmente à viga, como apresentado na figura 7.17 página 128. 


\section{9- REFERÊNCIAS BIBLIOGRÁFICAS.}

AMERICAN ASSOCIATION OF STATE HIGHWAY AND TRANSPORTATION OFFICIALS (1996). Types of loads and composite beams and girders. Washington, D.C., AASHTO.

AMERICAN INSTITUTE OF STEEL CONSTRUCTION (1986). Load and resistance factor design: specifications for structural steel buildings. Chicago, AISC.

ASSOCIAÇÃO BRASILEIRA DE NORMAS TÉCNICAS (2002). NBR 6118: Projeto e execução de obras de concreto armado. Rio de Janeiro, ABNT.

ABNT.

(2003). NBR 8681: Ações e segurança nas estruturas. Rio de Janeiro, (1988). NBR 6123: Forças devidas ao vento em edificações. Rio de Janeiro, ABNT.

(1988). NBR 5628: Componentes construtivos estruturais, determinação da resistência ao fogo. Rio de Janeiro, ABNT.

(1986). NBR 8800: Projeto e execução de estrutura de aço de edifícios. Rio de Janeiro, ABNT.

(1986). NBR 7187: Projeto e execução de pontes de concreto armado e protendido. Rio de Janeiro, ABNT.

(1985). NBR 7189: Carga móvel para projeto estrutural de obras ferroviárias. Rio de Janeiro, ABNT.

(1984). NBR 7188: Carga móvel para pontes rodoviárias e passarela de pedestres. Rio de Janeiro, ABNT. 
ABNT.

(1984). NBR 8681: Ações e segurança nas estruturas. Rio de Janeiro, (1980). NBR 6120: Cargas para cálculo de estruturas de edificações. Rio de Janeiro, ABNT.

BAZANT, Z. P. (1972). Prediction of concrete effects using age -adjusted effective modulus method. ACI Journal. Detroit. 69(4): 212-17, April 1972.

BERNARDO, G. (1980). Pontes. Grêmio Politécnico USP. $3^{\circ}$ edição, São Pulo.

BLODGETT, O. W. (1966). Design of welded structures. Copyright by: The James F. Lincon Arc Welding Foundation.

CANADIAN STANDARDS ASSOCIATION, CSA, CAN-S16.1-M84, "Steel structures for buildings (Limit states design)", 1984.

DIN 1072. Puentes de carreteras y caminos: hipótesis de carga (Tradução para o castelhano). Bilbao, Editora Balzola, 1973.

DUBAS, P. (1975). Pontes em viga mista. Convênio Pontifícia Universidade Católica do Rio de Janeiro. Fascículo 11. Usiminas S.A..

EPC: Engenharia projeto e consultoria LTDA (1989). Pontes rodoviárias metálicas. Introdução ao projeto e cálculo. Volume 3, parte 1.

Volume 3 , parte 2.

- (1989). Pontes rodoviárias metálicas. Introdução ao projeto e cálculo.

EL DEBS, K. M.; TOSHIAKI, T. (2003). Pontes de concreto. Notas de aulas. Fascículo 1,2,3,4,7. Universidade de São Paulo. EESC - São Carlos.

EUROCÓDIGO1 (1996). Bases de proyeto y acciones in estructuras. Parte1: Bases de proyeto. 
EUROCÓDIGO1 (1996). Bases de proyeto y acciones in estructuras. Parte2-1: Acciones in estructuras. Densidades, pesos proprios y cargas exteriores.

EUROCÓDIGO4 (1994). Proyecto de estructuras mixtas de hormigón y acero. Parte1-1: Reglas generales y reglas para edificación.

EUROCÓDIGO4 (1994). Proyecto de estructuras mixtas de hormigón y acero. Parte1-2: Reglas generales proyecto de estructuras.

FOURTH INTERNATIONAL BRIDGE ENGINEERING CONFERENCE (1995). Volume1 e 2. San Francisco, California. Sponsored by : Transportation Research Board; Federal Highway Administration; Federal Railroad Administration; American association of States Highway and Transportation Officials; California Departament of Transportation.

FRITZ, L. (1977). Construções de concreto. Princípios básicos de pontes de concreto. Volume 6. Editora Interciência LTDA.

GALAMBOS, T.V. (1988). Guide to stability design criteria for metal structures. 4.ed. New York, John Wiley \& Sons.

INTERNATIONAL CONFERENCE INNSBRUK (1997). Composite constructionconventional and innovative. Austria. Organised by IABSE in co-operation with the Austrian Group of IABSE.

JOHNSON, R. P.(1975). Composite structures of steel and concrete. Volume1. London: Crosby Lockwood Staples.

KAUNADIS, N.A. (1995). Proceedings of the $1^{\text {st }}$ European Conference on Steel Structures . Athens/Greece/18-20 May, 1995. Published by: A.A. Balkema, Rotterdam. Printed in the Netherlands. Apud Djuric (1963).

LAMAS A.; SILVA S.L.; Cruz P. (1999). Actas do II Encontro Nacional de Construção Metálica e Mista. Coimbra, Portugal. 
MACHADO, C.P. Tensões, deformações e deslocamentos em estruturas de concreto armado e protendido. Dissertação apresentada à Escola Politécnica da USP (1989).

MALITE, M. (2002). Vigas mistas aço-concreto. Ênfase em edifício. Universidade de São Paulo. EESC - São Carlos.

MALITE, M. (2002). Pontes em viga mista. Notas de aulas. Universidade de São Paulo. EESC - São Carlos.

MARTINELII, A.O.D. (1971). Solicitações nas pontes de concreto. Universidade de São Paulo. EESC - São Carlos. . (1982). Introdução as pontes de concreto. Universidade de São Paulo. EESC - São Carlos.

MASON, J. (1976). Pontes metálicas e mistas em viga reta. Projeto e cálculo. Livros técnicos e científicos. Editora S.A., Rio de Janeiro.

NATIONAL ACADEMY PRESS WASHINGTON,D.C.(1995). Fourth international bridge engineering conference. Volume1 e 2. San Francisco, California.

NEVILLE, A .M. (1982). Propriedades do concreto. Editora Pini, São Paulo.

O' CONNOR, COLIN; SHAW, P.A. (2000). Bridge loads an international perspective.

O' CONNOR, COLIN (1975). Pontes-Superestruturas1. Tradutor: Campelo, M.L.C.. Revisor técnico: Barreto, P.P. $3^{\circ}$ Edição. Livros técnicos e científicos. Editora S.A., Rio de Janeiro.

. (1975). Pontes-Superestruturas2. Tradutor: Campelo, M.L.C.. Revisor técnico: Barreto, P.P. $3^{\circ}$ Edição. Livros técnicos e científicos. Editora S.A., Rio de Janeiro.

. (1971). Design of bridge superstructures. Copyright by John Willy \& Sons. 
PRITCHARD, B. (1994). Continuos and integral bridges. Organized by the British Group of the International Association for Bridge and Structural Engineering.

QUEIROZ, G.; PIMENTA, J. ROBERVAL; MATA, C. A. LUCIENE. (2000). Elementos das estruturas mistas aço/concreto. Editora Lutador, Belo horizonte.

SALES, J.J.; MALITE M.; GONÇALVES, M. R.(1994). Sistemas estruturais, elementos estruturais. Universidade de São Paulo. EESC - São Carlos.

TIMOSHENKO, S. (1966). Resistência dos materiais2. Traduzido: Moreira, D. F.. Livros técnicos e científicos. Editora S.A..Rio de Janeiro.

TIMOSHENKO, S.P.; GERE, J.M. (1961). Theory of elastic stability. Tokyo, McGraw-Hill.

TROITSKY, M.S. (1990). Prestressed steel bridges. Theory and design. Copyright Van Nostrand Reinhold Company. New York.

XANTHAKOS, P. P. (1995). Bridge substructure and foundation design. Prentice: Hall, Inc. Simon \& Schuster Company Upper Saddle River, New Jersey. 